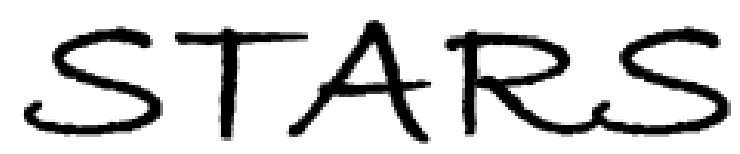

University of Central Florida

STARS

\title{
Methods Of Extrapolating Low Cycle Fatigue Data To High Stress Amplitudes
}

David Charles Radonovich

University of Central Florida

Part of the Mechanical Engineering Commons

Find similar works at: https://stars.library.ucf.edu/etd

University of Central Florida Libraries http://library.ucf.edu

This Masters Thesis (Open Access) is brought to you for free and open access by STARS. It has been accepted for inclusion in Electronic Theses and Dissertations, 2004-2019 by an authorized administrator of STARS. For more information, please contact STARS@ucf.edu.

\section{STARS Citation}

Radonovich, David Charles, "Methods Of Extrapolating Low Cycle Fatigue Data To High Stress Amplitudes" (2007). Electronic Theses and Dissertations, 2004-2019. 3308.

https://stars.library.ucf.edu/etd/3308

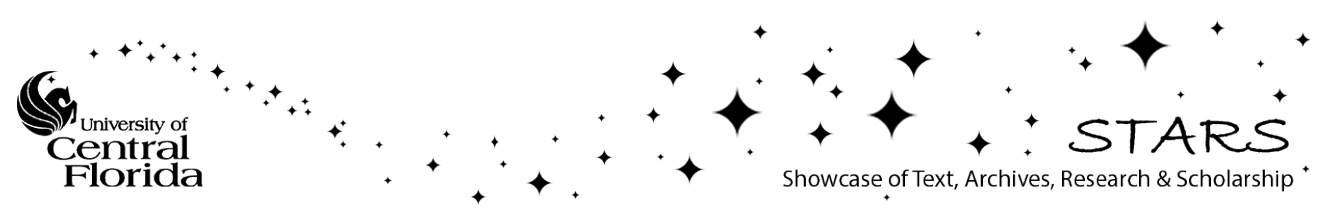




\title{
DAVID C. RADONOVICH
}

\author{
A thesis submitted in partial fulfillment of the requirements \\ for the degree of Master of Science \\ in the Department of Mechanical, Materials, and Aerospace Engineering \\ in the College of Engineering and Computer Science \\ at the University of Central Florida \\ Orlando, Florida
}

\author{
Fall Term
}




\begin{abstract}
Modern gas turbine component design applies much effort into prediction and avoidance of fatigue. Advances in the prediction of low-cycle fatigue (LCF) cracks will reduce repair and replacement costs of turbine components. These cracks have the potential to cause component failure. Regression modeling of low-cycle fatigue (LCF) test data is typically restricted for use over the range of the test data. It is often difficult to characterize the plastic strain curve fit constants when the plastic strain is a small fraction of the total strain acquired. This is often the case with high strength, moderate ductility Ni-base superalloys.

The intent of this project is to identify the optimal technique for extrapolating LCF test results into stress amplitudes approaching the ultimate strength. The proposed method to accomplish this is by finding an appropriate upper and lower bounds for the cyclic stress-strain and strain-life equations. Techniques investigated include: monotonic test data anchor points, strain-compatibility, and temperature independence of the CoffinManson relation.

A Ni-base superalloy (IN738 LC) data set with fully reversed fatigue tests at several elevated temperatures with minimal plastic strain relative to the total strain range was used to model several options to represent the upper and lower bounds of material behavior. Several high strain LCF tests were performed with stress amplitudes approaching the ultimate strength. An augmented data set was developed by combining the high strain data with the original data set. The effectiveness of the bounding equations is judged by comparing the bounding equation results with the base data set to a linear regression model using the augmented data set.
\end{abstract}


For Caroline and Joshua 


\section{ACKNOWLEDGMENTS}

Several people and organizations deserve recognition for contributing to this project. Dr. Ali Gordon of the University of Central Florida deserves credit for much technical support and encouragement. Thanks to Mr. Phillip Gravett, Dr. Harald Harders, Dr. Sachin Shinde, Mr. Allister James, Mr. Stefan Mazzola, and Mr. David Kosich of Siemens Power Generation for their efforts to support this project. Support provided by the United States Department of Energy was also very much appreciated. 


\section{TABLE OF CONTENTS}

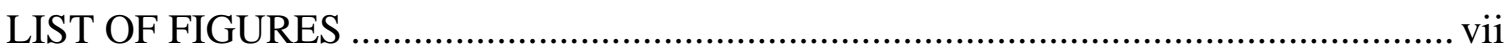

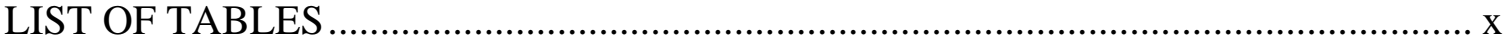

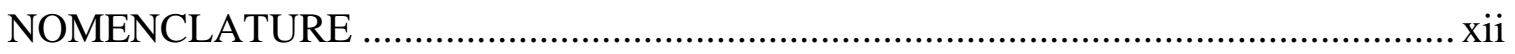

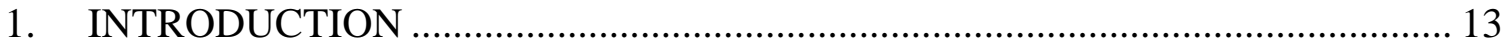

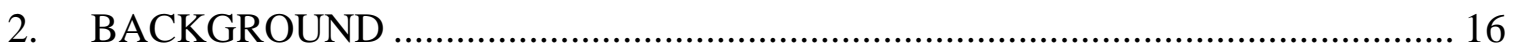

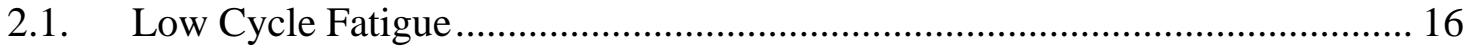

2.2. Reference Methods …………................................................................ 32

2.3. Existing Experimental Results ...................................................................... 40

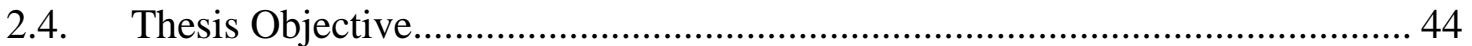

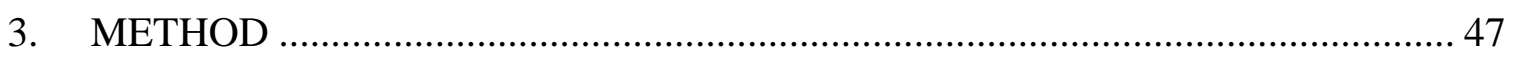

3.1. Normalization of Test Data............................................................................ 47

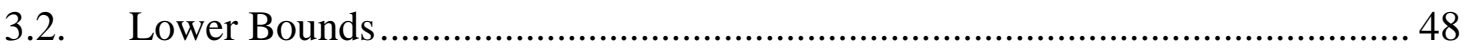

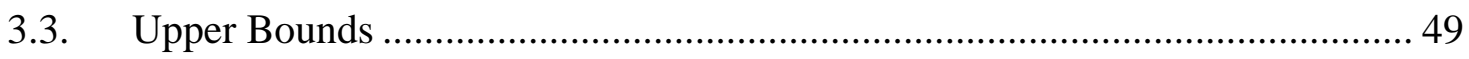

3.4. Test Equipment ........................................................................................ 57

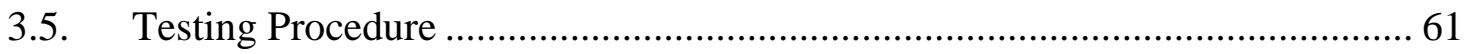

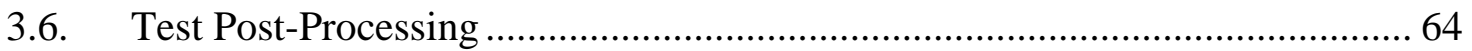

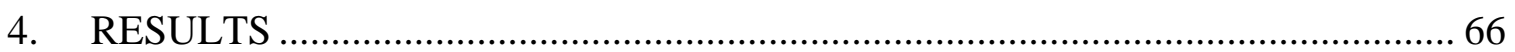

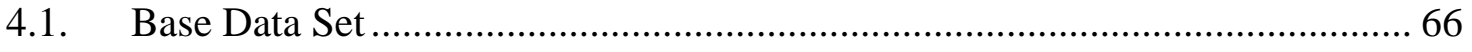

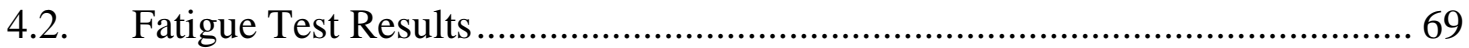

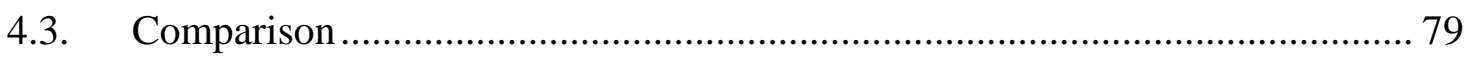

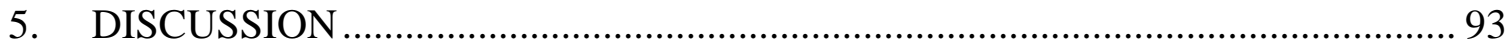


5.1. Augmented Data Model................................................................................. 93

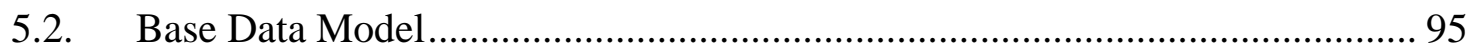

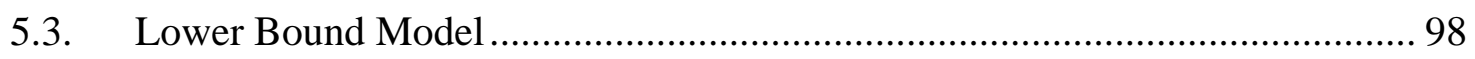

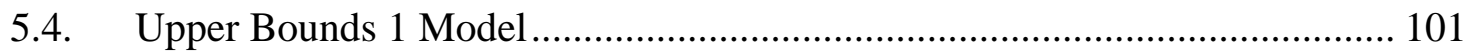

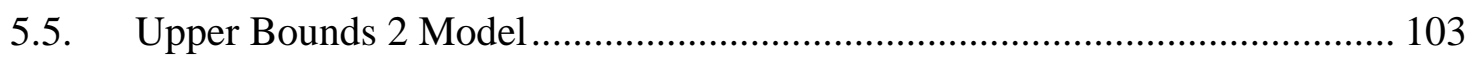

5.6. Upper Bounds 3 Model.............................................................................. 105

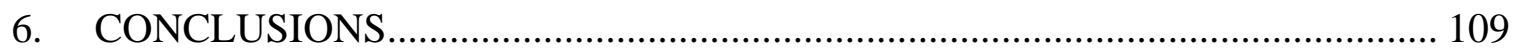

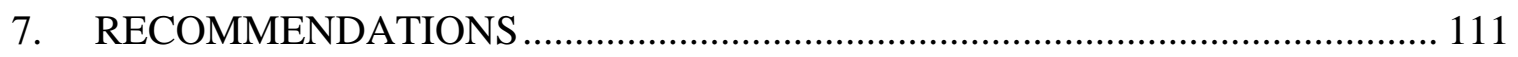
APPENDIX A - EXPERIMENTAL HYSTERESIS LOOPS AND STRESS HISTORIES

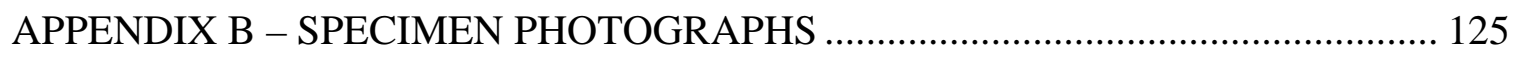

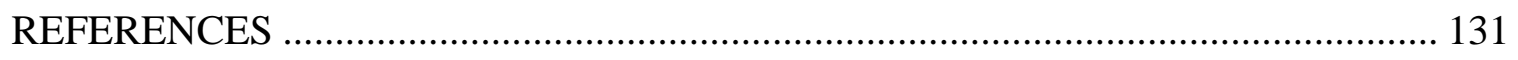




\section{LIST OF FIGURES}

Figure 1.1. Longitudinal section of SGT6-5000F industrial gas turbine....................... 14

Figure 2.1. Graphical depiction of the three types of fatigue. ..................................... 17

Figure 2.2. LCF test with stable hysteresis loops. .................................................. 18

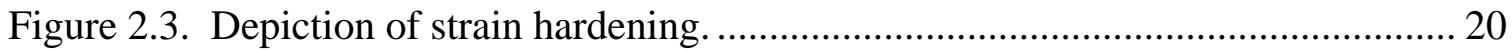

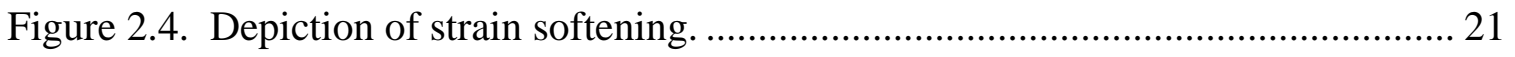

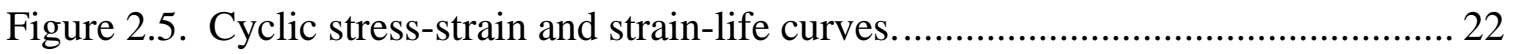

Figure 2.6. Depiction of sufficient data to characterize elastic and plastic strain. .......... 28

Figure 2.7. LCF data set with insufficient plastic strain data for definition of plastic

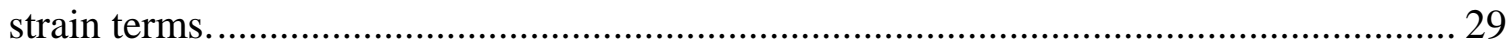

Figure 2.8. Linear-elastic FE model stress results. .............................................. 30

Figure 2.9. Process of LCF life determination....................................................... 31

Figure 2.10. Approximation methods to curve fit from LCF test data for IN738 LC at

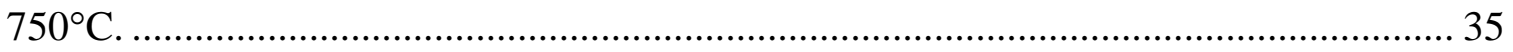

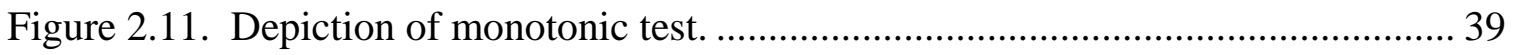

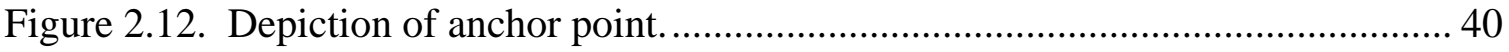

Figure 2.13. IN713 LC monotonic and cyclic stress-strain curve [6].......................... 43

Figure 2.14. Strain-life curve for IN713 LC at room temperature [6]........................... 44

Figure 2.15. Bounding estimates for the stress-strain and strain-life equations............. 45

Figure 3.1. Depiction of method for protection of proprietary test data........................ 48

Figure 3.2. Effect of strain hardening on initial versus stable mid-life hysteresis loops. 50 
Figure 3.3. Plots of (a) initial and stabilized stress range, and (b) initial and mid-life

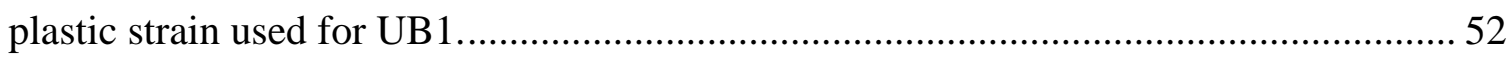

Figure 3.4. Scatter in strain-life equation with temperature. ..................................... 54

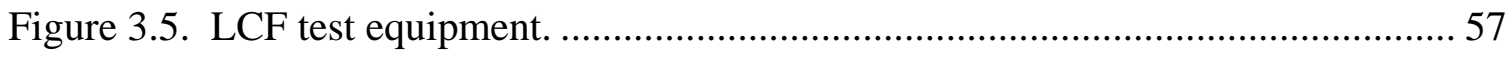

Figure 3.6. Photograph and Depiction of load frame component details. ...................... 58

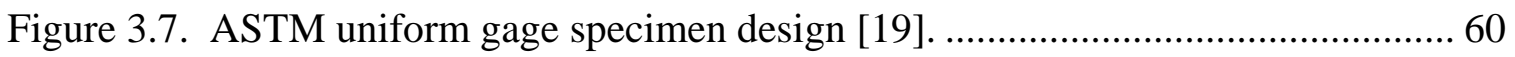

Figure 4.1. Experimental and modeled cyclic stress-strain and strain life behavior of

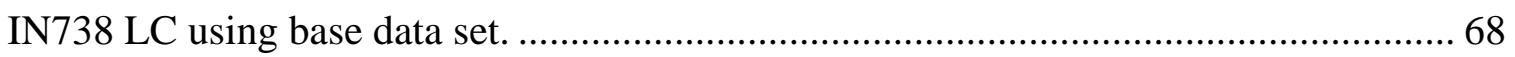

Figure 4.2. Cyclic (a) stress and (b) strain history for test D912-1 for IN738 LC at

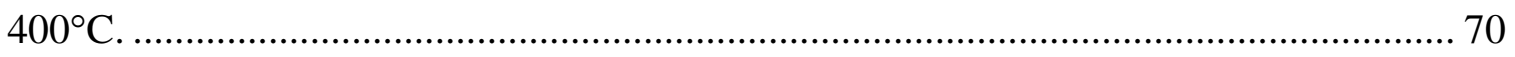

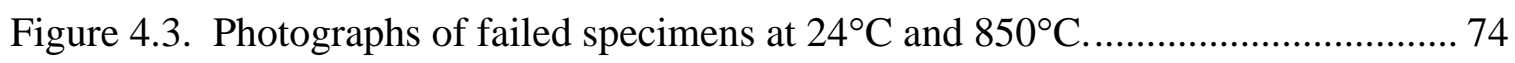

Figure 4.4. Stress versus time output for $1.4 \%$ strain range at $24^{\circ} \mathrm{C}, 750^{\circ} \mathrm{C}$, and $850^{\circ} \mathrm{C} .75$

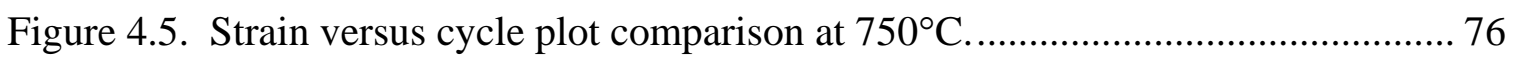

Figure 4.6. (a) Hystersis loop and (b) stress history plot for specimen D912-14 at 1.4\%

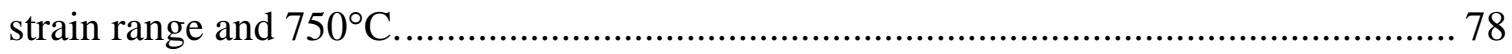

Figure 4.7. Comparison of calculated cyclic yield strengths using various methods...... 80

Figure 4.8. Comparison of (a) cyclic stress-strain models and (b) strain-life models for

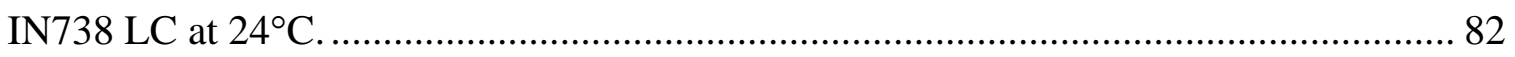

Figure 4.9. Comparison of (a) cyclic stress-strain models and (b) strain-life models for

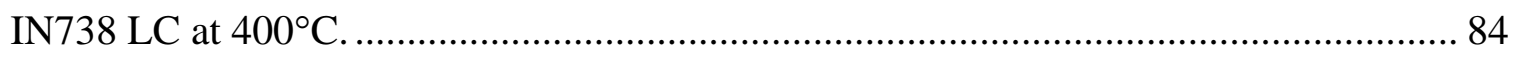
Figure 4.10. Comparison of (a) cyclic stress-strain models and (b) strain-life models for

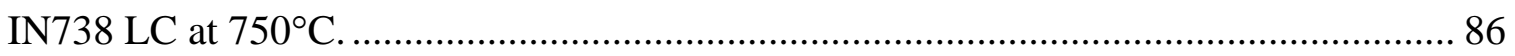


Figure 4.11. Comparison of (a) cyclic stress-strain models and (b) strain-life models for IN738 LC at $850^{\circ} \mathrm{C}$. 88

Figure 4.12. Comparison of (a) cyclic stress-strain models and (b) strain-life models for IN738 LC at $900^{\circ} \mathrm{C}$.

Figure 5.1. Comparison of (a) cyclic stress-strain curve and (b) strain-life curves using the augmented data model and data for IN738 LC at various temperatures.

Figure 5.2. Comparison of (a) cyclic stress-strain curve and (b) strain-life curves using the base model and base data for IN738 LC at various temperatures.

Figure 5.3. Comparison of (a) cyclic stress-strain curve and (b) strain-life curves using the LB model and base data for IN738 LC at various temperatures 100 Figure 5.4. Comparison of (a) cyclic stress-strain curve and (b) strain-life curves using the UB1 model and base data for IN738 LC at various temperatures. 102 Figure 5.5. Comparison of (a) cyclic stress-strain curve and (b) strain-life curves using the UB2 model and base data for IN738 LC at various temperatures. 104 Figure 5.6. Comparison of (a) cyclic stress-strain curve and (b) strain-life curves using the UB3 model and base data for IN738 LC at various temperatures. 106 


\section{LIST OF TABLES}

Table 2.1. Linear regressions required to find curve fit constants............................... 27

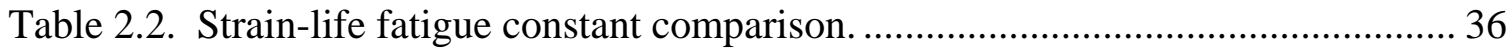

Table 2.3. Comparison of basic properties of IN713LC and IN738 LC......................... 42

Table 3.1. Constants $\mathrm{C}_{1}$ and $\mathrm{C}_{2}$ from linear regression using base data set.................. 51

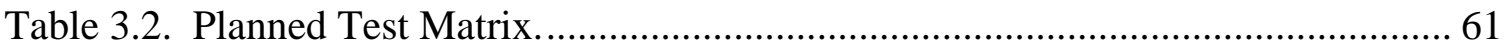

Table 4.1. Quantity, norm. strain range, and temp of LCF data points in base data for

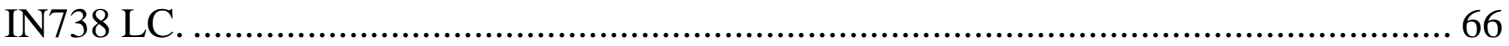

Table 4.2. Values of $\mathrm{R}^{2}$ from regression analysis using base data set......................... 67

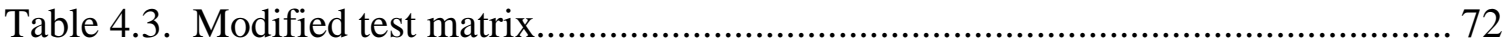

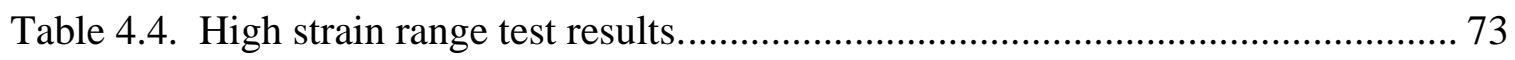

Table 4.5. Comparison of moduli and cyclic yield between base data set and additional

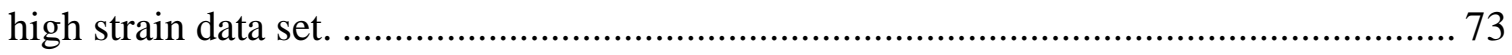

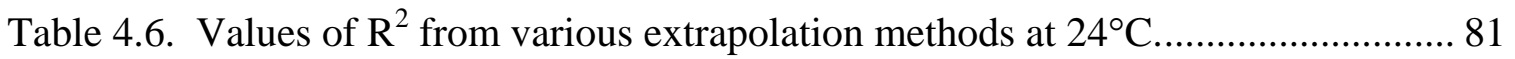

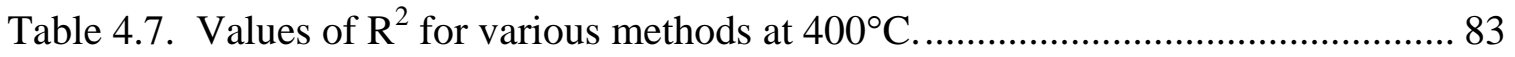

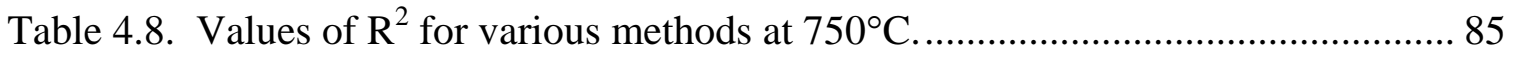

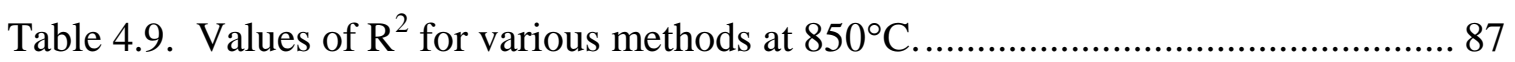

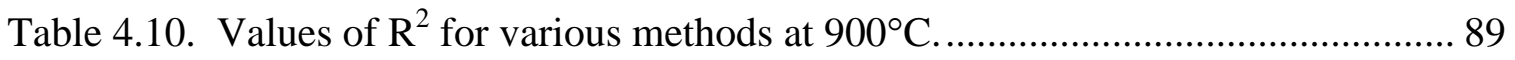

Table 4.11. Temperature average values of $\mathrm{R}^{2}$ for extrapolation methods..................... 91

Table 4.12. Temperature average values of R-squared error for best fit over all test data. 
Table 5.1. Constants $\mathrm{C}_{1}$ and $\mathrm{C}_{2}$ from linear regression with base data set and augmented

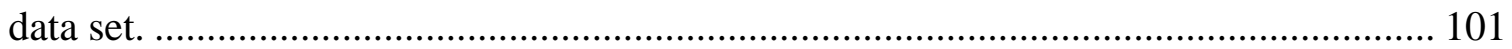

Table 5.2. Temperature average values of $\mathrm{R}^{2}$ for extrapolation methods..................... 107

Table 5.3. Temperature average values of $\mathrm{R}^{2}$ error for best overall test data................ 108 


\section{NOMENCLATURE}

\begin{tabular}{|c|c|}
\hline$\Delta \varepsilon_{e l}$ & Elastic strain range \\
\hline$\Delta \varepsilon_{e l} / 2$ & Elastic strain amplitude \\
\hline$\Delta \varepsilon_{i}$ & Initial strain range \\
\hline$\Delta \varepsilon_{s}$ & Stabilized strain range \\
\hline$\Delta \varepsilon_{p l}$ & Plastic strain range \\
\hline$\Delta \varepsilon_{t}$ & Total strain range \\
\hline$\Delta \varepsilon_{t} / 2$ & Total strain amplitude \\
\hline$\Delta \sigma$ & Stress range \\
\hline$\dot{\varepsilon}$ & Strain rate \\
\hline$\varepsilon_{a}$ & Strain amplitude \\
\hline$\varepsilon_{e l}$ & Elastic strain \\
\hline$\varepsilon_{f}$ & Failure strain \\
\hline$\varepsilon_{f}^{\prime}$ & Fatigue ductility coefficient \\
\hline$\varepsilon_{p l}$ & Plastic strain \\
\hline$\varepsilon_{t}$ & Total strain \\
\hline$\sigma$ & Stress \\
\hline$\sigma_{a}$ & Stress amplitude \\
\hline$\sigma_{f}^{\prime}$ & Fatigue strength coefficient \\
\hline$\sigma_{f}$ & Failure stress \\
\hline$\sigma_{m}$ & Mean stress \\
\hline$\sigma_{\max }$ & Maximum stress \\
\hline$\sigma_{\min }$ & Minimum stress \\
\hline$\sigma_{U L T}$ & Ultimate tensile strength \\
\hline$b$ & Fatigue strength exponent \\
\hline C & Fatigue ductility exponent \\
\hline$e$ & Elongation \\
\hline$K^{\prime}$ & Cyclic strength coefficient \\
\hline$n^{\prime}$ & Cyclic strain hardening exponent \\
\hline$N_{i}$ & Cycles to failure \\
\hline$N_{f}$ & Cycles to initiation \\
\hline$R_{\varepsilon}$ & Strain ratio \\
\hline$F E$ & Finite element \\
\hline$L C F$ & Low-cycle fatigue \\
\hline$T M F$ & Thermal-mechanical fatigue \\
\hline
\end{tabular}




\section{INTRODUCTION}

Modern industrial gas turbines utilize a combination of advanced analytical tools, high technology alloys, thermal barrier coatings, and thin-walled cooling design to achieve high power and efficiency. An advanced F-class industrial gas turbine engine operates at high firing temperatures of $1260^{\circ} \mathrm{C}\left(2300^{\circ} \mathrm{F}\right)$, and when operated in combine

cycle can generate up to $293 \mathrm{MW}$ and achieve efficiencies of up to 57\% [1]. An effect of designing high technology components is substantial replacement costs [2].

Improvement in the understanding of material behavior allows more accurate life prediction. More accurate tools allow designers to fully utilize material properties, which ultimately reduces the maintenance costs for industrial gas turbines.

Industrial gas turbines are often used for peaking duty operation, which accumulates numerous cycles due to frequent starting and stopping of the engine. A longitudinal section of an F-class industrial gas turbine is shown in Fig. 1.1. These conditions cause high cyclic stress on gas turbine components, which can result in thermal-mechanical fatigue (TMF). This phenomenon is caused by cyclic strains induced by superimposed thermal and mechanical loading.

Many TMF cracks on gas turbine components are dominated by thermal stress. Often, these cracks propagate until they reach a region where the thermal stress has diminished, and crack growth is arrested. Occasionally, TMF cracks propagate into a region where non-relenting loads dominate, and result in component failure. To avoid undue risk, TMF cracks are repaired or replaced at considerable expense and increase of component life cycle costs. 


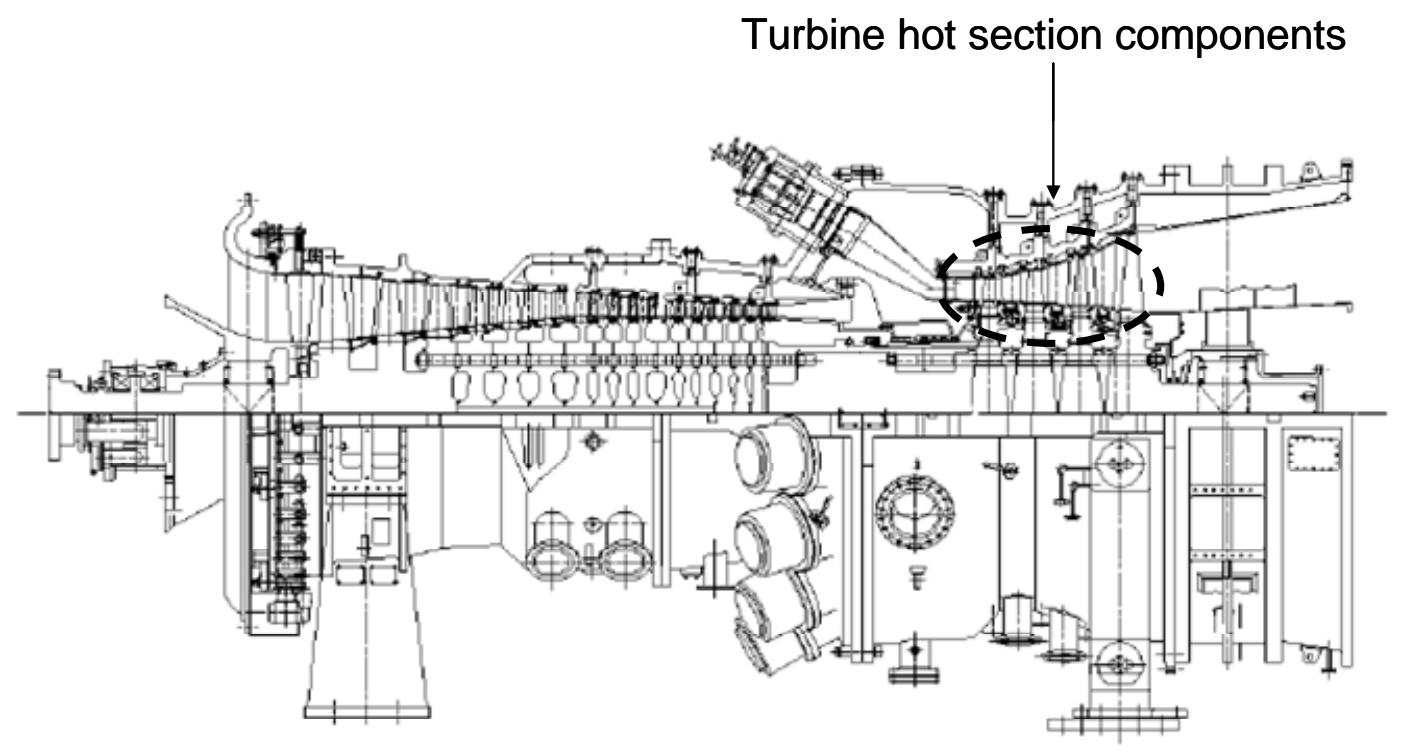

Figure 1.1. Longitudinal section of SGT6-5000F industrial gas turbine.

In practice, the phenomenon of TMF is quite complex. Most laboratory studies have focused on isothermal low-cycle fatigue (LCF) testing, assuming that tests conducted at the maximum temperature will show the worst behavior for the material [3]. Typically, a material is characterized by developing LCF characteristic curves at several temperatures of interest in the design. The effect of creep-fatigue interaction may be included by considering "hold-time" effects, or holding the specimen in tension or compression during isothermal fatigue testing. The low cycle fatigue range is typically considered less than 10,000 cycles in the gas turbine industry.

Many different alloys are used for their unique properties in a gas turbine, and properly characterizing the LCF life of each alloy is expensive and time consuming. Currently, the most widely used curve fitting method for LCF data discourages approximation and extrapolation outside of the data set. Most approximation methods that do exist have been calibrated to steel. 
The focus of this project is examination of an existing data set of IN738 LC, which has limited plastic strain data and shows some unexpected behavior. It is not initially known whether the cause of the apparent anomalies is due to normal experimental or modeling error. Resolving the unexpected behavior will reduce scatter and allow the fully capability of the material behavior to be utilized.

Several methods are employed to find the optimal technique for extrapolating LCF data into stress amplitudes approaching the ultimate strength. Predictions are made by utilizing a base data set with limited plastic strain data, which are compared to an accepted model of high strain behavior including high strain range data. The merit of the extrapolation techniques as a tool to determine whether data is anomalous is also investigated. 


\section{BACKGROUND}

\subsection{Low Cycle Fatigue}

The current methodology for low cycle fatigue is discussed in this section. Topics include: standard definitions in low cycle fatigue, the procedure used for linear regression curve fitting of test data, issues with the current methodology, and a procedure for component lifing.

Fatigue is the process of progressive localized permanent structural change occurring in a material subjected to conditions that produce fluctuating stresses and strains at some point or points, and that may culminate in cracks or complete fracture after a sufficient number of fluctuations [4]. Fatigue has been divided into three regimes, which depend on the number of cycles to failure as shown in Fig. 2.1. The number of cycles where transition from HCF to LCF behavior occurs varies by material. One source suggests that high cycle fatigue is for cycles to failure greater than $10^{5}$, and lowcycle fatigue is for cycles between $10^{2}$ and $10^{4}$ [5]. This source also advises that the phenomena of low-cycle fatigue changes below 20 cycles, and has termed this range very low-cycle fatigue (VLCF). 


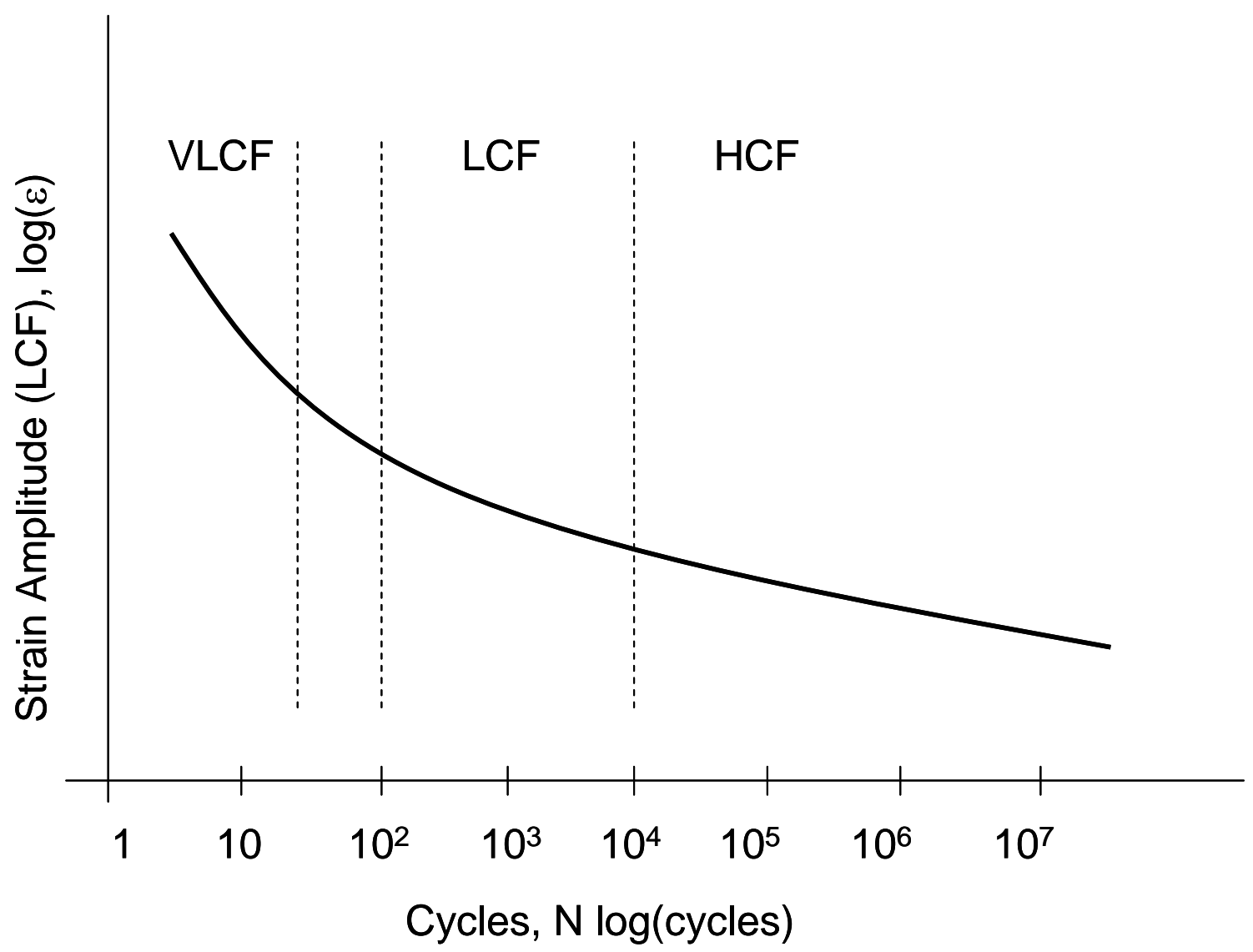

Figure 2.1. Graphical depiction of the three types of fatigue.

High cycle fatigue is defined by elastic stress governing the life, and low-cycle fatigue is defined where yielding effects (plasticity) govern the behavior [6]. Lemaitre describes high cycle fatigue having stress amplitudes less than yield, and low cycle fatigue as having stress amplitudes between yield and ultimate strength [5]. Stresscontrolled experiments are used to characterize HCF life, whereas strain-controlled testing is used to characterize LCF life. The key output of either type of test is a hysteresis loop. The shapes of the cyclic stress versus strain curves typically change from initial loading until it achieves a stabilized shape as shown in Fig. 2.2. 

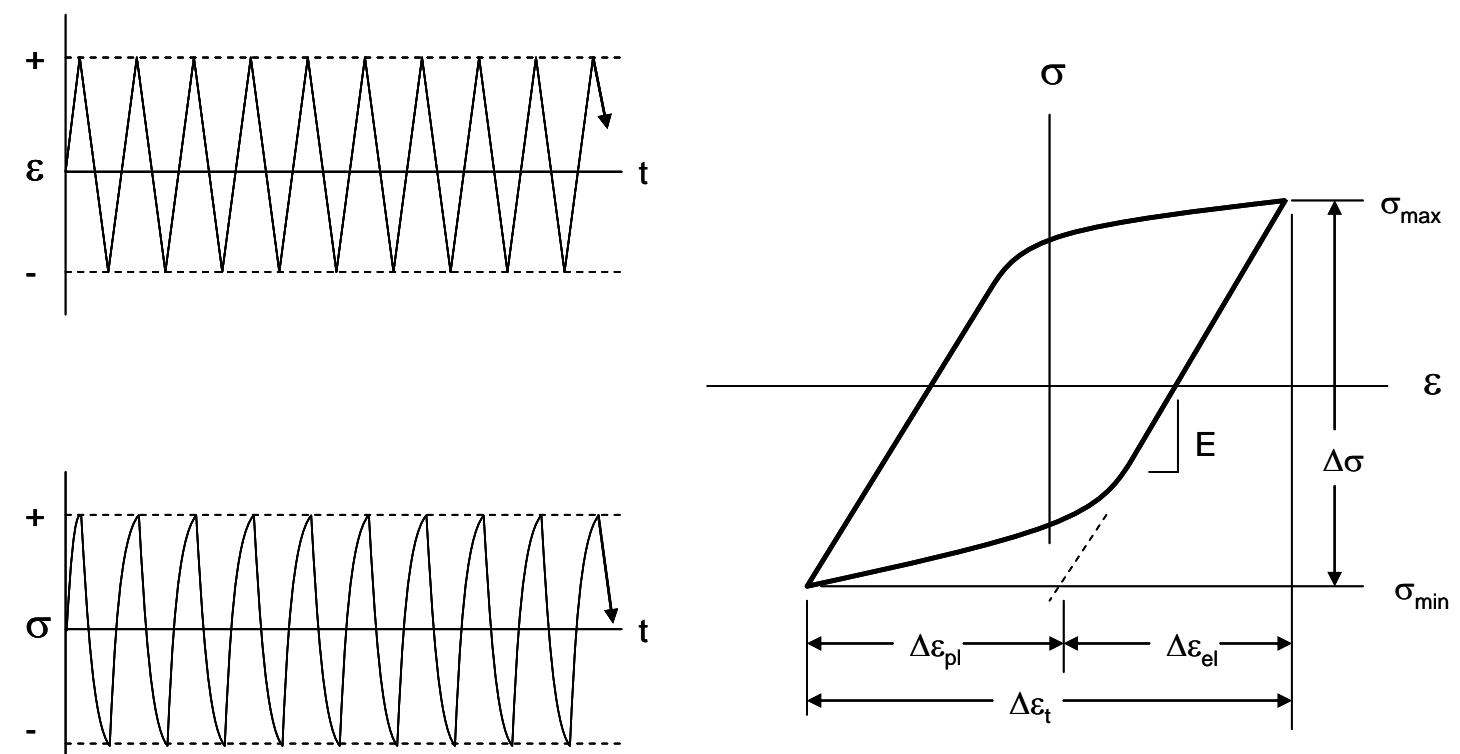

Figure 2.2. LCF test with stable hysteresis loops.

A collection of variables used to describe the cyclic stress versus strain curve are shown in the following. The stress range $(\Delta \sigma)$ is given by the maximum and minimum stress where $\sigma_{\max }$ is the maximum stress and $\sigma_{\min }$ is the minimum stress in the hysteresis loop, i.e.

$$
\Delta \sigma=\sigma_{\max }-\sigma_{\min }
$$

Mean stress $\left(\sigma_{\mathrm{m}}\right)$ is the average of the maximum and minimum stress in the hysteresis loop, i.e.

$$
\sigma_{m}=\frac{\sigma_{\max }+\sigma_{\min }}{2}
$$


The total strain range $\left(\Delta \varepsilon_{\mathrm{t}}\right)$ is defined as the sum of the elastic $\left(\Delta \varepsilon_{\mathrm{el}}\right)$ and plastic $\left(\Delta \varepsilon_{\mathrm{pl}}\right)$ strain ranges, i.e.

$$
\Delta \varepsilon_{t}=\Delta \varepsilon_{e l}+\Delta \varepsilon_{p l}
$$

The stress amplitude $\left(\sigma_{\mathrm{a}}\right)$ and strain amplitude $\left(\varepsilon_{\mathrm{a}}\right)$ is half of the stress range $(\Delta \sigma)$ and strain range $(\Delta \varepsilon)$ are respectively defined as

$$
\begin{gathered}
\varepsilon_{a}=\frac{\Delta \varepsilon}{2} \\
\sigma_{a}=\frac{\Delta \sigma}{2}
\end{gathered}
$$

The test conditions are also described by the strain ratio $\left(\mathrm{R}_{\varepsilon}\right)$. The strain ratio is the ratio of the minimum to maximum strain, i.e.

$$
R_{\varepsilon}=\frac{\varepsilon_{\min }}{\varepsilon_{\max }}
$$

The data in this thesis corresponds to fully reversed fatigue testing with an $\mathrm{R}_{\varepsilon}=-1$.

Nickel-base superalloys have been shown to exhibit strain hardening, strain softening, and strain rate dependence depending on LCF conditions $[8,9,10]$. Typically, the test conditions are specified by $\Delta \varepsilon, R_{\varepsilon}$, temperature, and strain rate $(\dot{\varepsilon})$. Strain- 
hardening is the increase in stress over time during constant strain-controlled testing as depicted in Fig. 2.3. Strain hardening increases the magnitude of the maximum and minimum stress in a hysteresis loop over time. Strain softening is the reduction in stress over time during constant strain testing as depicted in Fig. 2.4. The magnitude of the maximum and minimum stress in the hysteresis loop is reduced over time.

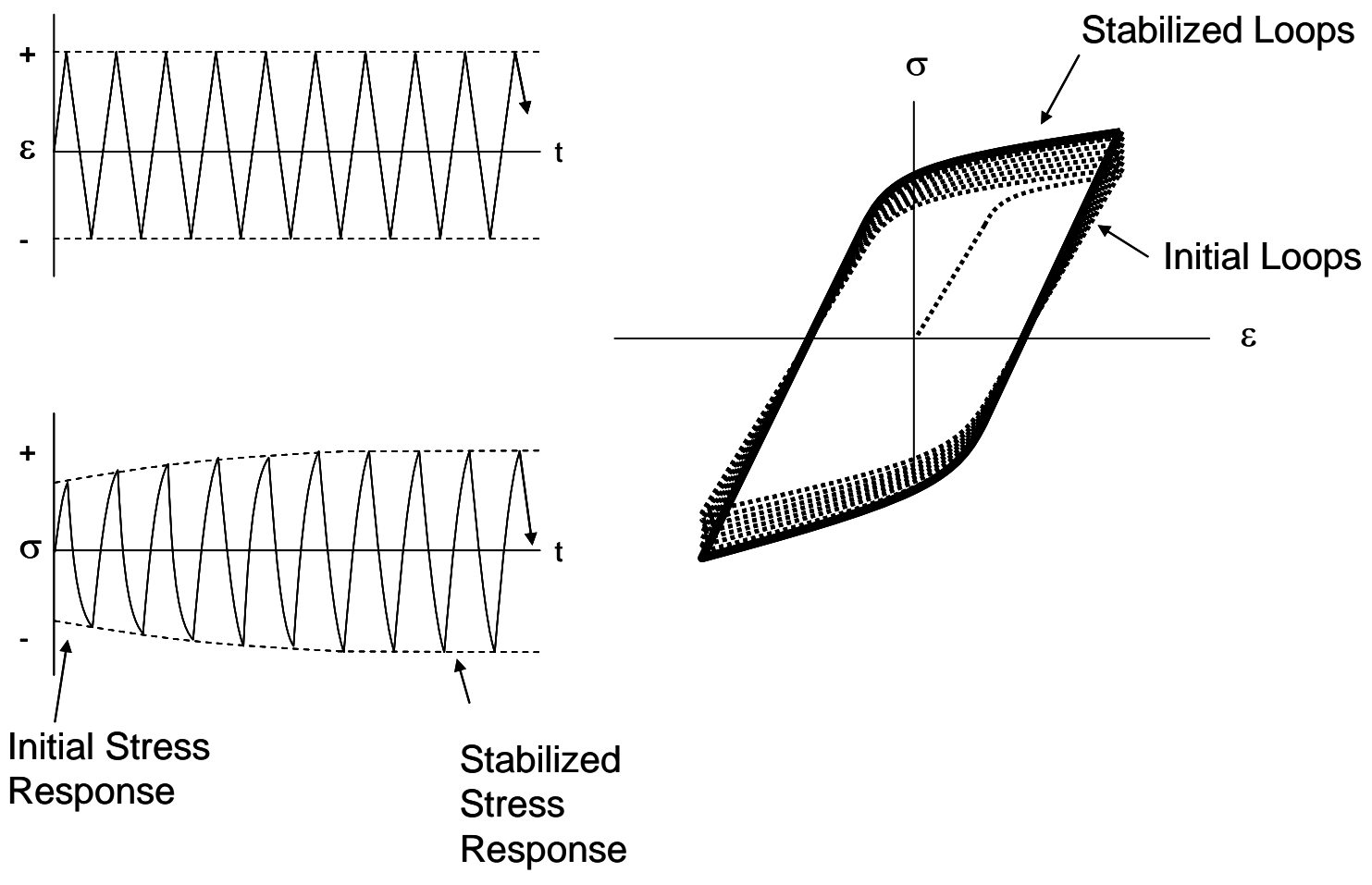

Figure 2.3. Depiction of strain hardening. 


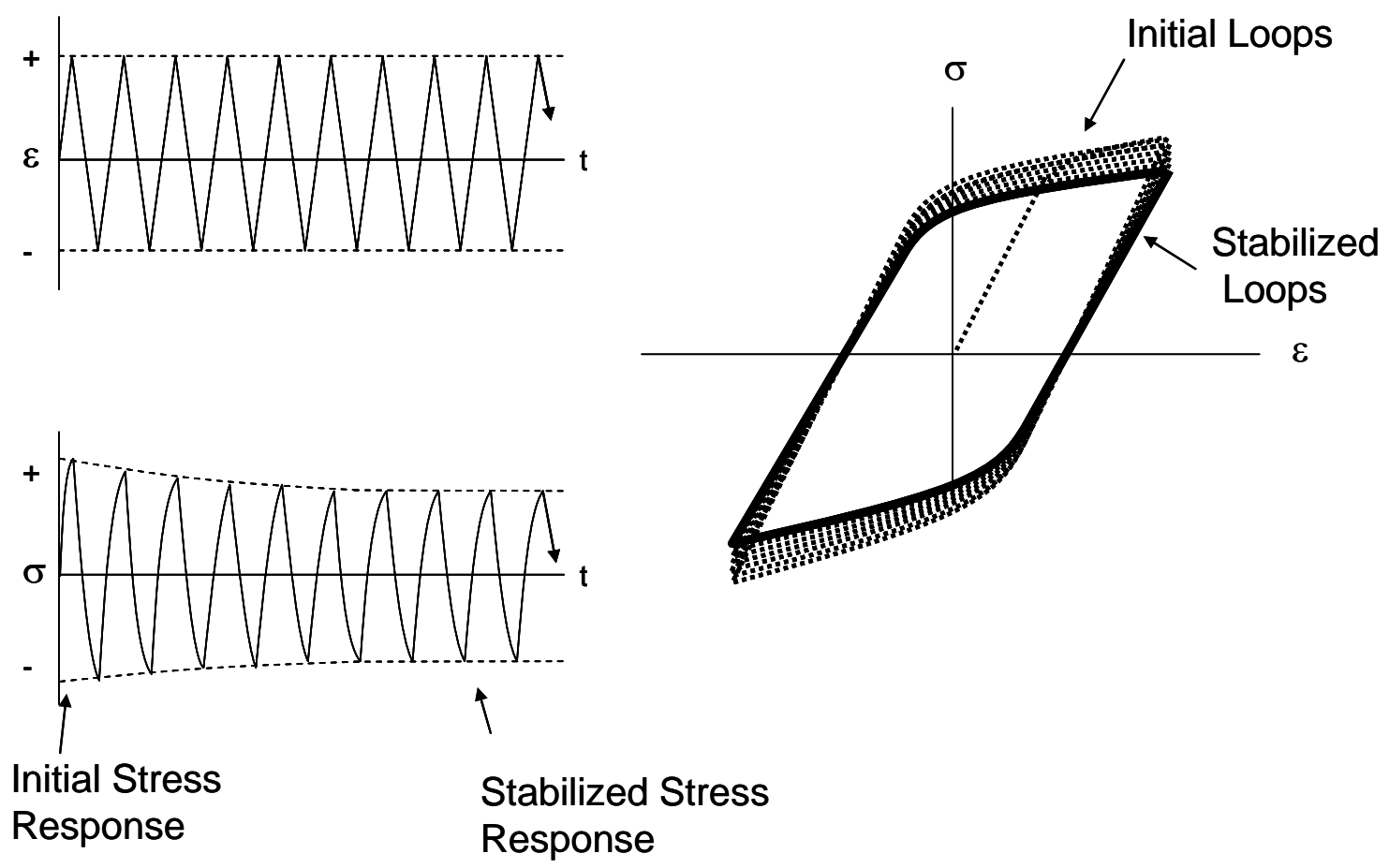

Figure 2.4. Depiction of strain softening.

Another important aspect of LCF data is strain rate dependence. Yield strength and ultimate strength have displayed strain rate dependence for IN738 LC [9, 11]. It is important to compare like similar strain rates when evaluating the differences between materials. All IN738 LC LCF test data used in this project was tested at a strain rate of $6.0 \% / \mathrm{min}$.

Linear regression analysis is used to interpolate the cyclic stress-strain and strainlife data at each temperature, as shown in Fig. 2.5. 

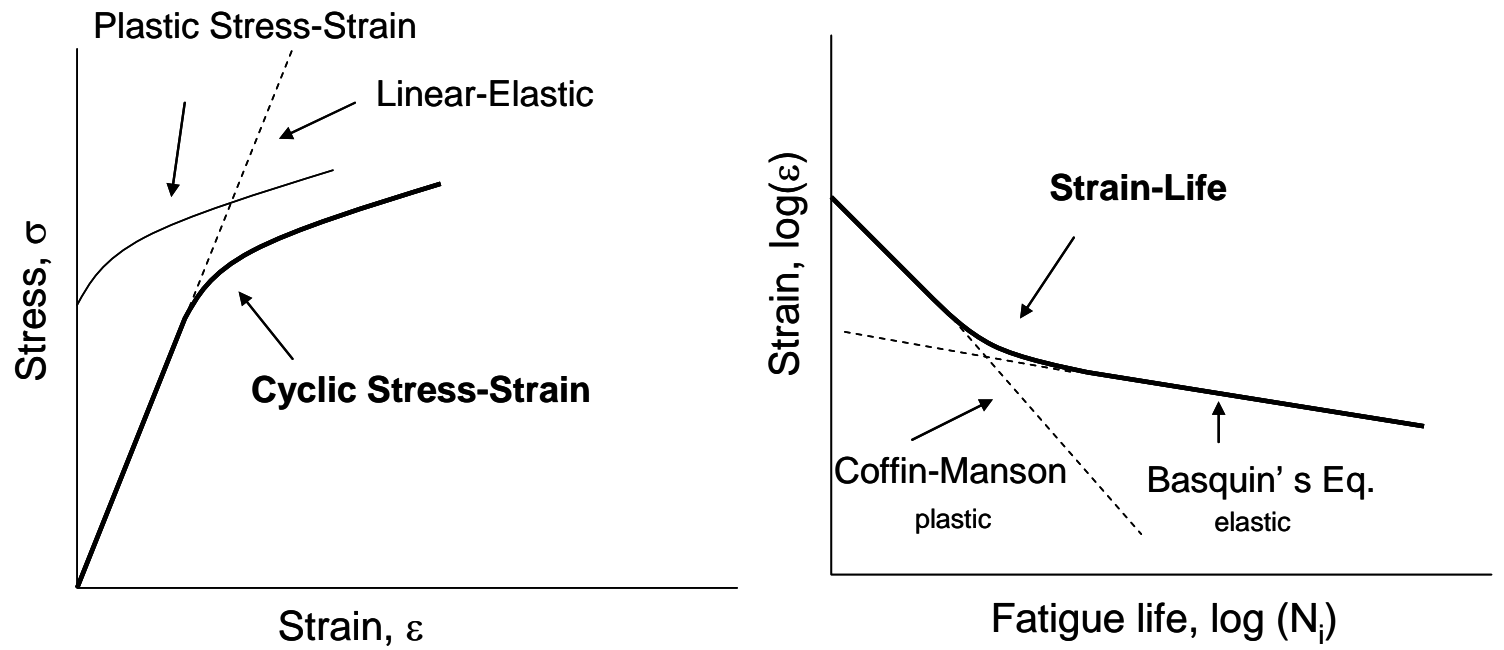

Fatigue life, $\log \left(\mathrm{N}_{\mathrm{i}}\right)$

Figure 2.5. Cyclic stress-strain and strain-life curves.

There are two strain components that make up the cyclic stress-strain curve, which are the linear-elastic portion $\left(\varepsilon_{\mathrm{el}}\right)$ and the plastic stress-strain $\left(\varepsilon_{\mathrm{pl}}\right)$. The linear-elastic strain is given by Eq. 2.7 for a uni-axial stress state as a function of the elastic modulus (E),

$$
\varepsilon_{e l}=\frac{\sigma}{E}
$$

The plastic strain $\left(\varepsilon_{\mathrm{pl}}\right)$, given by Eq.2.8, is a function of the strain hardening coefficient $\left(K^{\prime}\right)$, and the strain hardening exponent $\left(n^{\prime}\right)$,

$$
\varepsilon_{p l}=\left(\frac{\sigma}{K^{\prime}}\right)^{1 / n^{\prime}}
$$


The combined elastic and plastic strains constitute the total strain that is known as the cyclic stress-strain equation,

$$
\varepsilon_{t}=\frac{\sigma}{E}+\left(\frac{\sigma}{K^{\prime}}\right)^{1 / n^{\prime}}
$$

Likewise, the strain-life equation is made up of an elastic and plastic term. The elastic strain-life term is known as Basquin's Equation [7],

$$
\frac{\Delta \varepsilon_{e l}}{2}=\frac{\sigma_{f}^{\prime}}{E}\left(N_{i}\right)^{b}
$$

where $\sigma_{f}^{\prime}$ is the fatigue strength coefficient, $\mathrm{b}$ is the fatigue strength exponent, $\mathrm{E}$ is the elastic modulus.

The plastic strain-life term is known as the Coffin-Manson Equation [7],

$$
\frac{\Delta \varepsilon_{p l}}{2}=\varepsilon_{f}^{\prime}\left(N_{i}\right)^{c}
$$

where $\varepsilon_{f}^{\prime}$ is the strain ductility coefficient, c is the strain ductility exponent. 
The combined total strain equation is known as the strain-life equation,

$$
\frac{\Delta \varepsilon_{t}}{2}=\frac{\sigma_{f}^{\prime}}{E}\left(N_{i}\right)^{b}+\varepsilon_{f}^{\prime}\left(N_{i}\right)^{c}
$$

Note that the strain-life equation is defined in terms of cycles $(\mathrm{N})$. However, most published texts [6,7] show the strain-life equation as a function of reversals to failure $\left(2 N_{f}\right)$, where two reversals equals one cycle. However, the published texts also show graphs of strain-life as a function of strain amplitude versus cycles $(\mathrm{N})$. This is a source of confusion since the same symbol $(\mathrm{N})$ is used interchangeably to denote cycles or reversals based on the context of the discussion. Too avoid confusion, all equations and graphs will define $\mathrm{N}$ as cycles, and reversals will not be referred to in this text.

Cycles may be more precisely specified as cycles to failure $\left(N_{f}\right)$ or cycles to initiation $\left(N_{i}\right)$. Cycles to initiation is the number of cycles until initiation of a crack is determined by a certain percentage load drop during strain-controlled testing. Cycles to failure is defined as the number of cycles until specimen failure occurs. Basquin’s equation and the Coffin-Manson equation were originally published in terms of cycles to failure $\left(N_{f}\right)$. However, the more modern practice is to divide fatigue into crack initiation and crack growth after a crack has reached a minimum detectable size [12]. As such, Basquin's equation and the Coffin-Manson equation, which together form the strain-life equation will be defined in terms of cycles to initiation $\left(N_{i}\right)$. It is recognized that older reference data may use the convention of cycles to failure $\left(N_{f}\right)$. 
Although all of the data used within this thesis was intended to be fully-reversed data with zero mean stress, a small mean stress occurred due to normal material behavior. The method to account for the mean stress was by using the Modified Morrow [7] form of Basquin's equation,

$$
\frac{\Delta \varepsilon_{e}}{2}=\frac{\sigma_{f}^{\prime}-\sigma_{m}}{E}\left(N_{i}\right)^{b}
$$

where the $\sigma_{\mathrm{m}}$ term represents the mean stress for each data point.

The Modified Morrow [7] strain-life equation is given by

$$
\frac{\Delta \varepsilon_{t}}{2}=\frac{\sigma_{f}^{\prime}-\sigma_{m}}{E}\left(N_{i}\right)^{b}+\varepsilon_{f}^{\prime}\left(N_{i}\right)^{c}
$$

Linear regression is used to determine the seven constants $\left(E, K^{\prime}, n^{\prime}, \sigma_{f}^{\prime}, b, \varepsilon_{f}^{\prime}, c\right)$, which define the cyclic stress-strain, and strain-life equations. The procedure for linear regression curve fitting is defined by the ASTM standard practice [13]. Six constants are found from $\log -\log$ relationships ( $\varepsilon$ versus $\mathrm{N}$ and $\sigma$ versus $\varepsilon$ ), and one constant is from a linear relationship ( $\sigma$ versus $\varepsilon$ ). Linear regression is given by standard least squared curve fitting procedure for the linear functions. The SLOPE and INTERCEPT functions built into MS Excel can be used for linear regression. These functions readily provide the slope and intercept for two given arrays of dependent and independent variables. 
The standard least squares fitting procedure is slightly modified for a log-log fit. The data is input into the form shown in the following equation

$\log (y)=m \log (x)+b$

where $\log (\mathrm{x})$ is the independent variable, $\log (\mathrm{y})$ is the dependent variable, $\mathrm{m}$ is the slope, and $\mathrm{b}$ is the intercept.

To provide Eq. 2.15 in the power law form, the base 10 is taken of both sides, and rearranged to form Eq. 2.16

$y=10^{b} x^{m}$

This shows that the standard linear regression procedure can be used for log-log data to define the constant and exponent of a power law function, where $10^{\mathrm{b}}$ is the constant, and $\mathrm{m}$ is the exponent.

The standard procedure requires a separate linear regression be performed using data at each temperature level. Table 2.1 lists the required linear regressions to find the seven constants to determine the stress-strain and strain-life equations. 
Table 2.1. Linear regressions required to find curve fit constants.

\begin{tabular}{|l|l|l|l|l|}
\hline $\begin{array}{l}\text { Constant } \\
\text { Name }\end{array}$ & Dependent Variable & $\begin{array}{l}\text { Independent } \\
\text { Variable }\end{array}$ & $\begin{array}{l}\text { MS Excel } \\
\text { Function Used }\end{array}$ & $\begin{array}{l}\text { Constant } \\
\text { Value }\end{array}$ \\
\hline$\sigma f^{\prime} / \mathrm{E}$ & $\log \left(\varepsilon_{\mathrm{el}, \text { Modified Morrow }}\right)$ & $\log \left(\mathrm{N}_{\mathrm{i}}\right)$ & INTERCEPT & $10^{\circ}$ \\
\hline $\mathrm{b}$ & $\log \left(\varepsilon_{\mathrm{el}, \text { Modified Morrow }}\right)$ & $\log \left(\mathrm{N}_{\mathrm{i}}\right)$ & SLOPE & $\mathrm{m}$ \\
\hline $\mathrm{ff}^{\prime}$ & $\log \left(\varepsilon_{\mathrm{pl}}\right)$ & $\log \left(\mathrm{N}_{\mathrm{i}}\right)$ & INTERCEPT & $10^{\mathrm{D}}$ \\
\hline $\mathrm{c}$ & $\log \left(\varepsilon_{\mathrm{pl}}\right)$ & $\log \left(\mathrm{N}_{\mathrm{i}}\right)$ & SLOPE & $\mathrm{m}$ \\
\hline $\mathrm{E}$ & $\sigma_{\mathrm{a}}$ & $\varepsilon_{\mathrm{el}}$ & SLOPE & $\mathrm{m}$ \\
\hline $\mathrm{K}^{\prime}$ & $\log \left(\sigma_{\mathrm{a}}\right)$ & $\log \left(\varepsilon_{\mathrm{pl}}\right)$ & INTERCEPT & $10^{\mathrm{D}}$ \\
\hline $\mathrm{n}^{\prime}$ & $\log \left(\sigma_{\mathrm{a}}\right)$ & $\log \left(\varepsilon_{\mathrm{pl}}\right)$ & SLOPE & $\mathrm{m}$ \\
\hline
\end{tabular}

One issue arises that limits the allowable data for use in the regression analysis. In very high cycle fatigue (VHCF) testing, the plastic strain is approximately zero, and is too small for detection. Data points with negligible plastic strain must be neglected from regression analysis to find the constants involving plastic strain $\left(\varepsilon_{f}^{\prime}, c, K^{\prime}, n^{\prime}\right)$.

The ASTM standard practice [13] provides a recommended number of data points to find curve fits at two quality levels: preliminary and design. A preliminary curve fit is provided by 6 to 12 tests, and 12 to 24 data points is necessary to provide curve fits acceptable for design. The quantity of data points at $24^{\circ} \mathrm{C}, 750^{\circ} \mathrm{C}$, and $900^{\circ} \mathrm{C}$ are considered preliminary quality levels, and the $400^{\circ} \mathrm{C}$ and $850^{\circ} \mathrm{C}$ are considered design quality levels.

If the test matrix is chosen carefully, the test data points will include sufficient data to characterize both the elastic and plastic strains as depicted in Figure 2.6. This will provide curve fit constants, which are valid over the entire range of stress amplitude and cycles that are classified as low-cycle fatigue. Recall that LCF is typically defined by stress amplitudes between yield and ultimate strength, and cyclic lives between $10^{2}$ to $10^{4}$ cycles [5]. 


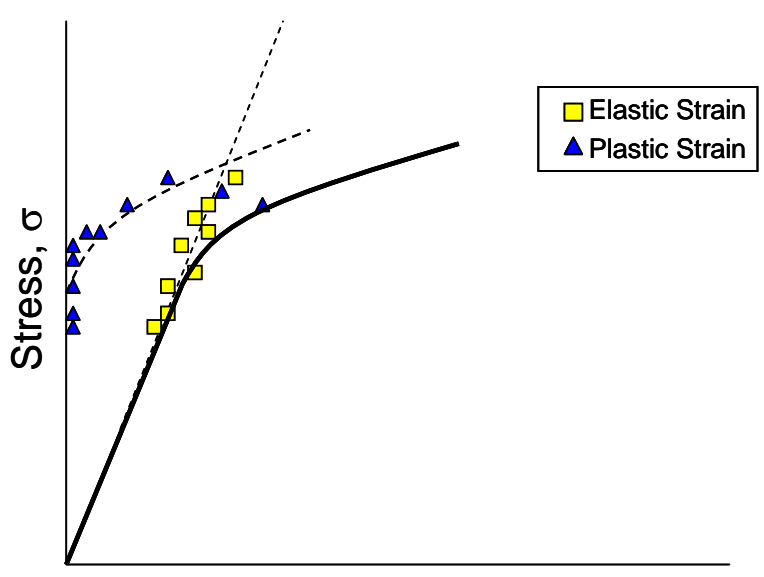

Strain, $\varepsilon$

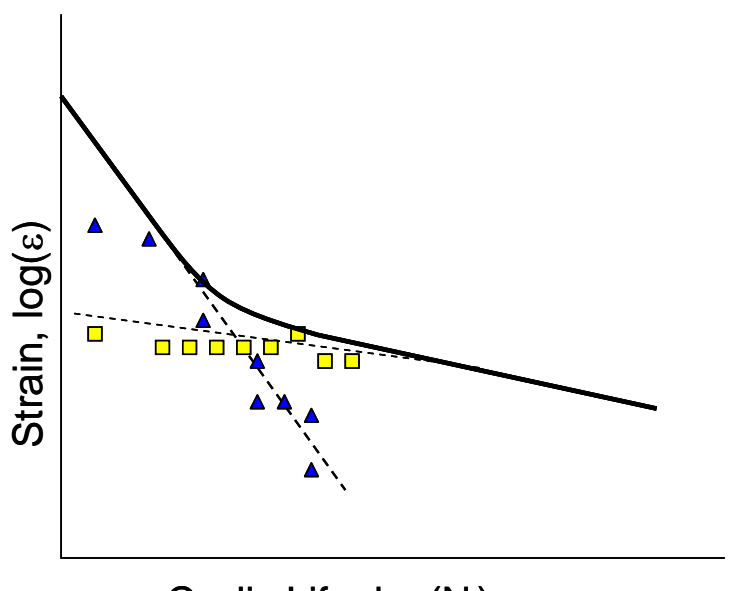

Cyclic Life, $\log \left(\mathrm{N}_{\mathrm{i}}\right)$

Figure 2.6. Depiction of sufficient data to characterize elastic and plastic strain.

Issues often arise when attempting to curve fit the stress-strain, and strain-life equation. One reference offers the following guidelines when attempting to fit the strainlife equation to test data [7]:

1) Not all materials may be represented by the total strain-life equation (Eq. 2.12).

2) The four fatigue constants $\left(\sigma_{f}^{\prime}, b, \varepsilon_{f}^{\prime}, c\right)$ may represent a curve fit to a limited number of data points. The values of these constants may be changed if more data points are included in the curve fit.

3) The fatigue constants are determined from a set of data points over a given range. Gross errors may occur when extrapolating fatigue life estimates outside this range.

4) The use of the strain-life equation is strictly a matter of mathematical convenience and is not based on a physical phenomenon. 
Fatigue data that comprise of experiments where the $\Delta \varepsilon_{\mathrm{pl}}<<\Delta \varepsilon_{\mathrm{t}}$ are very useful for characterizing the fatigue constants for Basquin’s equation. However, when the plastic strain data is negligible the plastic strain constants $\left(\varepsilon_{f}^{\prime}, c, K^{\prime}, n^{\prime}\right)$ are known to very limited accuracies. Figure 2.7 represents the condition where there is limited plastic strain data. In this case, many potential curve fits (shown as curves A, B, or C) could pass through the limited plastic strain data points.

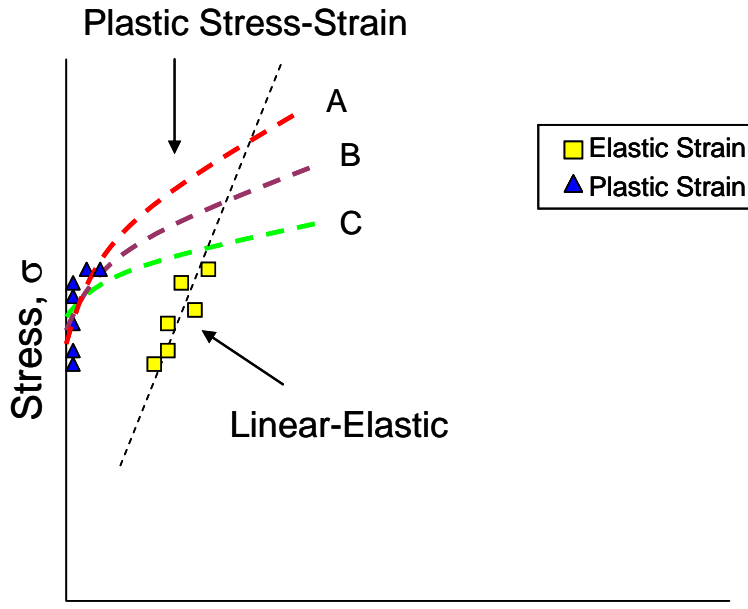

Strain, $\varepsilon$

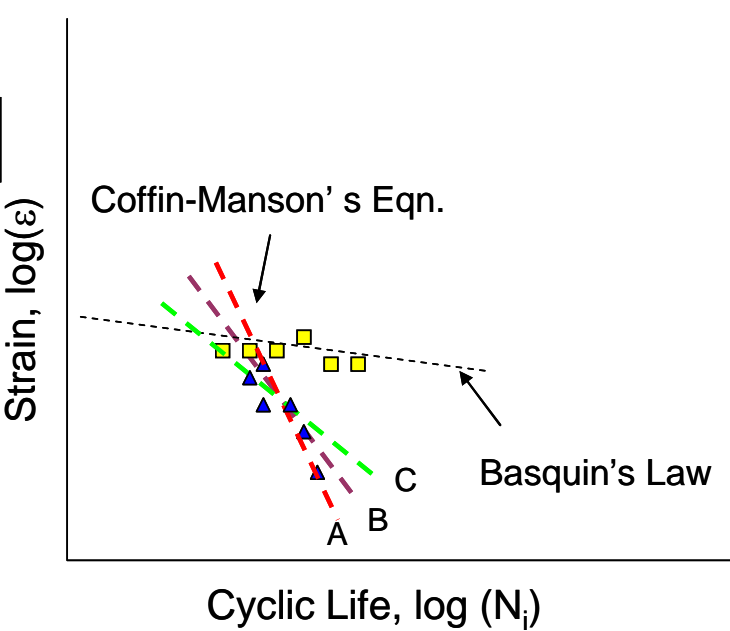

Figure 2.7. LCF data set with insufficient plastic strain data for definition of plastic strain terms.

Several other short-comings in the accepted methodology are noted. The current methodology is simply a curve fit through the acquired test data, and does not provide any guidance for determining whether the resulting model fits the anticipated behavior. Also, no published methods exist to estimate the fatigue properties of a Ni-base superalloy. This information would be very helpful for initial set up of an LCF test matrix.

The following is a presentation of one approach to estimating the LCF life of a gas turbine component. Steady-state component stress can be predicted by the use of a 
linear-elastic FE model as shown in Fig. 2.8. The model shown in this figure is of a rotating turbine blade, which must sustain significant thermal and mechanical loading. The first step in calculating LCF life is recording the stress and temperature $\left(\sigma_{a}\right.$ and $\left.T_{a}\right)$ in the region of concern in the FE model.

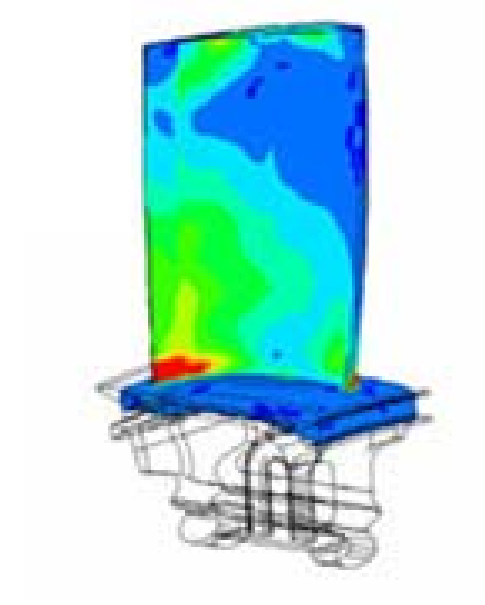

Turbine blade FE model

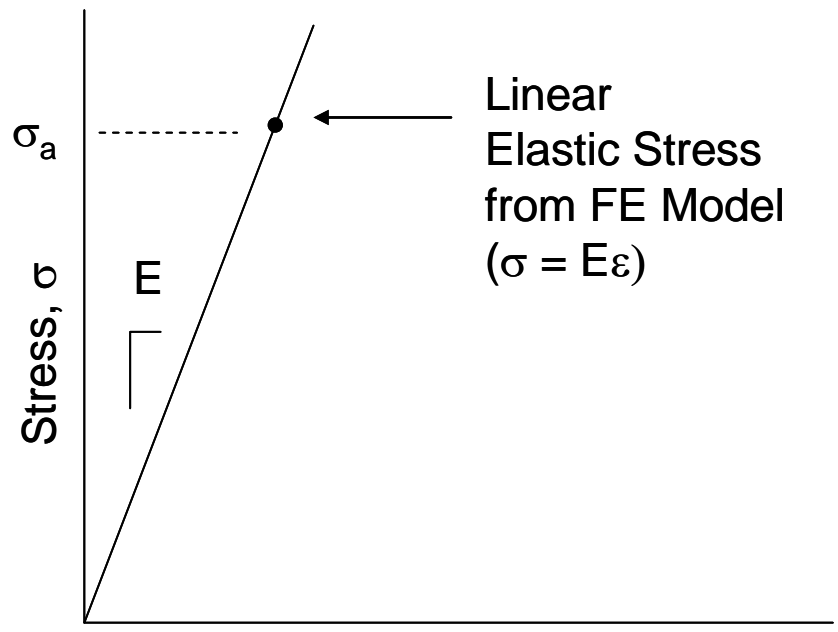

Strain, $\varepsilon$

Figure 2.8. Linear-elastic FE model stress results.

A stress shake-down must be performed to capture the effects of initial yielding. This initial yielding shake-down is used to find the stress $\left(\sigma_{\mathrm{A}}\right)$ and strain $\left(\varepsilon_{\mathrm{A}}\right)$ on the monotonic stress-strain curve, which corresponds to the elastic stress $\left(\sigma_{\mathrm{a}}\right)$ and strain $\left(\varepsilon_{\mathrm{a}}\right)$ from the FE model as shown in Fig. 2.9. The monotonic stress-strain curve is of the same form as the cyclic stress-strain curve (Eq. 2.9), except that the constants ( $K^{\prime}$ and $\left.n^{\prime}\right)$ are from tensile test data. The cyclic stress-strain curve is used at the peak temperature of interest $\left(T_{a}\right)$. A common method for shake-down uses Neuber's rule [6], 
$\sigma_{A} \varepsilon_{A}=\frac{\left(K_{t} \sigma_{a}\right)^{2}}{E}$

where $K_{t}$ a stress concentration factor applied to the linear elastic stress, and $E$ is the elastic modulus. The stress $\left(\sigma_{\mathrm{A}}\right)$ and strain $\left(\varepsilon_{\mathrm{A}}\right)$ are found by iteratively solving with the monotonic stress-strain equation (similar to Eq. 2.9).

The Bauschinger effect is commonly used to describe unloading, which is the observation that yielding upon unloading often occurs prior to the stress reaching the yield strength for monotonic compression. Kinematic hardening assumes that yielding occurs upon unloading at $2 \sigma_{y}$, and is in agreement with the Bauschinger effect [6].

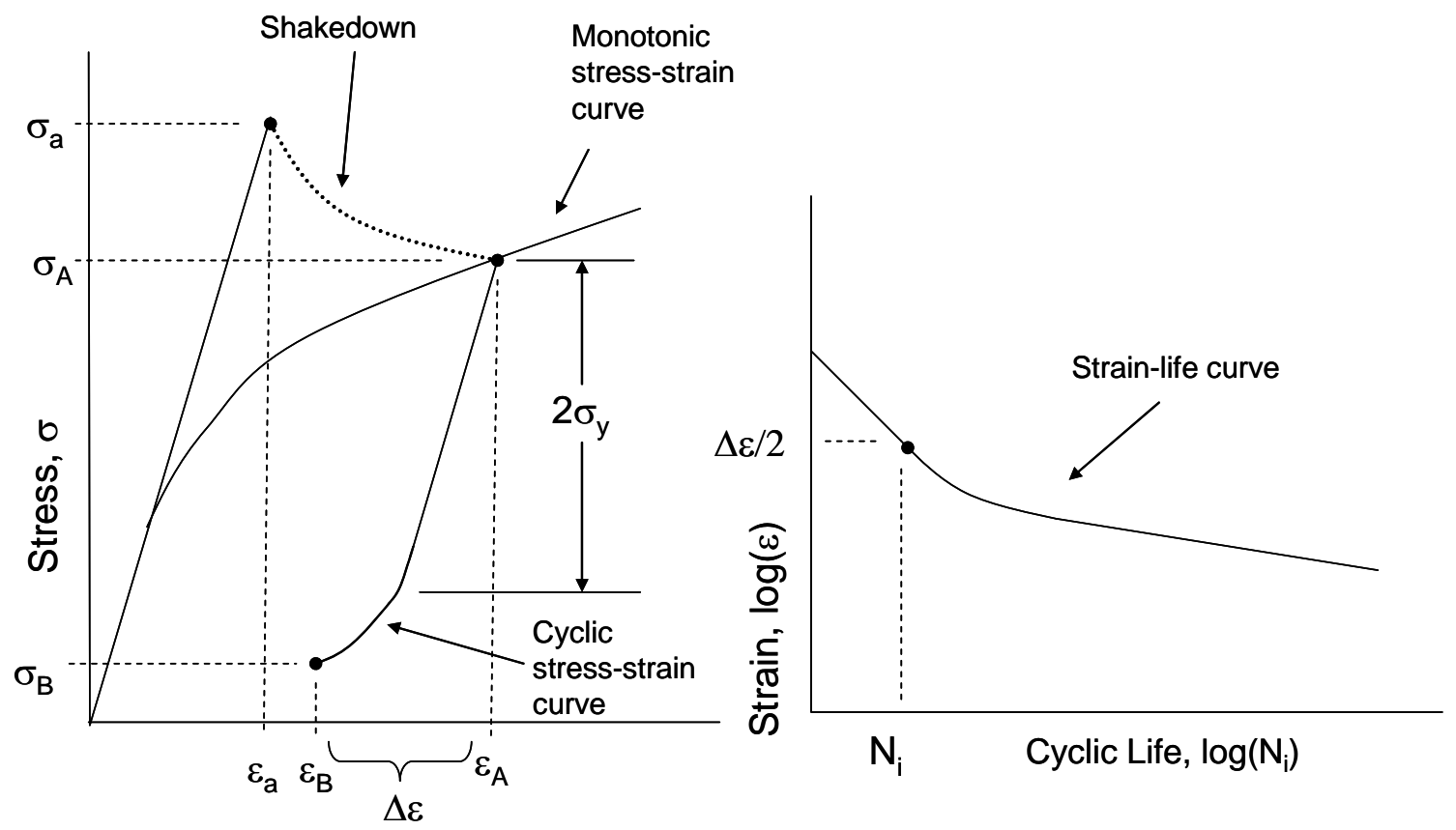

Figure 2.9. Process of LCF life determination.

If the stress $\left(\sigma_{\mathrm{B}}\right)$ and temperature $\left(\mathrm{T}_{\mathrm{b}}\right)$ upon shut-down are known, then kinematic hardening and the cyclic stress-strain curve can be used to solve for the strain $\left(\varepsilon_{\mathrm{B}}\right)$ upon 
unloading. This information can be used to estimate the strain range $(\Delta \varepsilon)$ that the component will experience during cyclic operation. This strain range can be compared to data from a strain-life curve to estimate the component cyclic life. The strain-life data is typically from tests corresponding to the steady-state operating temperature of the component $\left(\mathrm{T}_{\mathrm{a}}\right)$.

\subsection{Reference Methods}

Historically, there have been several methods used to estimate the low-cycle fatigue behavior of materials. These classes of methods include: equations of approximation, strain compatibility, and anchor points, and the following includes a discussion of each.

Many approximations exist for estimating the four fatigue constants $\left(\sigma_{f}^{\prime}, b, \varepsilon_{f}^{\prime}, c\right)$ in the strain-life curve (Eq. 2.12) [14, 15, 16, 17, 18]. Some of the most well known approximation methods include: Manson’s Universal Slopes, Manson’s Four Point, and the Modified Four Point by Ong. Each of these methods approximates fatigue data in terms of monotonic tensile test data. If monotonic tests at elevated temperatures are available, the temperature dependence effect can be estimated using these equations. Manson proposed the Four-Point Correlation Method, which provides an approximation for the strain-life constants [15], 


$$
\begin{aligned}
& \sigma_{f}^{\prime}=\frac{E}{2} \times 10^{b \log (2)+\log \left[\frac{2.5 \sigma_{U L T}(1+e)}{E}\right]} \\
& b=\frac{\log \left[\frac{2.5(1+e)}{0.9}\right]}{\log \left[\frac{1}{4 \times 10^{5}}\right]} \\
& \varepsilon_{f}^{\prime}=\frac{1}{2} \times 10^{c \log \left(\frac{1}{20}\right)+\log \left(\frac{1}{4} e^{3 / 4}\right)} \\
& c=\frac{1}{3} \log \left[\frac{0.0132-\Delta \varepsilon^{*}}{1.91}\right]-\frac{1}{3} \log \left(\frac{1}{4} e^{3 / 4}\right) \\
& \Delta \varepsilon^{*}=10{ }^{b \log \left(4 \times 10^{4}\right)+\log \left[\frac{2.5 \sigma_{U L T}(1+e)}{E}\right]}
\end{aligned}
$$

This method used knowledge of typical points on the strain-life curve for the elastic and plastic components to estimate the constants [14]. These equations are a function of the elongation to failure (e), and the ultimate tensile strength $\left(\sigma_{\mathrm{ULT}}\right)$. A new variable is defined in this equation $\left(\Delta \varepsilon^{*}\right)$, which is the elastic strain range at $10^{4}$ cycles.

The equations for Manson’s Universal Slopes approximation method are as follows [14]:

$$
\begin{aligned}
& \sigma_{f}^{\prime}=3.5 \sigma_{U L T} \\
& b=-0.12 \\
& \varepsilon_{f}^{\prime}=\left\{\ln \left[\frac{1}{1-R A}\right]\right\}^{0.6} \\
& c=-0.6
\end{aligned}
$$


This method is a function of the ultimate tensile strength $\left(\sigma_{\mathrm{ULT}}\right)$, and the reduction in area (RA). These equations assume that the slopes of the elastic and plastic strain terms in the strain-life equation are constant for all materials.

The constants for Ong's Modified Four-Point Correlation method [15] is given by:

$$
\begin{aligned}
& \sigma_{f}^{\prime}=\sigma_{U L T}(1+e) \\
& b=\frac{1}{6}\left\{\log \left[0.16\left(\frac{\sigma_{U L T}}{E}\right)^{0.81}\right]\right\}-\log \left(\frac{\sigma_{U L T}}{E}\right) \\
& \varepsilon_{f}^{\prime}=e \\
& c=\frac{1}{4} \log \left(\frac{0.00737-\Delta \varepsilon_{e}^{*}}{2.074}\right)-\log (e) \\
& \frac{\Delta \varepsilon_{e}^{*}}{2}=\left(\frac{\sigma}{E}\right) 10^{\frac{2}{3}\left\{\log \left[0.16\left(\frac{\sigma_{U L T}}{E}\right)^{0.81}\right] \log \left(\frac{\sigma_{f}^{\prime}}{E}\right)\right\}} \\
& \sigma_{f} \cong \sigma_{f}^{\prime}
\end{aligned}
$$

This approximation uses the same procedure as Manson’s Four-Point Method except that the author adjusted some terms to improve the curve fit to tensile data [17]. These equations are a function of the ultimate strength $\left(\sigma_{\mathrm{ULT}}\right)$, the elongation to failure $(\mathrm{e})$, and the elastic modulus (E). The term variable $\frac{\Delta \varepsilon_{e}^{*}}{2}$ is the elastic strain at $10^{4}$ cycles.

There are limitations to the approximation models. Of the 29 materials evaluated in Manson's paper which proposes his two methods, only one is a Ni-base superalloy (Inconel-X). Most of the tests used in deriving these relations were with steel, and used 
to examine the correlation are at room temperature. Several investigators [15,16, and 18] compare the approximation methods to test data, most of which is at room temperature. Meggiolaro and Castro [18] compare the strain-life curve in the low-cycle range for steel at various temperatures between room temperature to $800^{\circ} \mathrm{C}$, and come to the unlikely conclusion that the temperature effects do not generally affect the results.

The method used to evaluate the three approximation methods is by comparing the approximation models to the standard methodology model using strain-controlled test data at the test temperature of $750^{\circ} \mathrm{C}$. Comparison of the results show that the approximation methods are non-conservative, and use of these equations is expected to over-estimate life as shown in Fig. 2.10. Manson's Four Point correlation and Ong are very similar, but over estimate life by an order of magnitude. Manson’s Universal Slopes over-estimates life by two orders of magnitude.

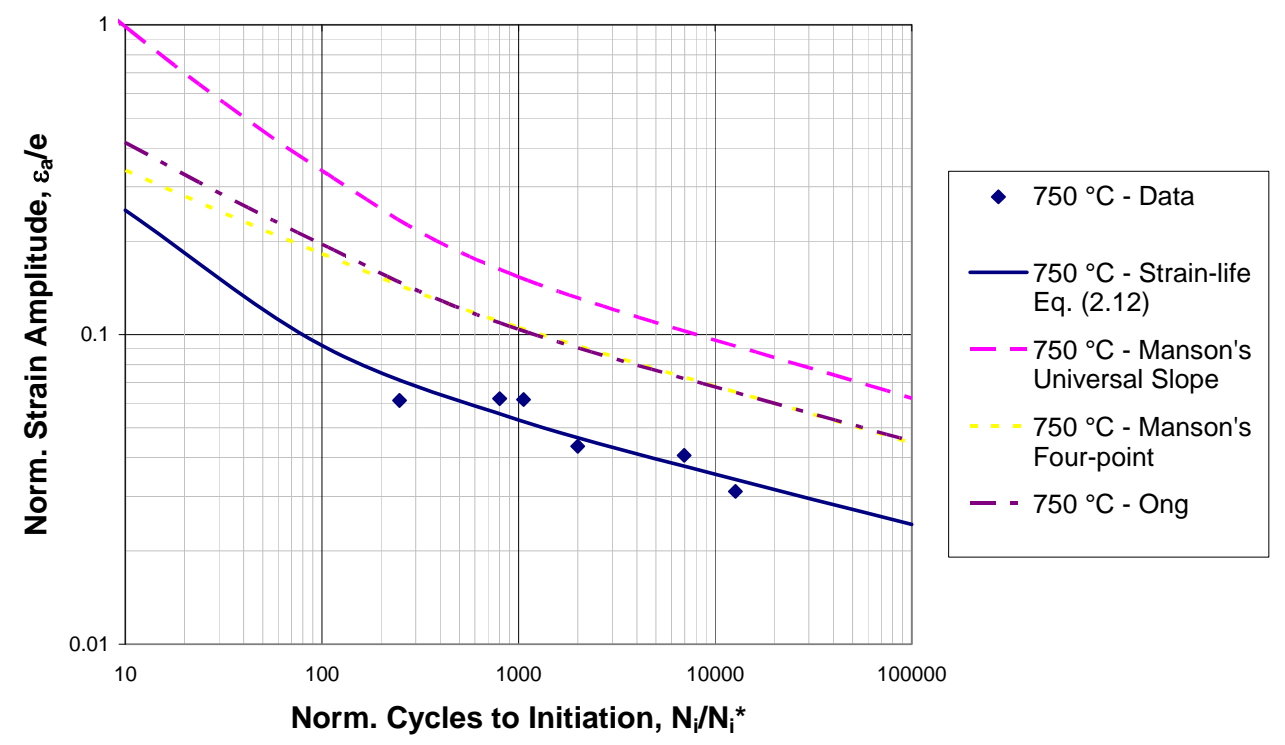

Figure 2.10. Approximation methods to curve fit from LCF test data for IN738 LC at $750^{\circ} \mathrm{C}$. 
The $\mathrm{R}^{2}$ errors listed in Table 2.2 confirm that the standard methodology provides the best fit through the test data. See section 3.4 for a thorough description of $\mathrm{R}^{2}$. As such, it was concluded that most approximation methods do not work well for predicting the behavior of this alloy at elevated temperatures.

Table 2.2. Strain-life fatigue constant comparison.

\begin{tabular}{|c|r|c|c|c|}
\hline & $\begin{array}{r}\text { Curve Fit } \\
\text { from LCF } \\
\text { Test Data }\end{array}$ & $\begin{array}{c}\text { Manson's } \\
\text { Slopes } \\
(1965)\end{array}$ & $\begin{array}{c}\text { Manson's } \\
\text { four point } \\
(1965)\end{array}$ & $\begin{array}{c}\text { Ong } \\
(1993)\end{array}$ \\
\hline $\mathrm{R}^{2}$ Error & 0.914 & 0.661 & 0.738 & 0.708 \\
\hline
\end{tabular}

Burke and Beck [10] offer a unique proposal by suggesting a modified-strain life equation (Eq. 2.12). This paper included LCF test data of Ni-base superalloy IN617 at $760^{\circ} \mathrm{C}$ and $871^{\circ} \mathrm{C}$. The proposed approximation method is to combine the plastic strain data for both temperatures in determining the slope for the Coffin-Manson equation (Eq. 2.10) given by the fatigue ductility exponent (c). Recall that the present methodology groups data into like temperatures for regression analysis. This proposed equation is shown in Eq. 2.21, with the constants defined the same as Eq. 2.12. Note that the temperature dependence is demonstrated by showing the constants as a function of $\mathrm{T}$.

$$
\frac{\Delta \varepsilon_{t}}{2}=\varepsilon_{f}^{\prime}(T)\left(N_{i}\right)^{-c}+\frac{\sigma_{f}^{\prime}(T)}{E(T)}\left(N_{i}\right)^{-b(T)}
$$

A method exists for approximating the constants in the stress-strain equation (e.g. $\left.K^{\prime}, n^{\prime}\right)$ from known constants in the strain-life equation $\left(\sigma_{f}^{\prime}, b, \varepsilon_{f}^{\prime}, c\right)$ from Eq. 2.12. This method is provided by an assumption of strain equality between the elastic and 
plastic strains from the stress-strain relation (Eq. 2.9) and the elastic and plastic terms from the strain-life relation (Eq. 2.12). Equality of the elastic and plastic terms yields the following,

$$
\frac{\Delta \varepsilon_{e}}{2}=\frac{\sigma}{E}=\frac{\sigma_{f}^{\prime}}{E}\left(N_{i}\right)^{b}
$$

$$
\frac{\Delta \varepsilon_{p}}{2}=\left(\frac{\sigma}{E}\right)^{1 / n^{\prime}}=\varepsilon_{f}^{\prime}\left(N_{i}\right)^{c}
$$

If Eqs. 2.22 and 2.23 are solved for stress, and set equal to each other, then the following relation represents the strain compatibility in terms of cycles to initiation,

$$
\sigma_{f}^{\prime}\left(N_{i}\right)^{b}=K^{\prime} \varepsilon_{f}^{\prime n^{\prime}}\left(N_{i}\right)^{c n^{\prime}}
$$

Since the cycles to failure must be equal to each other, the intercept and slope of the two power law fits must be equal. This equality results in the two well known compatibility relations [7] solved for $K^{\prime}$ and $n^{\prime}$, i.e.,

$$
\begin{aligned}
& K^{\prime}=\frac{\sigma_{f}^{\prime}}{\varepsilon_{f}^{n^{\prime}}} \\
& n^{\prime}=\frac{b}{c}
\end{aligned}
$$


Recent studies [6,7, and 12] suggest that the preferred method to calculate $K^{\prime}$ and $n^{\prime}$ is by linear regression from stress and strain test data rather than Eqs. 2.25. Stephens and colleagues [12] offer some insight into why linear regression should be used. The resulting values of $K^{\prime}$ and $n^{\prime}$ could be similar or different depending on whether Eq. 2.25 is used instead for linear regression. A large difference can indicate that the elastic and plastic strain-life equation (Eq. 2.12) is not well represented by log-log linearized fits.

Most approximation methods estimate fatigue constants from monotonic test data. A common approximation $[8,14]$ used to estimated the failure stress $\left(\sigma_{f}\right)$ by including the increase in stress in a monotonic test after necking, or reduction in the cross-sectional area of the specimen has begun is given by:

$$
\sigma_{f}=\sigma_{U L T}(1+e)
$$

which is a function of the ultimate strength $\left(\sigma_{\mathrm{ULT}}\right)$ and elongation (e). This estimate of the failure stress is depicted in Fig. 2.11.

Likewise, the failure strain $\left(\varepsilon_{\mathrm{f}}\right)$ is often estimated by the failure elongation (e) or plastic deformation measured from a failure specimen.

$\varepsilon_{f}=e$ 

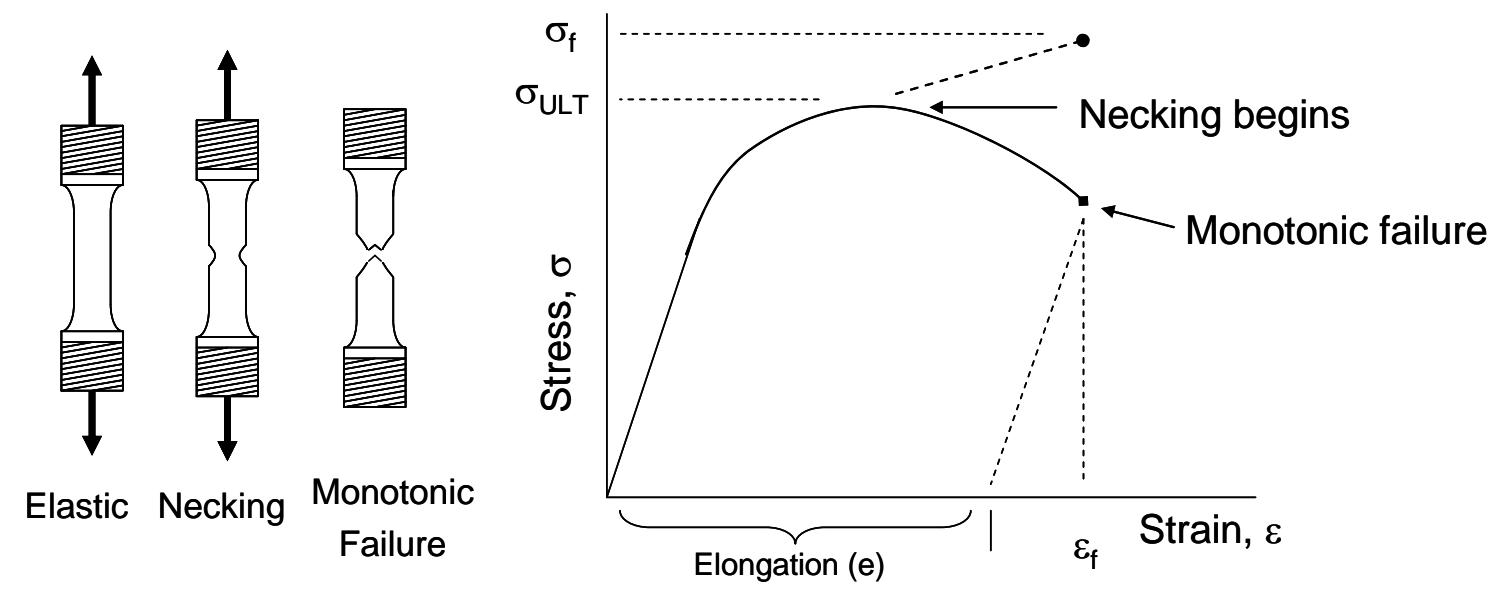

Figure 2.11. Depiction of monotonic test.

Another approximation technique is to include a monotonic test data point in with an existing LCF data set, which has been termed an anchor point. The purpose of the anchor point is to provide an improved qualitative fit of the stress-strain and strain-life curves outside of the LCF data points. A well chosen anchor point must not affect the curve fit over the range where actual LCF test data exists. The method of including the anchor point is to treat it as a fatigue data point during the linear regression modeling process. An anchor point is included with a typical LCF data set in Fig. 2.12. The anchor point is included at $1 / 2$ cycle, where the stress amplitude is the failure stress and the elongation is the failure strain. 

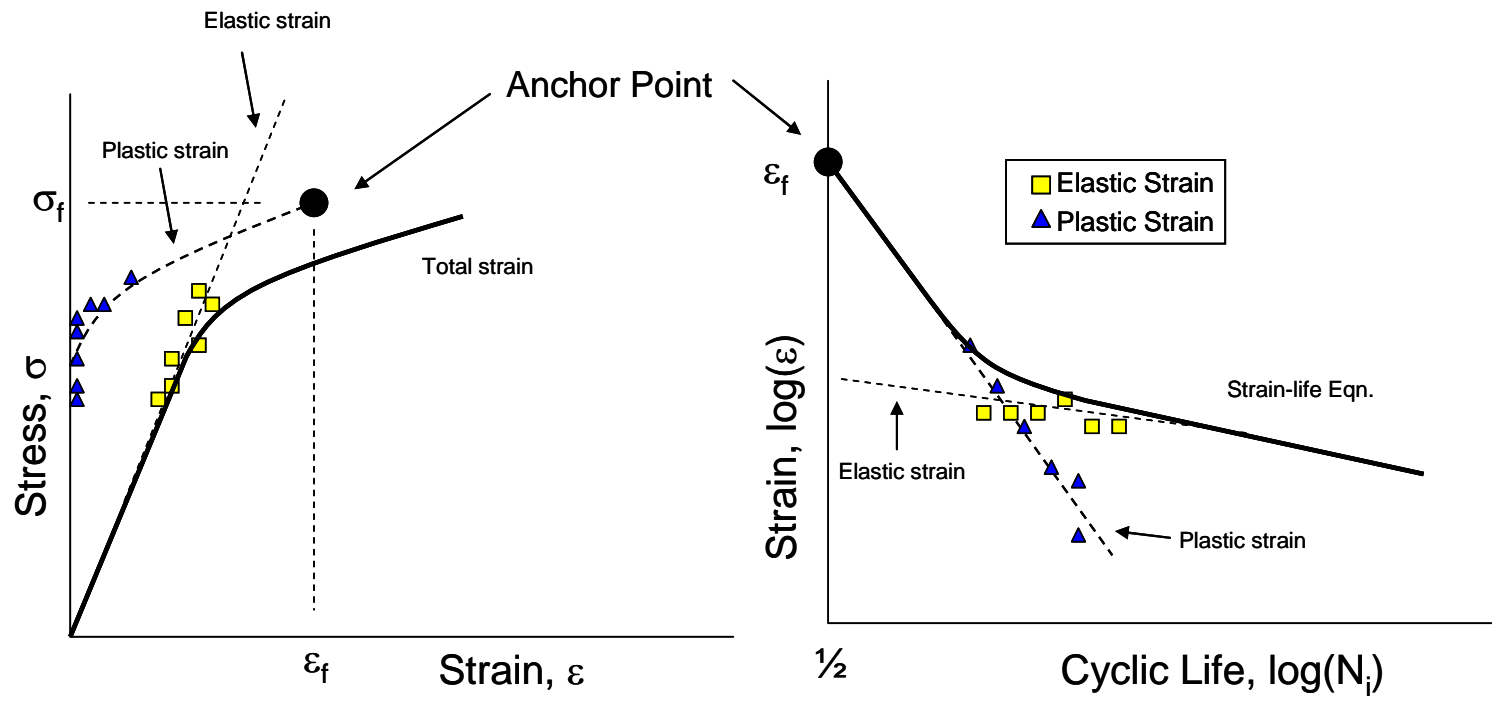

Figure 2.12. Depiction of anchor point.

\subsection{Existing Experimental Results}

Several references include IN738 LC strain-life data in the open literature $[3,9,11,19,20,21]$. Note that IN738 LC is a cast, Ni-base superalloy typically used for turbine components, where the LC stands for low carbon. Viswanathan [3] compares IN738 LCF and TMF strain-life data at $427^{\circ} \mathrm{C}$ and $871{ }^{\circ} \mathrm{C}$ at several strain rates. The Aerospace Structural Metals Handbook [19] contains strain-life data points for IN738 and IN738 LC, which includes critical information such as temperature, heat treatment, and strain rate. However, none of this data is of the same heat treatment, strain rate, and temperature as the data used for this thesis. Stress amplitude information is not available in this data as well. Yandt [20] studied IN738 $\mathrm{LC}$ at $950^{\circ} \mathrm{C}$ in a similar condition, and used a standard ASTM specimen design; however these tests were at a lower strain rate of $0.1 \%$ /minute, which is much lower than $6.0 \%$ /minute as used in this data. 
Danzer and Bressers [21] have published work using IN738 LC to consider the creep-fatigue interaction effects, rather than extrapolation of LCF test data to high stress amplitudes as with this project. Their work involves testing creep rupture and LCF tests independently, and are combining the effects with a linear time dependent damage accumulation rule.

Another source for data is provided by Marchionni [11], whom includes LCF test data at $850^{\circ} \mathrm{C}$ at the same strain rate as this project $(6.0 \% / \mathrm{min})$. However, the cyclic lives are a fraction of the measured values using data from this project for an unknown reason. The strain range is very high in this data with values up to $2.5 \%$. The specimen design is tubular for induction heating, and it is plausible that the difference in life is affected by the tubular cross-section. This data also shows the effect of testing in air rather than inert gas reduces the cyclic life at $850^{\circ} \mathrm{C}$ for IN738 LC.

Data from Morrow and Tuler [8] proved valuable by providing a reference data set with some very high strain LCF tests using Ni-base alloy IN713 LC. This data set is unique because it includes a broad range of test data into the very low cycle regime ( $0.67 \%$ to $4.1 \%$ strain and 5390 to 3 cycles). This data is from fully reversed tests at room temperature. One difference is that the specimens were from cast cylinders, whereas the IN738 LC data in the project was from a cast slab, and machined into specimens. The base material of IN713 LC is somewhat similar to IN738 LC. IN738 LC is typically used for turbine blades, and IN713 LC is a disk material. Both materials similar basic mechanical properties at room temperature as shown in Table 2.3. 
Table 2.3. Comparison of basic properties of IN713LC and IN738 LC.

\begin{tabular}{|c|c|c|}
\hline Material & IN 713 LC & IN 738 LC \\
\hline Reference & {$[6]$} & {$[17]$} \\
\hline \multicolumn{3}{|c|}{ Main Constituents (Weight \%) } \\
\hline Nickel & 73.5 & 61.5 \\
\hline Chromium & 13.0 & 16.1 \\
\hline Cobalt & 2.3 & 8.4 \\
\hline Titanium & 0.6 & 3.6 \\
\hline Aluminum & 6.0 & 3.3 \\
\hline Tungsten & - & 2.6 \\
\hline Molybedenum & 4.5 & 1.7 \\
\hline Tantalum & - & 1.7 \\
\hline Niobium & - & 0.9 \\
\hline Carbon & 0.1 & 0.2 \\
\hline Silicon & 0.4 & \\
\hline Iron & 1.0 & \\
\hline Manganese & 0.2 & \\
\hline \multicolumn{3}{|c|}{ Basic Properties at $25^{\circ} \mathrm{C}$} \\
\hline $\begin{array}{l}\text { Ultimate Tensile } \\
\text { Strength (MPa) }\end{array}$ & 1069 & 1062 \\
\hline $0.2 \%$ Yield & & \\
\hline Strength (MPa) & 831 & 883 \\
\hline Elongation \% & 10 & 8 \\
\hline $\begin{array}{l}\text { Reduction in Area } \\
\%\end{array}$ & 10 & 11 \\
\hline
\end{tabular}

The data set for IN713 LC shows some interesting trends at high strain ranges. A plot of the stress-strain curve is shown in Figure 2.13. It is seen that the data tends to follow a consistent power law fit, but above about $1.45 \%$ strain, the data shows a decrease towards the monotonic curve. Since the data points above $1.45 \%$ strain show a steep drop off in stress amplitude, only the data points below $1.45 \%$ strain were used to create the cyclic stress-strain curve fit. 


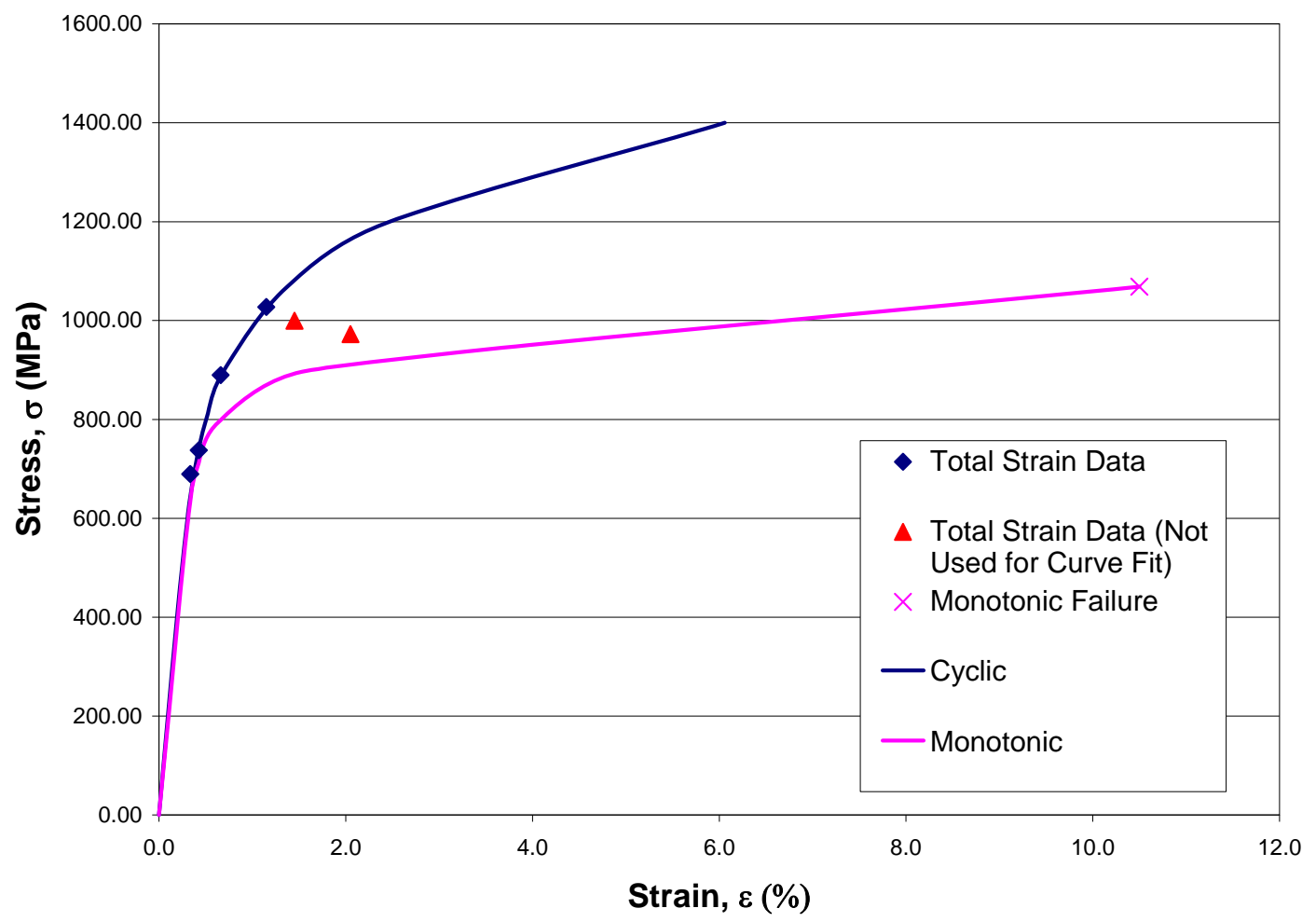

Figure 2.13. IN713 LC monotonic and cyclic stress-strain curve [6].

The data reveals that significant strain hardening has occurred below 1.45\% strain. Recall that Fig. 2.3 shows the effect of strain hardening, which results in a cyclic stress-strain curve above the monotonic stress-strain curve. An interesting feature of this data is that it appears to reveal an upper limit provided by the cyclic stress-strain curve, and a lower limit provided by the monotonic stress-strain curve.

A similar plot of the strain-life data for IN713 LC at room temperature is shown in Fig. 2.14. Lemaitre and Dufailly [5] report that the Coffin-Manson relationship overpredicts the reversals to failure at very low cycles. It is possible that this data shows a similar trend since the $4.1 \%$ strain data shows a drop from the strain-life equation. 
However, the strain-life equation is typically determined from data from stable hysteresis loops, and it is doubtful whether these could be achieved at only 3 cycles.

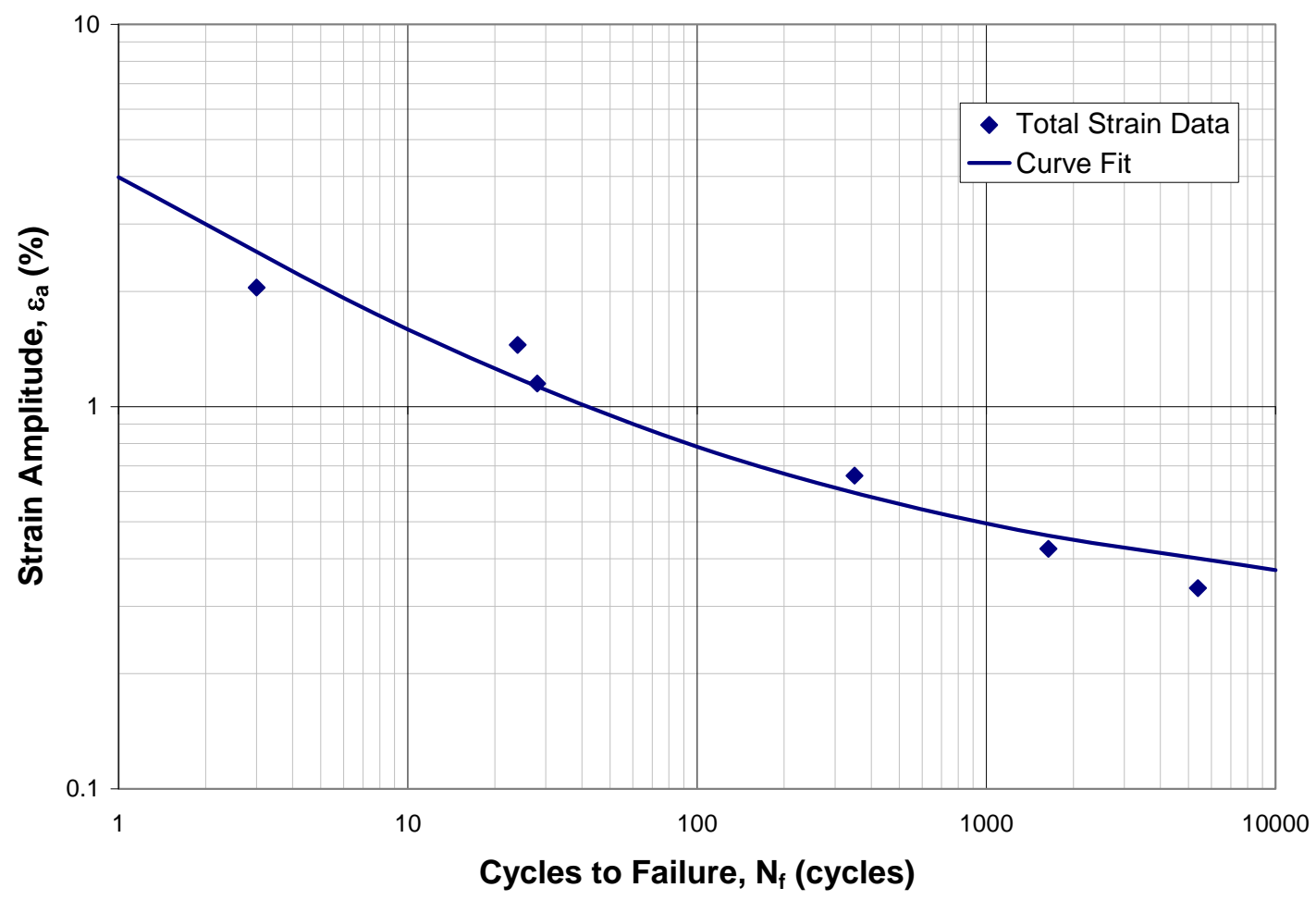

Figure 2.14. Strain-life curve for IN713 LC at room temperature [6].

\subsection{Thesis Objective}

Section 2.1 highlighted several of the issues have been discussed with the current LCF methodology. This methodology stipulates that the stress-strain equation (Eq. 2.9) and strain-life equation (Eq. 2.12) are only valid over the range of the available data. There are few publications showing efforts to extrapolate from moderate strain-range data sets into high strain-range and high stress amplitudes. It was demonstrated that several published extrapolation methods did not work well at approximating the high temperature strain-life behavior of a Ni-base superalloy. 
An investigation will be used to prove or disprove the following:

1) Low cycle fatigue behavior is described by an "upper bounds" when strain hardening or softening affects the stress-strain and strain-life equation, and a “lower bounds” when strain hardening or softening effects are negligible or at very high strain ranges where strain hardening or softening does not have sufficient cycles to occur. This hypothesis is shown graphically in Figure 2.15.

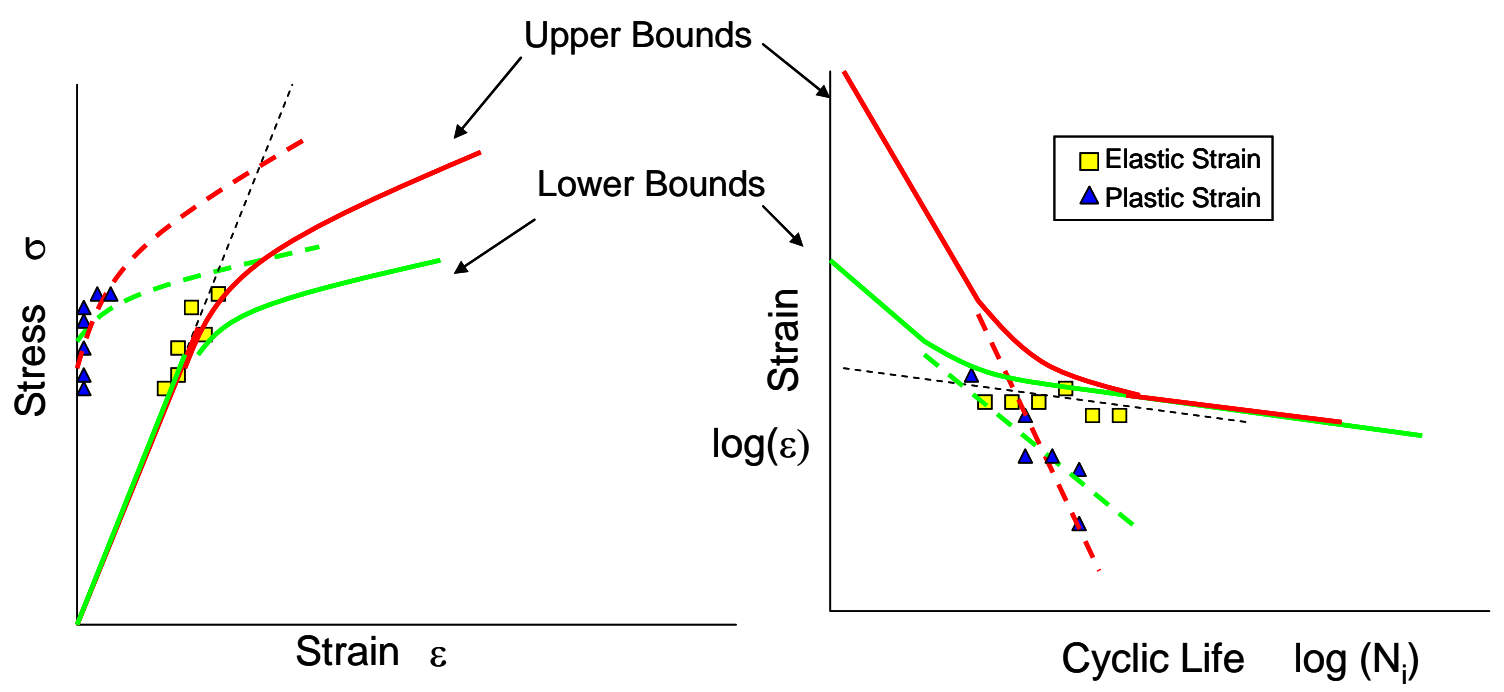

Figure 2.15. Bounding estimates for the stress-strain and strain-life equations.

2) The anchor point approach of including monotonic test data with fatigue test data is an accurate method for extrapolating high strain low cycle fatigue behavior when strain hardening or softening is negligible or at very high strain ranges where strain hardening or softening does not have sufficient cycles to occur.

3) An anchor point can provide an accurate representation of the upper bounds of material behavior, when it is scaled by estimated changes in the shape of the 
hysteresis loop between initial and mid-life cycles for to account for strain hardening or softening.

4) If the constants describing the elastic strains are known, then an effective anchor point failure stress can be calculated from monotonic test data at $1 / 2$ cycle, and making an assumption that the failure strain is equal to the elongation at failure. This effective anchor point will describe an upper bounds of material behavior including strain hardening or softening effects as necessary.

5) If significant scatter exists in the plastic strain-life data used for the CoffinManson (Eq. 2.11), and data exists for several different temperatures, then it is more accurate to group together all strain-life data, and assume temperature independence of the Coffin-Manson equation for all temperature data.

If these goals are achieved, the results will be improved fidelity in modeling the behavior of IN738 LC at high stress amplitudes and high strain ranges. 


\section{METHOD}

The following section presents several methods which allow improved ability to extrapolate from an existing test data set to predict high strain behavior of a Ni-base superalloy. The procedures for obtaining and handling the experimental fatigue data are discussed in the following sections.

\subsection{Normalization of Test Data}

The objective of this document is to show trends from a test data set, but the actual data points cannot be disclosed to the reader. Therefore, the value of each test data point has been normalized. The LCF test data used in this thesis is defined in terms of both the stress-strain curve and strain-life curves. Each stress $(\sigma)$ has been divided by the ultimate strength $\left(\sigma_{\mathrm{ULT}}\right)$ at temperature, and each strain $(\varepsilon)$ has been divided by the failure elongation (e) at temperature. The measured cyclic lives to crack initiation $\left(N_{i}\right)$ have been divided by an arbitrary constant $\left(N_{i}^{*}\right)$ as shown in Fig. 3.1. A similar process has been utilized as necessary to avoid disclosing the values of other test data throughout this document. 


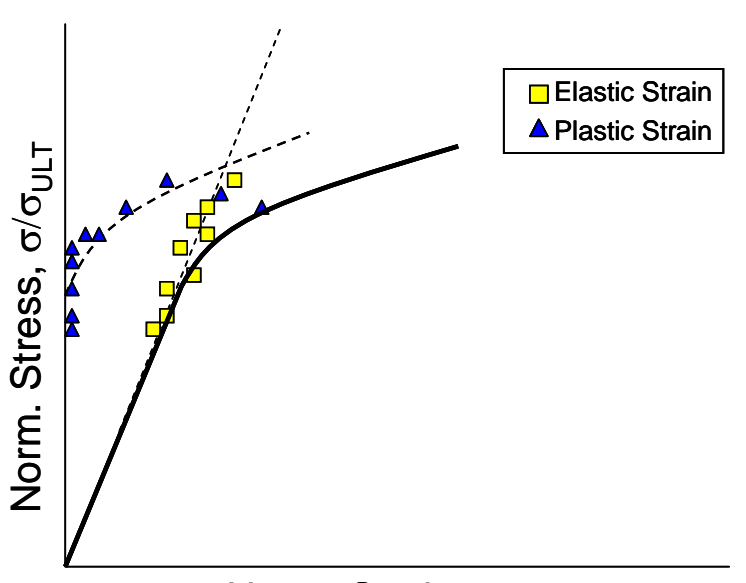

Norm. Strain, $\varepsilon / \mathrm{e}$

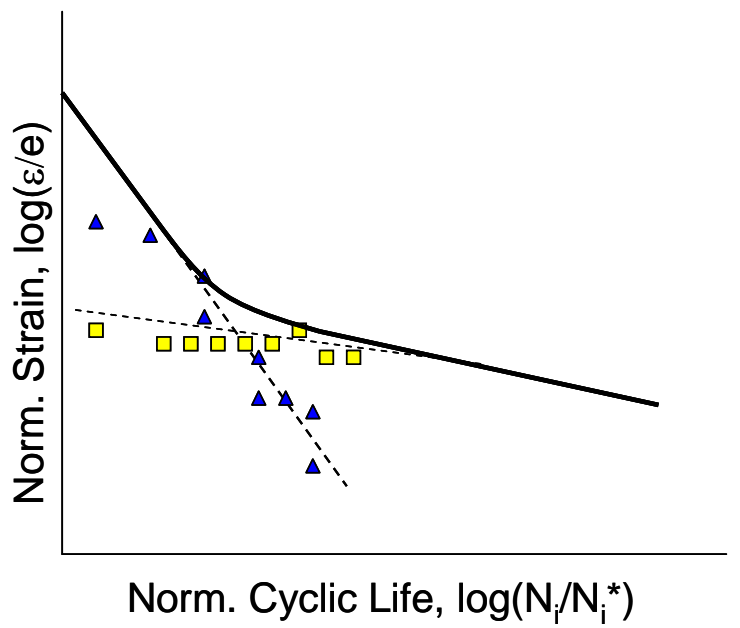

Norm. Cyclic Life, $\log \left(\mathrm{N}_{\mathrm{i}} / \mathrm{N}_{\mathrm{i}}^{*}\right)$

Figure 3.1. Depiction of method for protection of proprietary test data.

\subsection{Lower Bounds}

Recall that Section 2.3 includes a reference data set with high strain test data for IN713 LC at room temperature (RT), which shows significant strain hardening. Recall that the base anchor point is considered a method for providing a qualitative improvement in the cyclic stress-strain and strain-life curves at strain ranges outside of LCF test data. However, this method assumes that the base anchor point will provide an accurate estimate of behavior under certain circumstances. It is believed that the base anchor point will be accurate when very little strain hardening or softening occurs, or at very high strain ranges where failure occurs prior to having sufficient cycles for strain hardening or softening to take place.

The proposed method for predicting the lower bounds (LB) behavior is to include an anchor point representing monotonic failure into the base data set. This is equivalent to the reference anchor point as described in Section 2.2, and depicted in Fig. 2.12. 


\subsection{Upper Bounds}

The first method is denoted as Upper Bounds, Option 1 (UB1). This technique recognizes that that the anchor point method described in Section 2.2 does not account for strain hardening or softening, and the intention of UB1 is to modify the base anchor point to account for these effects. The reference test data shown in Section 2.3 demonstrates that strain hardening effects are significant in a similar Ni-base superalloy.

The proposed methodology uses evolution in the hysteresis loop between the first cycle and the mid-life stabilized cycle to extrapolate the monotonic anchor point to include strain hardening or softening effects as necessary. Fig. 2.3 shows the typical changes in the hysteresis loops between the initial and stabilized mid-life cycles that occur during strain hardening.

Strain hardening is defined as an increase in the stress amplitude until achievement of a stabilized value, and the initial stress range $\left(\Delta \sigma_{i}\right)$ will increase to the stabilized stress range $\left(\Delta \sigma_{s}\right)$. However, strain hardening may also change the amount of the plastic strain $\left(\Delta \varepsilon_{p l}\right)$, even if the total strain must remain constant during testing, as depicted in Fig. 3.2. Here, the initial plastic strain is termed $\Delta \varepsilon_{p l, i}$, and the stabilized plastic strain is termed $\Delta \varepsilon_{p l, s}$. 

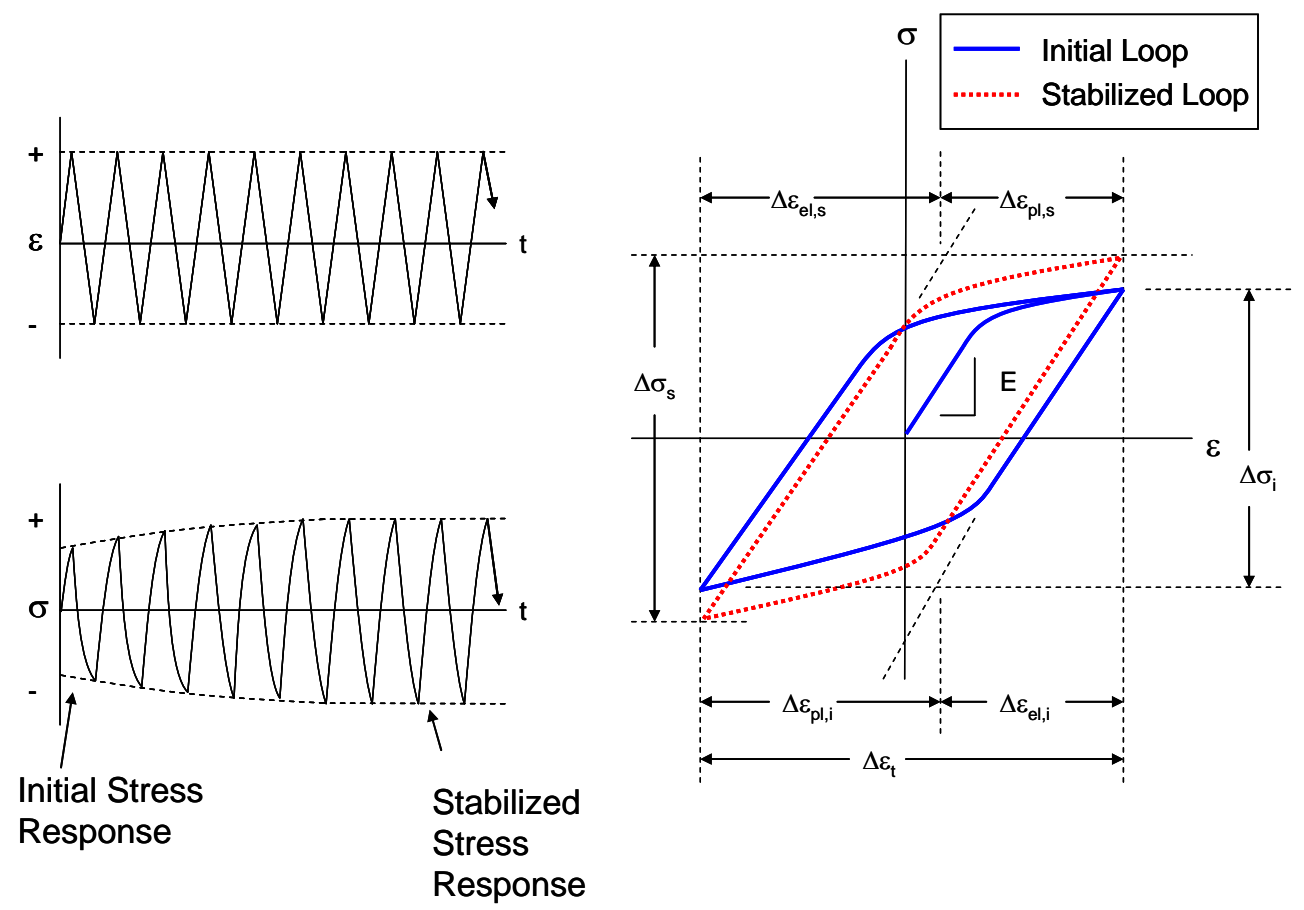

Figure 3.2. Effect of strain hardening on initial versus stable mid-life hysteresis loops.

The cycle dependent evolution in the initial stress range compared to the mid-life stress range for each data point for each temperature are illustrated in Fig. 3.3a.

Likewise, the changes in the initial plastic strain range as compared to the stable mid-life plastic strain range for each data point at each temperature is given in Fig. 3.3b. Here, the normalized initial and stabilized stress range are termed $\frac{\Delta \sigma_{i}}{\sigma_{U L T}}$ and $\frac{\Delta \sigma_{s}}{\sigma_{U L T}}$, and the normalized initial and stabilized strain range are $\frac{\Delta \varepsilon_{i}}{\Delta \varepsilon_{i} *}$ and $\frac{\Delta \varepsilon_{s}}{\Delta \varepsilon_{s} *}$ respectively.

Assuming linear interpolation, a conversion factor can be applied to the monotonic test data anchor point to account for strain hardening effects. Note that it is assumed that the intercept is approximately zero. The new anchor point defined for the failure stress is given as: 


$$
\sigma_{f}=C_{1} \sigma_{U L T}(1+e)
$$

Here, $\mathrm{C}_{1}$ is the correction factor from linear regression as described, $\sigma_{\mathrm{ULT}}$ is the ultimate strength, and e is the failure elongation. The intercept is assumed to be zero.

Similarly, the failure strain is written with a correction factor $\mathrm{C}_{2}$ from linear regression as described, which is scaled by the failure elongation (e) as given by

$$
\varepsilon_{f}=C_{2} e
$$

The constants $C_{1}$ and $C_{2}$ have been calculated using the base IN738 LC test data, which provided values as shown in Table 3.1.

Table 3.1. Constants $C_{1}$ and $C_{2}$ from linear regression using base data set.

\begin{tabular}{|r|r|r|}
\hline $\begin{array}{l}\text { Temperature } \\
\left({ }^{\circ} \mathrm{C}\right)\end{array}$ & $\begin{array}{l}\mathrm{C}_{1}-\text { Base } \\
\text { Data } \\
\text { Model }\end{array}$ & $\begin{array}{l}\mathrm{l}_{2} \text { - Base } \\
\text { Data Model }\end{array}$ \\
\hline 24 & 1.090 & 0.694 \\
\hline 400 & 1.437 & 0.543 \\
\hline 750 & 1.049 & 0.632 \\
\hline 850 & 0.876 & 1.105 \\
\hline
\end{tabular}

The resulting anchor point is the same as that depicted in Fig. 2.12. One may note that negligible strain hardening may actually occur at a cyclic fatigue anchor point at few cycles. If very high strain cycles are expected, then the lower bounds (LB) life estimate equations should be used instead. The purpose of this correction factor, rather, is to 
capture the effect of strain hardening on the stress-strain and strain-life curve that moderate strain range LCF data points may experience.
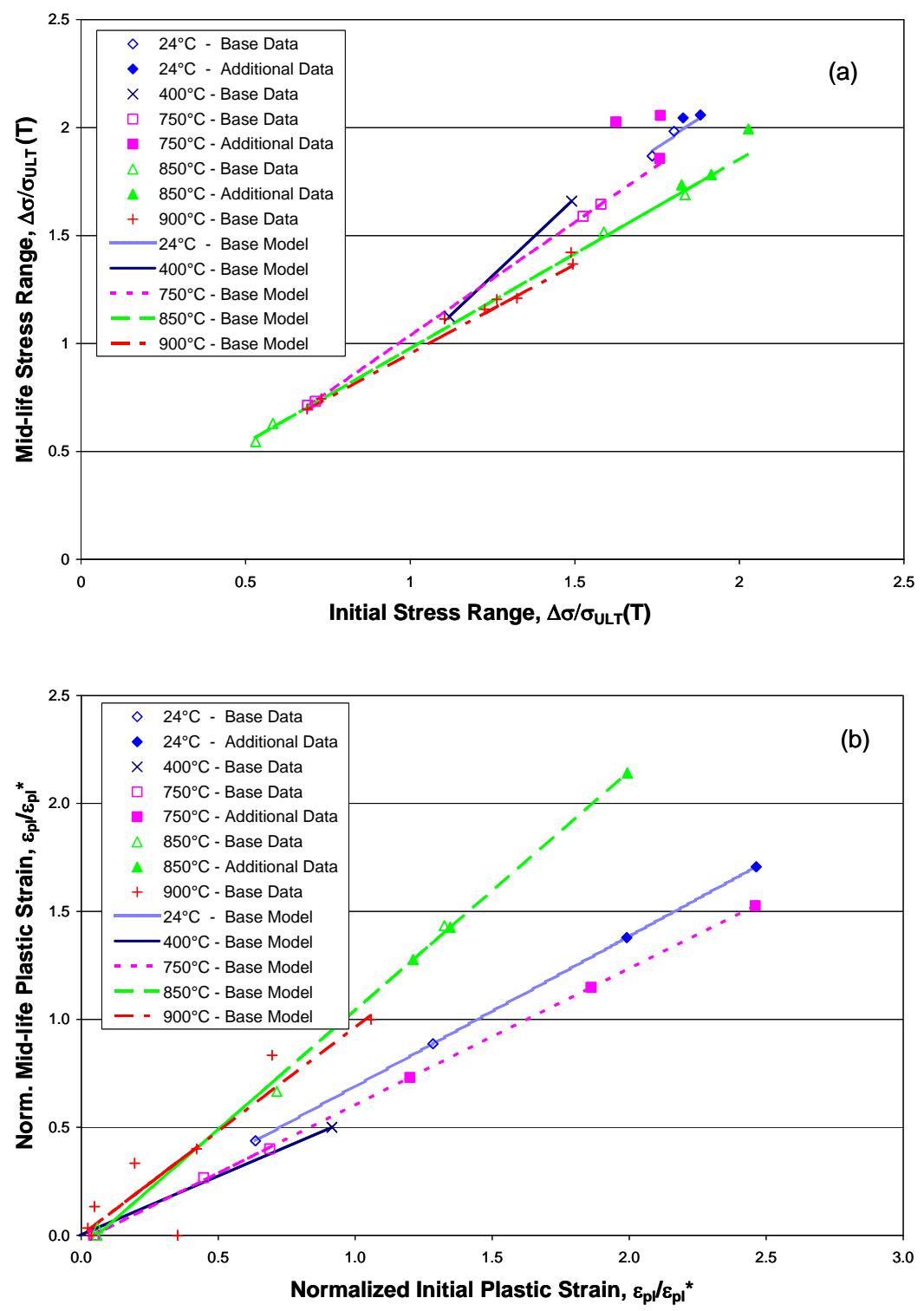

Figure 3.3. Plots of (a) initial and stabilized stress range, and (b) initial and mid-life plastic strain used for UB1.

The second option is denoted as Upper Bounds, Option 2 (UB2). This option utilizes an anchor point calculated by assuming strain compatibility to provide an 
estimate of upper bounding behavior. Recall that Section 2.2 described strain compatibility for the stress-strain and strain-life equation.

The condition of the base data set is that insufficient plastic strain data exists to characterize plastic strain terms in the stress-strain and strain-life equations as depicted in Fig. 2.6. Sufficient data does exist, however, to characterize the elastic strain terms in the stress-strain and strain-life equations. As such, the constants describing the elastic strain terms are known (i.e. $\sigma_{f}^{\prime}, E, b$ ). Strain compatibility applied to the elastic strain terms resulted in Eq. 2.22. If the elastic modulus is cancelled from each side of the equation, then the following results

$$
\sigma=\sigma_{f}^{\prime}\left(N_{i}\right)^{b}
$$

where $\sigma_{f}^{\prime}$ is the fatigue strength coefficient, b is the fatigue strength exponent, and $N_{i}$ is the number of cycles to initiation.

Since the anchor point of choice corresponds to one-half cycle, and strain compatibility has been assumed, the failure stress can be calculated, e.g.

$$
\sigma_{f}=\sigma_{f}^{\prime}\left[\frac{1}{2}\right]^{b}
$$

The failure strain is assumed to be equal to the elongation as shown in Eq. 3.5, which is identical to the original reference anchor point described in Section 2.2. 
A depiction of the anchor point for UB2 is the same as that shown for the base anchor point in Fig. 2.12. The proposed method is to treat this anchor point as an LCF data point, and include it in the normal linear regression process.

The third technique for the upper bounds is denoted as Upper Bounds, Option 3 (UB3). This hypothesis resulted from an observation that much scatter exists in the plastic strain-life data for IN738 LC as shown in Fig. 3.4. The resulting strain-life curves show a similar slope at $400^{\circ} \mathrm{C}, 750^{\circ} \mathrm{C}$, and $850^{\circ} \mathrm{C}$, a shallow slope at $24^{\circ} \mathrm{C}$, and a steep change in slope at $900^{\circ} \mathrm{C}$. The shallow slope at $24^{\circ} \mathrm{C}$ is most likely due to a lack of test data at this temperature. The combined slope and intercept is very similar to the $400^{\circ} \mathrm{C}$ data, which appears to be along a median of the cluster of data.

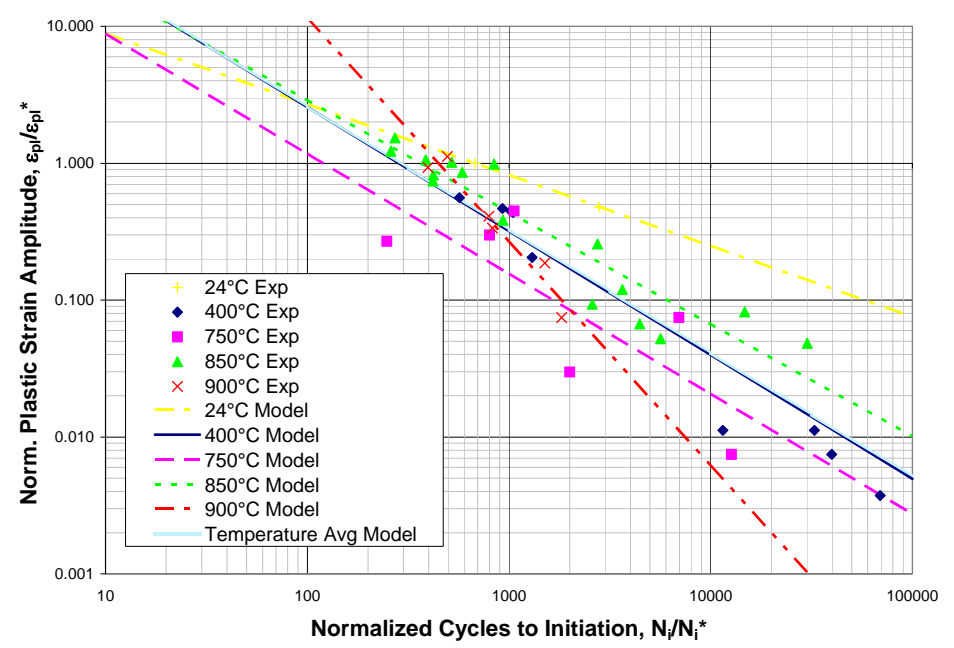

Figure 3.4. Scatter in strain-life equation with temperature.

Method UB3 is provided by grouping together all of the strain-life data, and treating it as temperature independent. The underlying assumption for using this method is that the error due to treating the plastic strain life data as temperature independent is 
smaller than the error due to scatter in the data. This is similar to the method proposed by Burke and Beck [10] for IN 617, except that both the strain hardening coefficient ( $\left.\varepsilon_{f}^{\prime}\right)$ and the strain hardening exponent (c) are assumed to be temperature independent. The revised strain-life equation is given by:

$$
\frac{\Delta \varepsilon_{t}}{2}=\varepsilon_{f}^{\prime}\left(2 N_{f}\right)^{-c}+\frac{\sigma_{f}^{\prime}(T)}{E(T)}\left(2 N_{f}\right)^{-b(T)}
$$

where $\frac{\Delta \varepsilon_{t}}{2}$ is the total strain amplitude, $\varepsilon_{f}^{\prime}$ is the fatigue ductility coefficient, c is the fatigue ductility exponent, $\sigma_{f}^{\prime}$ is the fatigue strength coefficient, and $\mathrm{b}$ is the fatigue strength exponent. The constants which are temperature dependent are shown as a function of T. Finally, the strain compatibility equations solved for $K^{\prime}$ and $n^{\prime}$ (Eq. 2.25) are employed to find the cyclic strength coefficient $\left(K^{\prime}\right)$ and the strain hardening exponent $\left(n^{\prime}\right)$. 
Comparison Method

The tool used for curve fit comparison is calculation is the coefficient of determination otherwise known as $\mathrm{R}^{2}$. This is a commonly used measure of the degree of linear association between an independent and dependent variable [22], i.e.,

$$
R^{2}=\frac{\left[\sum(x-\bar{x}) \sum(y-\bar{y})\right]^{2}}{\sum\left(x-\bar{x}^{2} \sum\left(y-\bar{y}^{2}\right.\right.}
$$

where $\mathrm{x}$ is the independent variable, and $\bar{x}$ is the mean independent variable, $\mathrm{y}$ is the dependent variable, and $\bar{y}$ is the mean independent variable. The calculation tool is embedded in MS Excel by means of the RSQ command. The output from the $\mathrm{R}^{2}$ calculation is a value between one and zero, where zero shows no linear correlation between the two variables, and one shows a perfect linear correlation. This command has two arrays as inputs, which include a list of independent variables, and dependent variables.

The input to $\mathrm{R}^{2}$ is two arrays of strain, one being calculated and the other measured. After all seven of the curve fit constants (i.e. $\sigma_{f}^{\prime}, b, \varepsilon_{f}^{\prime}, E, K^{\prime}, n^{\prime}$ ) have been determined by linear regression using a particular method, the strain amplitudes may be calculated by either the stress-strain equation (Eq. 2.9) or the Modified Morrow strain-life equation (Eq. 2.14) as a function of the stress amplitude or cycles and mean stress. The $\mathrm{R}^{2}$ function is used to compare the calculated strains versus the measured strains. Specifically, the calculated strains from the stress-strain equation are compared to the 
strain amplitudes, and the Morrow-adjusted strains from the Modified Morrow strain-life equation are compared to the Modified Morrow strains.

\subsection{Test Equipment}

All mechanical tests were carried out using an MTS TestStar system. The main components of the system include: a computer, a digital controller, a manual load control unit, a load frame, and a hydraulic pump, as shown in Fig. 3.5.

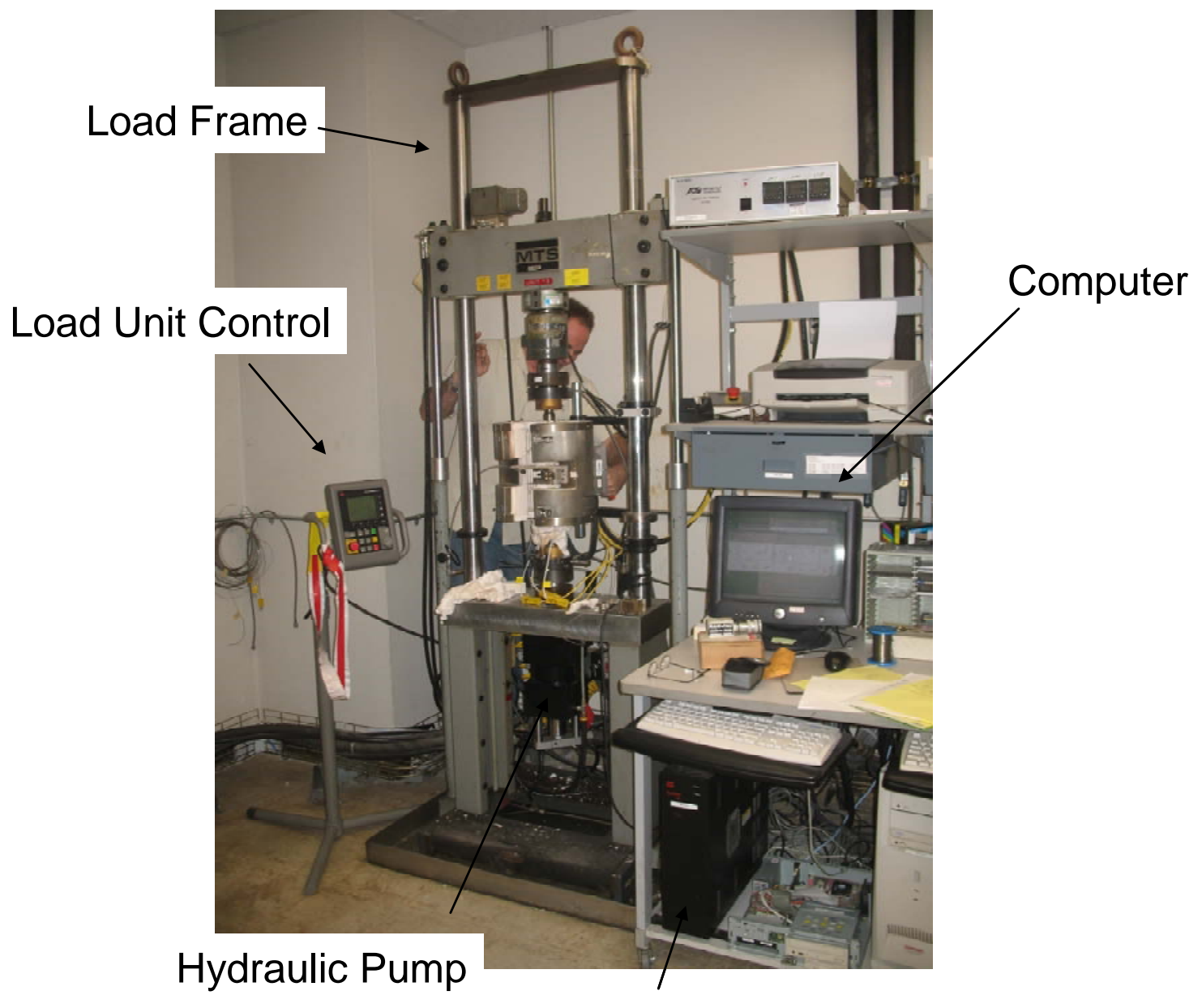

Digital Controller

Figure 3.5. LCF test equipment. 
The load frame contains all of the active equipment for loading and testing the specimen. The load control unit provides a local input device for manual operation of the hydraulics, and input of test parameters. The hydraulic pump provides the force for loading the specimens.

The digital controller and computer control the test during operation. The TestStar software is the main user interface, which allows the operator to control the test parameters, and post-process the results. Test parameters that can be controlled include: test temperature, strain rate, strain range, waveform shape, and testing control settings. The resulting data include: cycle count, strain, and load with respect to time.
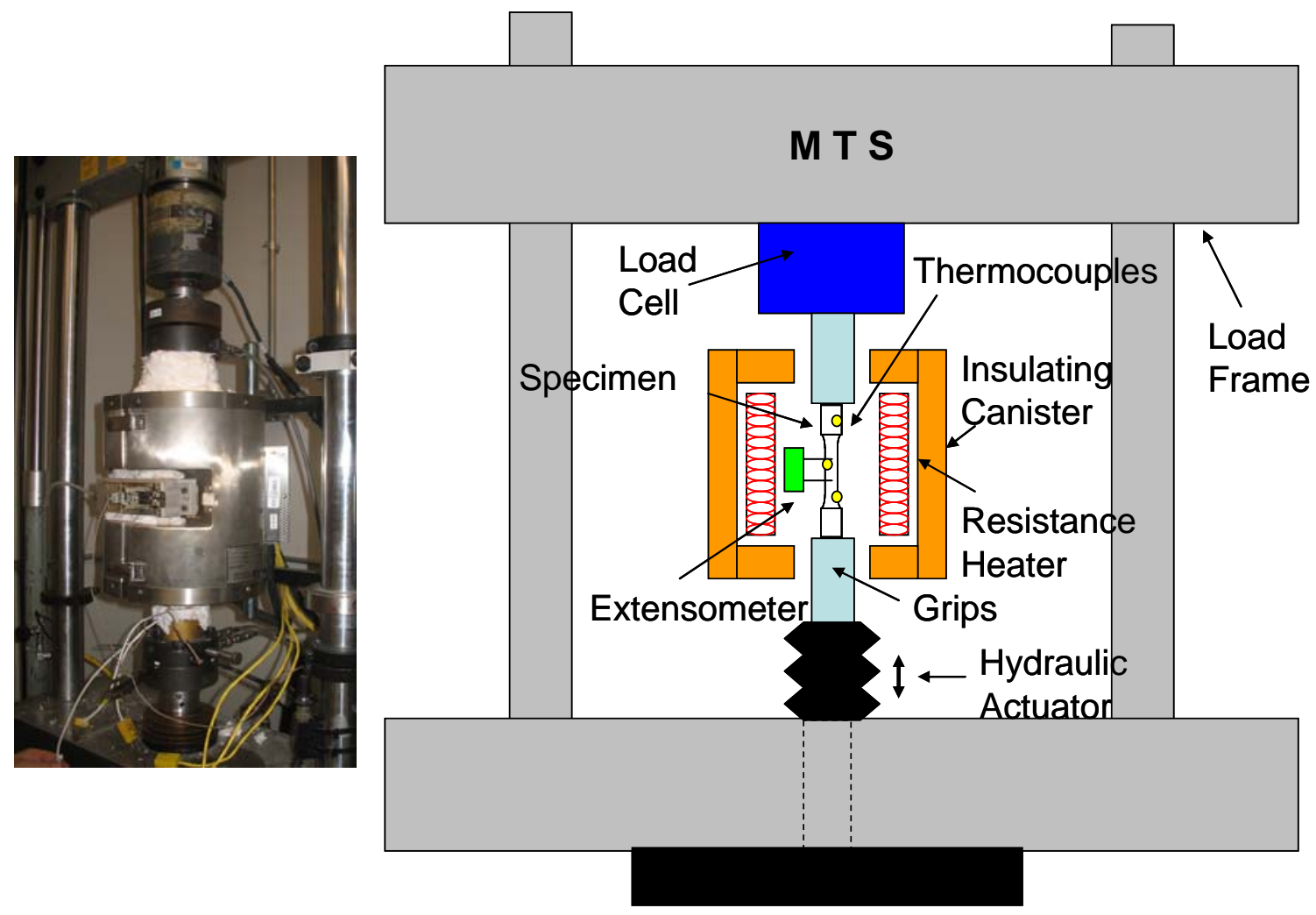

Figure 3.6. Photograph and Depiction of load frame component details. 
Many critical components are located within the load frame. The specimen is mounted in the grips, as depicted in Fig. 3.6. It is necessary to water cool the grips during elevated temperature testing. The specimen is loaded by the hydraulic actuator as directed by the controller. The load cell measures the force applied to the specimen.

The extensometer is the strain measurement device, and it measures the strain within the gage length (Fig. 3.7). The type of extensometer used for this testing is spring loaded against the specimen, with direct contact rods made of a high temperature ceramic. The contact rods have a notch to match the diameter of the specimen to maximize the contact area between the specimen and extensometer to avoid slipping during testing.

Heat is provided to the specimen via resistance heating, which is fairly inefficient. Heat loss to the environment during testing is reduced by encasing the coils in an insulated canister. The insulating canister is hard mounted to the load frame, and split into two halves which pivot about a bar to allow opening and closing. Latches are on the canister for securing closed during testing. An insulating felt material is placed about the inner and outer holes of the canister to avoid heat loss.

Low-cycle fatigue life is strongly affected by temperature, and temperature measurement is provided by thermocouples. Three thermocouple leads are wire tied along the specimen to capture temperature distribution. The control unit uses feedback from the thermocouples to maintain constant temperature during testing.

The specimens were made from a cast slab of IN738 LC, which was hot isostatically pressed (HIP’d), heat treated, and solution aged. The slab was blanked into 
rectangular blocks, and the blocks were machined into specimens. Thirty specimens were machined from the slab, of which twenty are available for testing.

A specimen design in conformance with the ASTM standard [23] uniform-gage test section specimen was used for testing. The ends are threaded, and neck down in the center in an area known as the gage section, which is where specimen failure is intended to occur. The specimens were of 0.25 inch diameter, and a gage length of 0.75 inch. The surface finish of the specimen is polished to $0.2 \mu \mathrm{m}$ surface finish to minimize the surface effects on the measured life of the specimen.

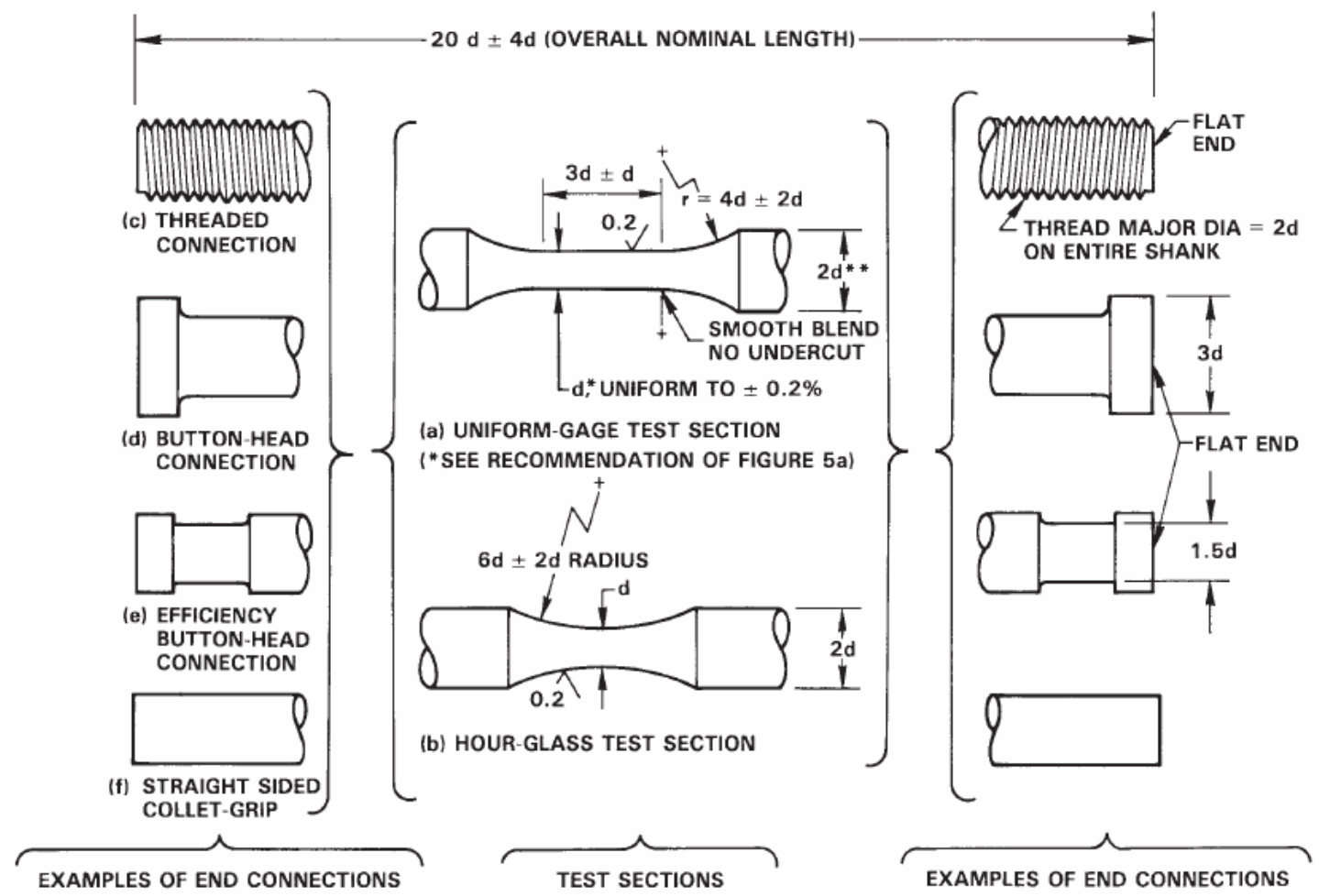

Figure 3.7. ASTM uniform gage specimen design [19]. 


\subsection{Testing Procedure}

The test matrix was planned to provide test data to characterize the high stress amplitude, high strain range behavior of IN738 LC. High stress amplitudes are defined as approaching the ultimate strength, and are defined by $\sigma_{\mathrm{a}} / \sigma_{\mathrm{ULT}}$ near unity as shown in Table 3.2. The normalized strain amplitudes $(\Delta \varepsilon / \mathrm{e})$ were estimated from the existing data set to provide stress amplitudes approaching the ultimate strength. The plan was to gather additional high strain range test data to supplement the existing data set at four temperatures of interest (e.g. $400^{\circ} \mathrm{C}, 750^{\circ} \mathrm{C}, 850^{\circ} \mathrm{C}$, and $900^{\circ} \mathrm{C}$ ). Each test would be duplicated in order to understand the amount of variability in the data.

Table 3.2. Planned Test Matrix.

\begin{tabular}{|c|c|c|c|}
\hline $\begin{array}{l}\text { Test } \\
\text { Temp }\left({ }^{\circ} \mathrm{C}\right)\end{array}$ & $\begin{array}{l}\text { Norm. } \\
\text { Stress } \\
\text { Amplitude } \\
\left(\sigma_{a} / \sigma_{U L T}\right)\end{array}$ & $\begin{array}{l}\text { Norm. } \\
\text { Strain } \\
\text { Range } \\
(\Delta \varepsilon / e)\end{array}$ & $\begin{array}{l}\text { Test } \\
\text { Quantity }\end{array}$ \\
\hline 400 & 0.876 & 0.222 & \\
\hline 400 & 0.919 & 0.295 & 2 \\
\hline 750 & 1.006 & 0.187 & 2 \\
\hline 750 & 1.111 & 0.249 & 2 \\
\hline 850 & 0.934 & 0.145 & 2 \\
\hline 850 & 1.036 & 0.194 & 2 \\
\hline 900 & 0.743 & 0.114 & 2 \\
\hline 900 & 0.772 & 0.153 & 2 \\
\hline \multicolumn{3}{|c|}{$\overline{\mathrm{OTAL}}$} & 16 \\
\hline
\end{tabular}

The tests shall be performed per the standard strain-controlled LCF testing procedure per the ASTM standard [23]. The planned normalized strain range is within the maximum allowable per the ASTM standard for a standard uniform gage section 
specimen which is being used. The ASTM standard suggests an hour-glass specimen design for tests above $2.0 \%$ strain range.

ASTM standard E606 stipulates several requirements for a test to be valid. The metal temperature in the gage section must be uniform over the duration of the test, which is defined by:

$T_{n}=\Delta T$

where $T_{n}$ is the nominal test temperature in ${ }^{\circ} \mathrm{C}$, and $\Delta T$ is $2^{\circ} \mathrm{C}$ or $1 \%$, whichever is greater. A test should be kept in strain control during the duration of the test. If material behavior permits, the strain range should be constant to within a few percent of the applied strain value.

Specimens made from coupons will have a surface finish history due to manufacturing process. Unless the test is meant to characterize the surface finish effect on LCF life, the surface finish should be finely polished to minimize this impact on the results. Testing in an inert gas atmosphere may be necessary to eliminate oxidation and corrosion effects.

The first step in LCF testing is preparation of the specimen for testing. The grips are removed from the load frame. A specimen is given a visual inspection. The gage section diameter and length of the specimen are measured and recorded. The specimen is threaded into each end of the grips, and torqued to the proper value. The grips with the specimen attached are installed to the load frame. 
The attachment bolts between the load cell and the grips are properly torqued. A gap will remain between the lower grip and the hydraulic ram. This gap is nearly always not equally distributed about the circumference. If the bolts between these components are tightened as-is, then a residual bending moment would result in the specimen, which would reduce the LCF life in the specimen, and skew the results.

The method for removing the bending moment is to shim the gap between the lower grip and the hydraulic ram with feeler gages. The gap between the components is measured, and shims are inserted to remove the gap. When the gap has been removed, the bolts between the grips and hydraulic actuator are tightened to the proper torque. Thermocouple wires are wire tied to the specimen in three locations. The insulating canister is closed, and centered about the specimen.

A calibrated extensometer is mounted to the canister, and spring loaded against the specimen. The strain gage measures the longitudinal displacement of the specimen, and converts the displacements to a strain measurement using a Wheatstone bridge circuit. The extensometer used in elevated temperature testing has high temperature ceramic rods, which must be centered upon the gage section. The location of the extensometer is typically offset at cold build by a distance known as the stroke. The stroke is the offset required to correct for the thermal growth of the specimen during elevated temperature testing. Offsetting the specimen by the stroke at cold build allows the extensometer to be centered on the specimen during hot running conditions. Additional ceramic insulator felt is placed about the openings at the top and bottom of the insulating canister. 
A test program is created in the TestStar software by choosing the test conditions, which often include temperature, strain amplitude, strain rate, and waveform. An initial estimate of the control gains (P, I, and D) must also be chosen. The test conditions which will stop testing are chosen to avoid damaging a specimen due to testing anomalies. These conditions are known as unit trip settings.

A modulus check is normally performed to determine if the system and specimen are operating as expected. The heaters are turned on, and set to the desired temperature of the test. It is important that the unit does not overshoot the desired temperature since this could affect the results. Sufficient time is allowed for the specimen to achieve uniform steady-state temperatures after the thermocouples have stabilized to the set temperature prior to the beginning of testing.

The LCF test program begins, and the first few cycles are typically monitored to insure that the test is proceeding as expected. Most LCF tests run over a period of hours or days, and are often run unsupervised. The test conditions which will stop testing have already been established. Assuming the test runs as planned, the test is normally terminated when the test specimen fails by rupture, or the limiting number of tests has been reached, which is called run-out.

\subsection{Test Post-Processing}

After a test has been completed, the operator must post-process the data to determine if the test was valid by comparing the results to allowable limits from the ASTM E606 standard [23]. Often the initial and mid-life hysteresis loops, strain versus cycle, and stress versus cycle (stress history) plots are created for the test. The operator 
must consider whether any anomalies in the test have occurred that would invalidate the test. If so, the source of error is located, and the test is re-run.

Another aspect of post-processing is reduction of the data. If the data is considered valid, then the mid-life hysteresis loops are examined to determine the minimum and maximum stress, total strain range, and the inelastic strain range for the test. Design curves are generally based on the cycles to initiation $\left(\mathrm{N}_{\mathrm{i}}\right)$ of a crack, where the initiation is assumed when a certain percentage load drop has occurred during the test prior to failure. A 5\% load drop was assumed for these tests. Often, some of the hysteresis loop data is digitally recorded for addressing questions that may arise regarding the data point. The data are then stored for use in the curve fitting procedure. 


\section{RESULTS}

This section presents the results including the data and models developed in the course of this project. Data are both from the pre-existing data set and the additional data from high strain range tests gathered. The models include the base linear regression process and the various models as explained in Chapter 3.

\section{1. $\quad$ Base Data Set}

The base data set includes 48 pre-existing data points for IN738 LC at $R_{\varepsilon}=-1$, as shown in Table 4.1.

Table 4.1. Quantity, norm. strain range, and temp of LCF data points in base data for IN738 LC.

\begin{tabular}{|c|c|c|c|c|c|c|c|c|c|}
\hline \multicolumn{2}{|c|}{$24^{\circ} \mathrm{C}$} & \multicolumn{2}{|c|}{$400^{\circ} \mathrm{C}$} & \multicolumn{2}{|c|}{$750^{\circ} \mathrm{C}$} & \multicolumn{2}{|c|}{$850^{\circ} \mathrm{C}$} & \multicolumn{2}{|c|}{$900^{\circ} \mathrm{C}$} \\
\hline $\begin{array}{l}\text { Norm. } \\
\text { Strain } \\
\text { Range } \\
(\Delta \varepsilon / \mathrm{e})\end{array}$ & Quantity & $\begin{array}{l}\text { Norm. } \\
\text { Strain } \\
\text { Range } \\
(\Delta \varepsilon / \mathrm{e})\end{array}$ & Quantity & $\begin{array}{l}\text { Norm. } \\
\text { Strain } \\
\text { Range } \\
(\Delta \varepsilon / e)\end{array}$ & Quantity & $\begin{array}{l}\text { Norm. } \\
\text { Strain } \\
\text { Range } \\
(\Delta \varepsilon / \mathrm{e})\end{array}$ & Quantity & $\begin{array}{l}\text { Norm. } \\
\text { Strain } \\
\text { Range } \\
(\Delta \varepsilon / \mathrm{e})\end{array}$ & Quantity \\
\hline \begin{tabular}{|l}
0.147 \\
\end{tabular} & 1 & 0.059 & 1 & $\begin{array}{l}0.074 \\
\end{array}$ & 1 & 0.039 & 2 & 0.023 & 2 \\
\hline 0.184 & 1 & 0.074 & 2 & 0.103 & 2 & 0.048 & 2 & 0.038 & 2 \\
\hline & & 0.089 & 7 & 0.148 & 3 & 0.058 & 2 & 0.053 & 2 \\
\hline & & 0.118 & 1 & & & 0.068 & 1 & 0.069 & 2 \\
\hline & & 0.148 & 5 & & & 0.077 & 1 & & \\
\hline & & & & & & 0.097 & 8 & & \\
\hline TOTAL & 2 & & 16 & & 6 & & 16 & & $\varepsilon$ \\
\hline
\end{tabular}

The base model is provided by linear regression of the data as described in Chapter 2 using the base methodology. Curve fit constants were calculated and graphed using MS Excel. The stress-strain models were obtained using the stress-strain equation (Eq. 2.9), and the strain-life was obtained by curve fitting the data using the Morrow-adjusted strain-life equation (Eq. 2.14).

The cyclic stress-strain curves plot the normalized stress amplitude $\left(\sigma_{\mathrm{a}} / \sigma_{\mathrm{ULT}}\right)$ versus the normalized strain amplitude $\left(\varepsilon_{\mathrm{a}} / \mathrm{e}\right)$. The effect of data normalization must be 
considered when interpreting the plots. The effect of normalizing the stress amplitude by the ultimate strength should create stress-strain curves of similar slope regardless of temperature. However, normalizing the strain amplitude by the elongation tends to shift the normalized strains at higher temperatures to lower values as shown in Fig. 4.1a. The $\mathrm{R}^{2}$ error values show a relatively good fit for the cyclic stress-strain curve with a notable low at $900^{\circ} \mathrm{C}$.

The effects of normalization must also be considered when interpreting the strainlife curve. The effect of normalizing the strain amplitudes by the elongation is a progressive decrease in normalized strain amplitude with an increase in temperature. Therefore, the expected trend that LCF life decreases with increased temperature is exaggerated as shown in Fig. 4.1b. The effect of normalizing the cycles to initiation by a constant is an even shift of all data by a certain amount.

It is noted that the $400^{\circ} \mathrm{C}$ data is intermixed with the $750^{\circ} \mathrm{C}$ data between 200 and 1,000 normalized cycles, and has a low $\mathrm{R}^{2}$ value despite having a relative high number of data points as shown in Table 4.2. It is noted that the $\mathrm{R}^{2}$ values are low at $24^{\circ} \mathrm{C}$ and $750^{\circ} \mathrm{C}$, but these can be rationalized by the small amount data points. The $900^{\circ} \mathrm{C}$ model shows a large unexpected slope change relative to other model temperatures at cyclic lives less than 1,000 cycles.

Table 4.2. Values of $\mathbf{R}^{2}$ from regression analysis using base data set.

\begin{tabular}{|l|r|r|r|r|r|r|}
\hline & \multicolumn{7}{|c|}{ Temperature } \\
\hline Method & $24^{\circ} \mathrm{C}$ & $400^{\circ} \mathrm{C}$ & $750^{\circ} \mathrm{C}$ & $850^{\circ} \mathrm{C}$ & $900^{\circ} \mathrm{C}$ & Average \\
\hline Quantity of Data Points & 2 & 16 & 6 & 16 & 8 & 9.6 \\
\hline Stress-strain & 0.973 & 0.952 & 0.975 & 0.954 & 0.906 & 0.952 \\
\hline Strain-life & 0.939 & 0.904 & 0.911 & 0.955 & 0.982 & 0.938 \\
\hline
\end{tabular}



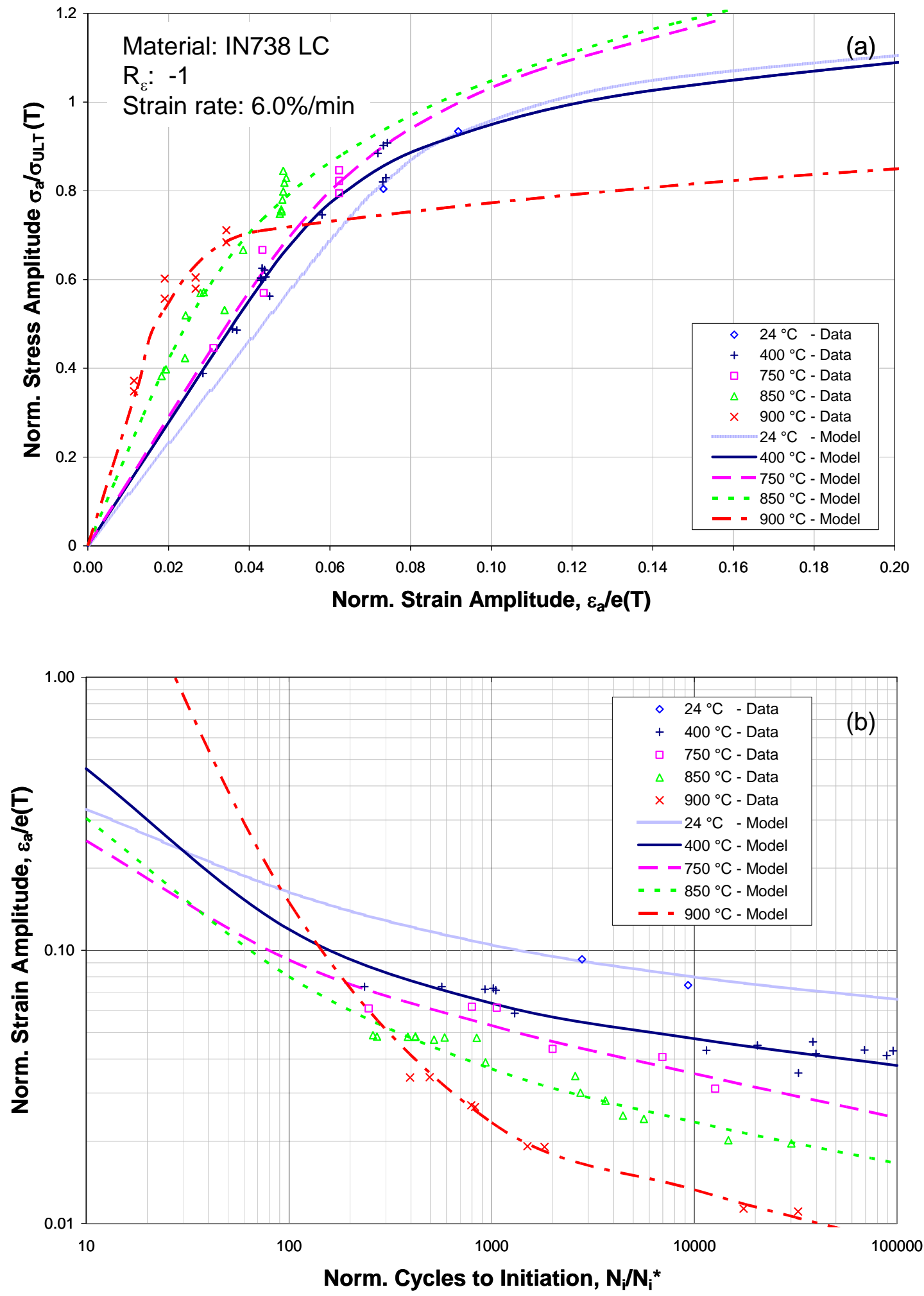

Figure 4.1. Experimental and modeled cyclic stress-strain and strain life behavior of IN738 LC using base data set. 


\subsection{Fatigue Test Results}

A total of 20 specimens were available for testing, and a strain rate of $6.0 \% / \mathrm{min}$ was used. The test operator was very experienced with LCF testing, and engineering input was provided. The operator stated that previous attempts at the higher than typical strain ranges using similar Ni-base alloys have experienced difficulty. The problem has reportedly been the unit "tripping” during testing due to violation of a test requirement prior to specimen failure.

Testing began at the lowest temperature of $400^{\circ} \mathrm{C}$, and the 0.222 normalized strain range per the planned test matrix shown in Table 3.1. The first test (specimen D912-1) revealed random fluctuations in the load and inability to achieve the desired strain control history. The stress versus time plot shows several spikes in the stress history plot at 65 and 92 normalized cycles as shown in Fig. 4.2a. An inability to achieve strain control is also shown by the strain versus cycle plot in Fig. 4.2b.

The test conditions were repeated using specimen D912-2. Again, an inability to achieve strain control was noted, when a large spike in strain occurred at 8 normalized cycles, and the specimen failed shortly thereafter at 19 normalized cycles. 

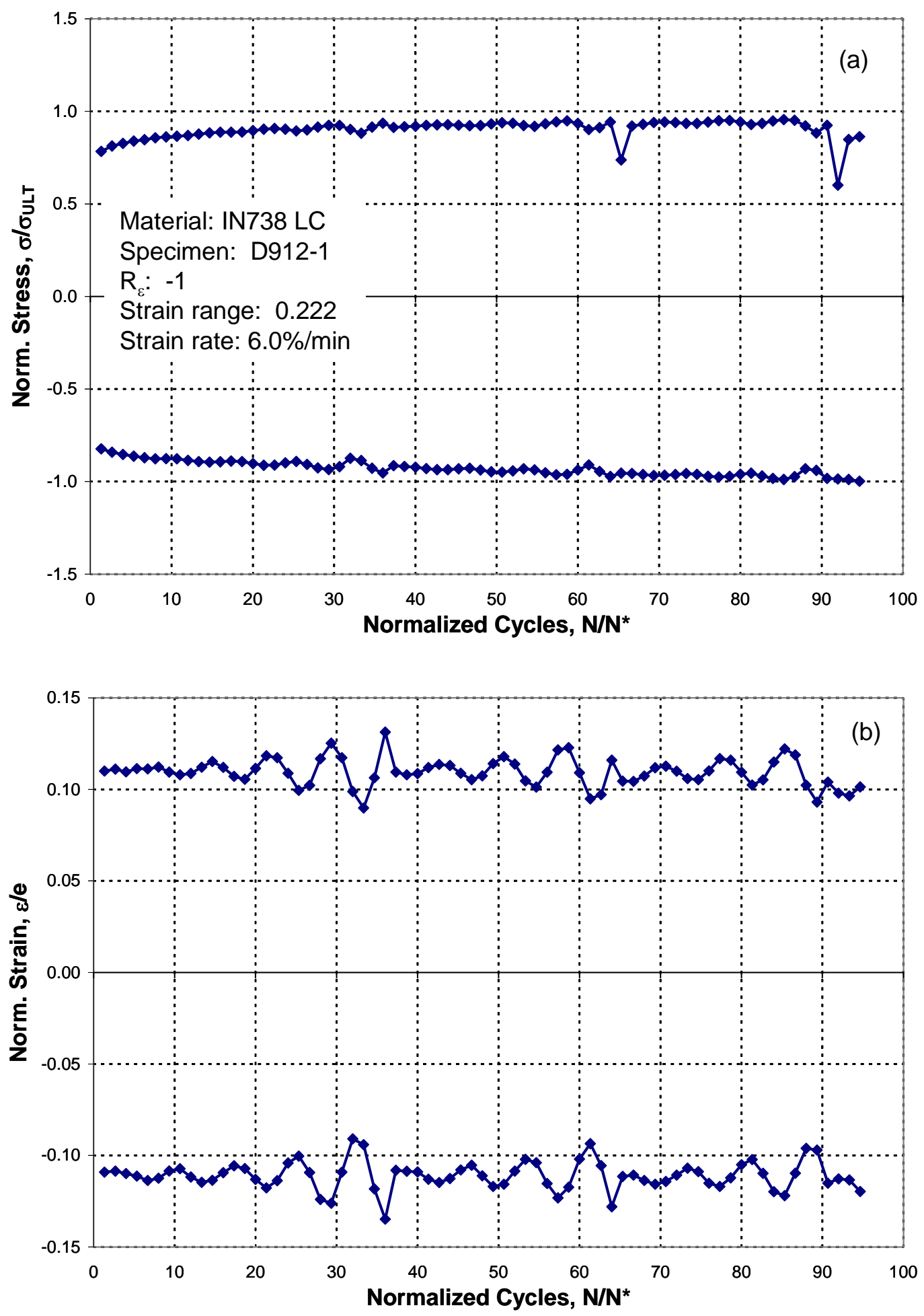

Figure 4.2. Cyclic (a) stress and (b) strain history for test D912-1 for IN738 LC at $400^{\circ} \mathrm{C}$. 
This behavior was potentially indicative of serrated yielding, which is also known as discontinuous yielding or jerky flow. These effects have been explained by interstitial atoms pinning dislocations. The phenomenon occurs at strain rates where interstitial atoms can diffuse to the dislocation cores quickly enough to re-pin the dislocations after initial yielding. This is observed as repeated serrations throughout the stress-strain curve [24]. Serrated yielding is of interest because it has been known to interfere with reliable tensile tests, and causes strain overshoots during strain-controlled LCF testing. It is known to occur with certain alloys, temperatures, and strain rates. Huron [24] does specify that it has been observed in superalloys such as IN600, IN718, or Waspalloy at temperatures in the range of $400^{\circ} \mathrm{C}$.

Another noted issue in Fig. 4.2b is the inability to maintain strain-control. Typical tests often show acceptable strain control with the default adjustment of the control settings. The high strain range tests in this project, however, will require an improved tuning technique, where the control settings were tuned for each specimen prior to testing after the specimen reaches a steady-state test temperature.

Several aspects of the test plan were modified. Tests at $400^{\circ} \mathrm{C}$ were eliminated to avoid the potential of serrated yielding affecting the results. However, this left only data at $750^{\circ} \mathrm{C}$ and $850^{\circ} \mathrm{C}$, and it was desired to have data over a wider temperature range to test the extrapolation methods. As such, a room temperature data set was provided as a third temperature for application of the extrapolation methods. Five data points were gathered at $24^{\circ} \mathrm{C}$, which allowed for two to be used to establish a base data set, and 3 additional high strain data points to establish the augmented data set as shown in Table 4.3. The strain rate will remain at $6 \% / \mathrm{min}$, and the strain ratio is $R_{\varepsilon}=-1$. 
Table 4.3. Modified test matrix.

\begin{tabular}{|c|c|c|c|}
\hline $\begin{array}{l}\text { Test } \\
\text { Temp }\left({ }^{\circ} \mathrm{C}\right)\end{array}$ & $\begin{array}{l}\text { Norm. } \\
\text { Stress } \\
\text { Amplitude } \\
\left(\sigma_{a} / \sigma_{U L T}\right)\end{array}$ & $\begin{array}{l}\text { Norm. } \\
\text { Strain } \\
\text { Range } \\
(\Delta \varepsilon / \mathrm{e})\end{array}$ & $\begin{array}{l}\text { Test } \\
\text { Quantity }\end{array}$ \\
\hline 24 & 0.804 & 0.147 & 1 \\
\hline 24 & 0.903 & 0.184 & 1 \\
\hline 24 & 0.970 & 0.220 & 1 \\
\hline 24 & 1.017 & 0.257 & 1 \\
\hline 24 & 1.054 & 0.294 & 1 \\
\hline 750 & 0.909 & 0.150 & 1 \\
\hline 750 & 0.977 & 0.174 & 1 \\
\hline 750 & 1.030 & 0.199 & 1 \\
\hline 850 & 0.851 & 0.116 & 1 \\
\hline 850 & 0.908 & 0.136 & 1 \\
\hline 850 & 0.957 & 0.155 & 1 \\
\hline \multicolumn{3}{|c|}{ TOTAL } & 11 \\
\hline
\end{tabular}

The high strain range test results are shown in Table 4.4, and 11 tests were provided. All requirements were met for the tests to be valid per the ASTM standard E606 [19], except that tests D912-8, D912-15, and D912-11 had significant excursions from maintaining strain control of up to $25 \%$. This was despite efforts to tune the controls for each specimen prior to testing. The deviation from strain control was calculated as a maximum deviation for any one cycle from the applied strain range in percent. All of other tests were within 3\%.

It was noted that significant cyclic hardening or softening occurred in this alloy, which was calculated by comparing the initial stress range to the stable mid-life stress range. It is interesting that more strain hardening occurred at $750^{\circ} \mathrm{C}$ than $24^{\circ} \mathrm{C}$, but strain softening occurred at $850^{\circ} \mathrm{C}$. It was also noted at the temperatures which showed strain hardening $\left(24^{\circ} \mathrm{C}\right.$ and $\left.750^{\circ} \mathrm{C}\right)$, that the effect of higher strain range test generally increased the hardening effects. However, higher strain range tests generally decreased the strain 
softening at $850^{\circ} \mathrm{C}$. A stress history and stress-strain mid-life hysteresis loop plot for each test is shown in the Appendix. The notable exception is test D912-17 because data was inadvertently erased.

Table 4.4. High strain range test results.

\begin{tabular}{|c|c|c|c|c|c|c|c|c|}
\hline Specimen ID & $\begin{array}{c}\text { Test } \\
\text { Temperature } \\
\left({ }^{\circ} \mathrm{C}\right)\end{array}$ & $\begin{array}{l}\text { Norm. } \\
\text { Strain } \\
\text { Range } \\
(\Delta \varepsilon / \mathrm{e})\end{array}$ & $\begin{array}{c}\text { Max } \\
\text { Deviation } \\
\text { From Strain } \\
\text { Range (\%) }\end{array}$ & $\begin{array}{c}\text { Mid-life } \\
\text { Norm. } \\
\text { Stress } \\
\text { Amplitude } \\
\left(\sigma_{\mathrm{a}} / \sigma_{\mathrm{ULT}}\right)\end{array}$ & $\begin{array}{c}\text { Strain } \\
\text { Hardening } \\
\text { or } \\
\text { Softening } \\
(+/-\%)\end{array}$ & $\begin{array}{l}\text { Norm. Mid- } \\
\text { life } \\
\text { Modulus } \\
\left(E / \sigma_{U L T}\right)\end{array}$ & $\begin{array}{c}\text { Normalized } \\
\text { Cycles to } \\
\text { Initiation } \\
\left(\mathrm{N}_{\mathrm{i}} / \mathrm{N}_{\mathrm{i}}^{*}\right)\end{array}$ & $\begin{array}{l}\text { Figure in } \\
\text { Appendix }\end{array}$ \\
\hline LCF-D912-35 & 24 & 0.147 & $2.7 \%$ & 0.804 & $2.6 \%$ & 209 & 9333 & A.2 \\
\hline $\begin{array}{l}\text { LCF-912-17 } \\
\end{array}$ & 24 & 0.184 & $2.0 \%$ & 0.934 & $7.7 \%$ & 222 & 2795 & \\
\hline LCF-912-20 & 24 & 0.220 & $1.9 \%$ & 0.992 & $10.1 \%$ & 224 & 680 & A.3 \\
\hline \begin{tabular}{|l} 
LCF-D912-19 \\
\end{tabular} & 24 & 0.257 & $1.9 \%$ & 1.029 & $9.4 \%$ & 238 & 107 & A.4 \\
\hline LCF-D912-25 & 24 & 0.294 & $1.5 \%$ & 1.022 & $11.8 \%$ & 216 & 196 & A.5 \\
\hline LCF-D912-6 & 750 & 0.150 & $2.9 \%$ & 0.929 & $5.6 \%$ & 149 & 245 & A.6 \\
\hline LCF-D912-14 & 750 & 0.174 & $0.7 \%$ & 1.028 & $16.8 \%$ & 214 & 160 & A.7 \\
\hline LCF-D912-8 & 750 & 0.199 & $19.5 \%$ & 1.013 & $24.7 \%$ & 188 & 100 & A.8 \\
\hline LCF-D912-16 & 850 & 0.116 & $1.2 \%$ & 0.891 & $-6.9 \%$ & 238 & 209 & A.9 \\
\hline LCF-D912-15 & 850 & 0.136 & $13.2 \%$ & 0.867 & $-4.9 \%$ & 196 & 184 & A.10 \\
\hline LCF-D912-11 & 850 & 0.155 & $24.5 \%$ & 0.997 & $-1.7 \%$ & 226 & 96 & A.11 \\
\hline
\end{tabular}

The similarity of the resulting data between the base and additional high strain data sets was judged by comparing the elastic moduli and yield strengths at $750^{\circ} \mathrm{C}$ and $850^{\circ} \mathrm{C}$. The resulting ratios show that the base data set and additional data set elastic moduli are within $8 \%$, and the cyclic yield strengths are within $2 \%$. Therefore, it was considered acceptable to mix the base data and additional data to form the augmented data set.

Table 4.5. Comparison of moduli and cyclic yield between base data set and additional high strain data set.

\begin{tabular}{|r|l|l|}
\hline & $\begin{array}{l}\text { Modulus } \\
\text { Ratio } \\
\text { Temp }\left({ }^{\circ} \mathrm{C}\right)\end{array}$ & $\begin{array}{l}\text { Cyclic Yield } \\
\text { Ratio } \\
\left(\mathrm{E}_{\text {base }} / \mathrm{E}_{\text {add }}\right)\end{array}$ \\
\hline 750 & 0.94 & $\left.1 \sigma_{y, \text { base }} / \sigma_{\mathrm{y}, \text { add }}\right)$ \\
\hline 850 & 1.08 & 0.98 \\
\hline
\end{tabular}


The failed specimens show that significant oxidation has occurred at $850^{\circ} \mathrm{C}$ as compared to $24^{\circ} \mathrm{C}$ and $750^{\circ} \mathrm{C}$. The fracture surface was characterized as fairly brittle at all temperatures. Figure 4.3 compares the condition of specimen D912-20 tested at $24^{\circ} \mathrm{C}$ and normalized strain range of 0.220 versus specimen D912-16 tests at $850^{\circ} \mathrm{C}$ and normalized strain range of 0.116 . The complete set of failed specimen photographs is shown in the Appendix, Fig. A.12 to A.25.

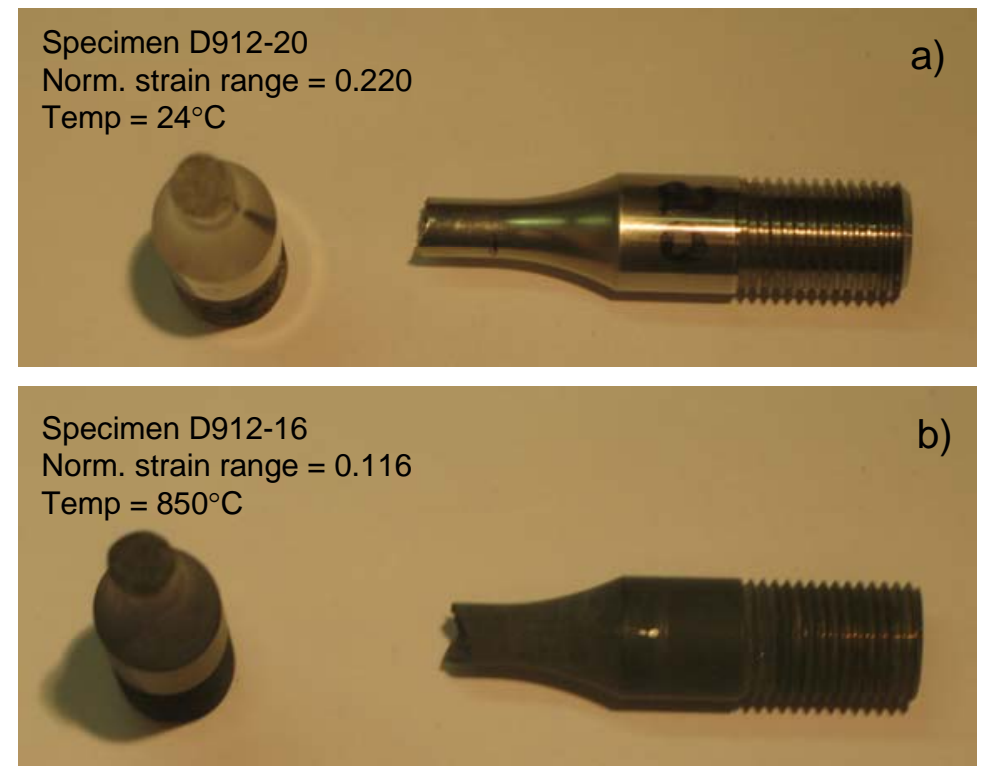

Figure 4.3. Photographs of failed specimens at $24^{\circ} \mathrm{C}$ and $850^{\circ} \mathrm{C}$.

The following shows a sample of the outputs from various tests that were performed including stress versus time, stress versus cycles (stress history), and strain versus cycle, and stress versus strain (hysteresis loop) plots. This information is used in post-processing and assessing whether a test is valid.

The output of a stress versus time plot reveals whether there is plasticity occurring during the test. Several features are revealed by comparing the stress versus time plot for specimens D912-19, D912-14, and D912-15 at temperatures of $24^{\circ} \mathrm{C}, 750^{\circ} \mathrm{C}$, and $850^{\circ} \mathrm{C}$, 
respectively as shown in Fig. 4.4. There is more plasticity occurring for each cycle at lower temperatures. Also, strain hardening is seen at $24^{\circ} \mathrm{C}$ and $750^{\circ} \mathrm{C}$, but strain softening is occurring at $850^{\circ} \mathrm{C}$.

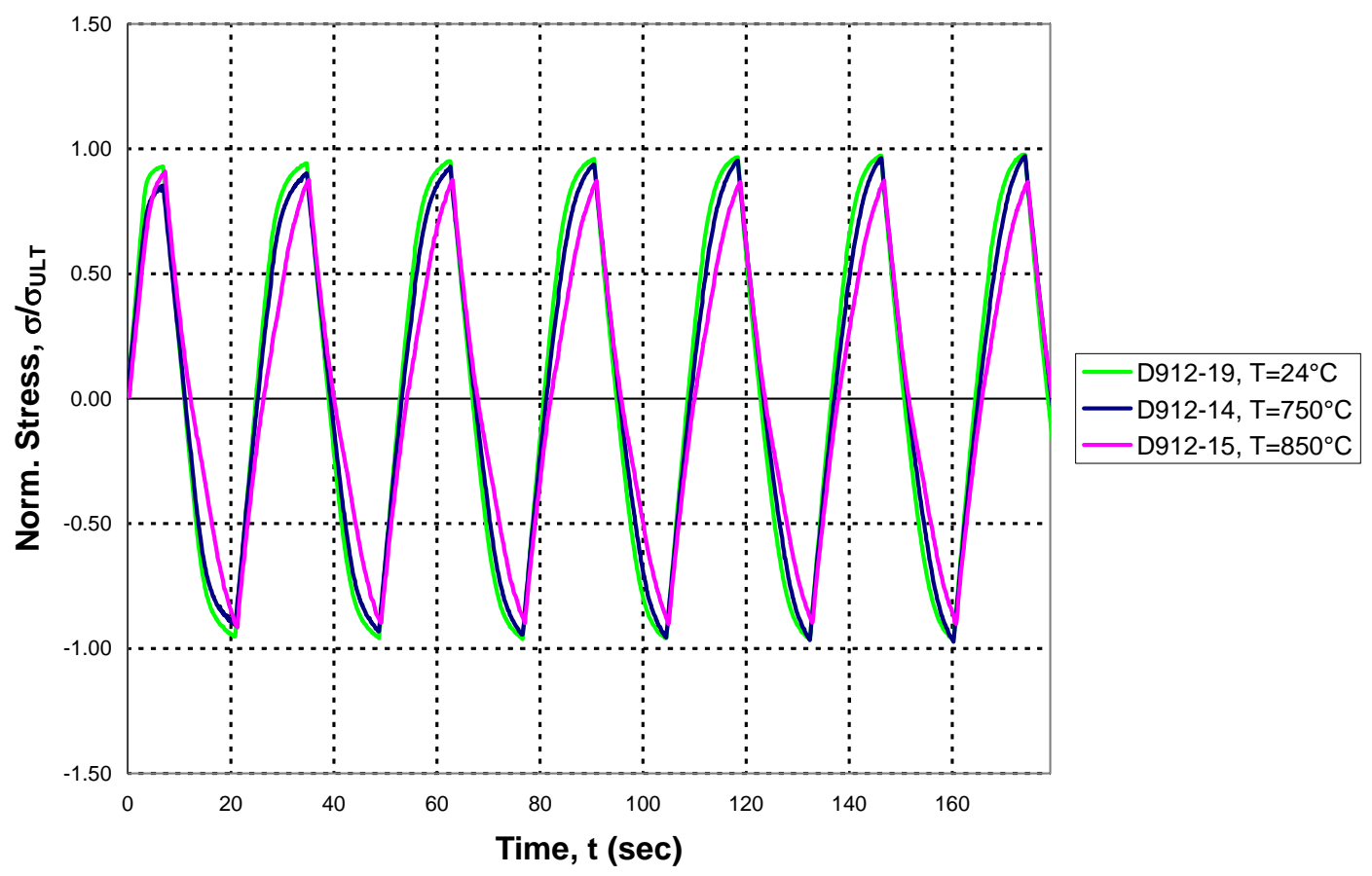

Figure 4.4. Stress versus time output for $1.4 \%$ strain range at $24^{\circ} \mathrm{C}, 750^{\circ} \mathrm{C}$, and $850^{\circ} \mathrm{C}$.

Since low-cycle fatigue tests are strain-controlled, the strain range should be constant over the duration of the test. Any deviation from the strain control will be revealed by the strain versus cycle plot, and difficulty was noted maintaining strain control during the high strain ranges of tests in this project. Most of these issues were resolved by using a special tuning method to optimize the control settings prior to testing. An example of the deviation is shown in Fig. 4.5 which allows comparison of two tests at $750^{\circ} \mathrm{C}$ : the 0.174 normalized strain range test, which had only $0.7 \%$ strain control 
deviation, and the 0.199 normalized strain range test, which had 19.5\% deviation from strain control. It is seen that the 0.199 strain range test actually experienced a few cycles up to a normalized strain range of 0.236 , and few cycles down to 0.160 . Several efforts were made to tune the system to minimize these excursions, but they could not be completely eliminated. The expected effect of excursions above the set strain range is reduction in the measured cyclic life from a true constant strain range test.

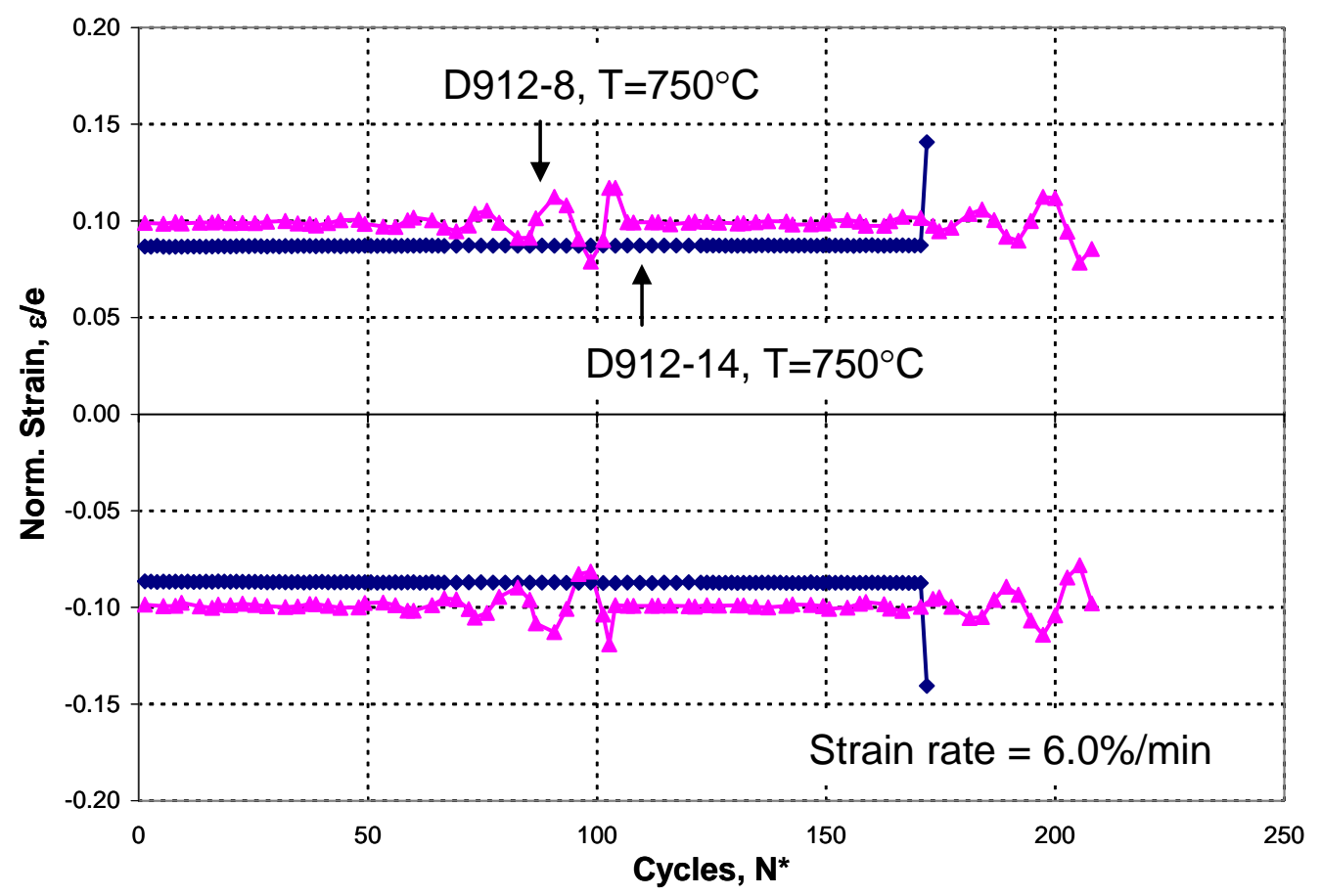

Figure 4.5. Strain versus cycle plot comparison at $750^{\circ} \mathrm{C}$.

The outputs from an LCF test include the elastic strain $\left(\varepsilon_{e l}\right)$, plastic strain $\left(\varepsilon_{p l}\right)$, and stress range $(\Delta \sigma)$, and are most readily shown by stress-strain plots created during cycles otherwise known as hysteresis loops. The hysteresis loop for the 0.174 normalized strain range at $750^{\circ} \mathrm{C}$ is shown in Fig. 4.6a. Strain hardening occurs in the first twenty loops until the hysteresis loops stabilize, which is when subsequent hysteresis loops are 
unchanged from previous loops. The mid-life loop is the median life hysteresis loop, and this hysteresis loop used to determine the amount of plastic strain. During fully reversed testing, symmetry is expected between the tensile and compressive side of hysteresis plot. Normal variation in material behavior may allow more strain hardening or softening on the tensile or compressive side, which results in a small mean stress.

The stress versus cycle plot or cyclic stress history plot is used to show the evolution in stress, and indicates that a crack has formed in the specimen prior and up to failure. Fig. 4.6b shows the stress history plot for D912-14 test at $750^{\circ} \mathrm{C}$ and 0.174 normalized strain range. It is noteworthy that the majority of the strain hardening has occurred by normalized cycle 40 . The stress range starts to drop at about normalized cycle 145 indicating a crack has formed in the specimen until final failure occurs at normalized cycle 170. 

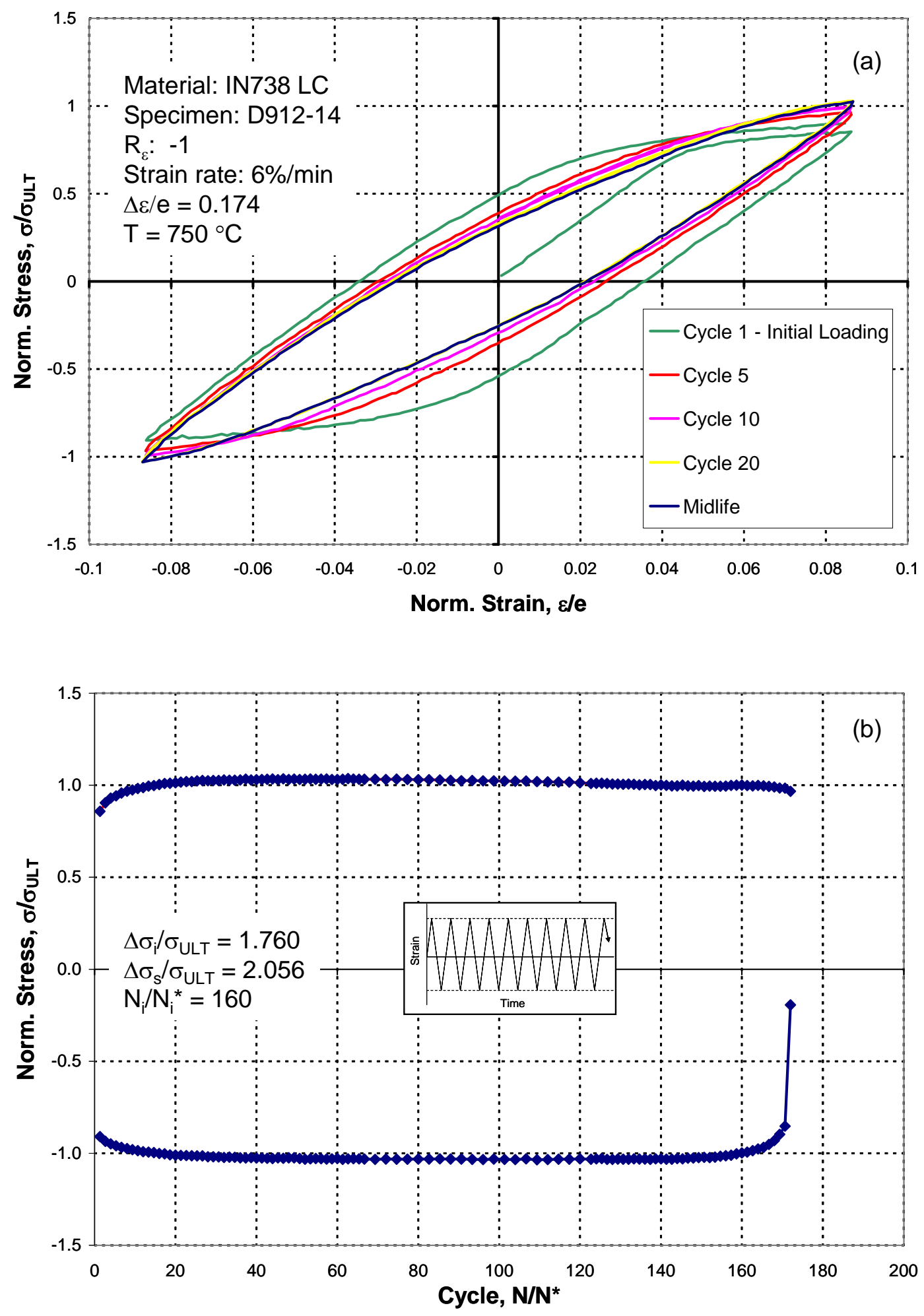

Figure 4.6. (a) Hystersis loop and (b) stress history plot for specimen D912-14 at 1.4\% strain range and $750^{\circ} \mathrm{C}$. 


\subsection{Comparison}

In the following section, a comparison is made between the various models generated during this project. The base model is compared to the extrapolation methods

including: lower bounds (LB), upper bounds 1 (UB1), upper bounds 2 (UB2), and upper bounds 3 (UB3). The base model is provided by a standard linear regression using the base data set. Likewise, the “augmented model” is provided by a linear regression including both the base data set and the additional high strain data gathered in this project. It is expected that the augmented data set model will provide the best model for predicting the actual high strain behavior of the material. What remains to be determined is which model will provide the best approximation using data from the base data set: the base curve fit, LB, UB1, UB2, or UB3.

As an introduction to direct comparison of the stress-strain and strain-life curves, it is first informative to compare the cyclic yield strengths. The values of the cyclic yield have been normalized by the values from the base model. The base model and augmented models show nearly identical values, which is expected since the yield strength is already defined by the base data set. There is significant variation in the cyclic yield between the extrapolation models as shown in Fig. 4.7. In comparison to the base model, UB2 is generally higher for the entire temperature range. Alternately, the LB and UB1 consistently show a lower cyclic yield than the base curve fit except at $900^{\circ} \mathrm{C}$ where they are equal. The UB3 shows much variation compared to base model, where it matches at $24^{\circ} \mathrm{C}$ and $850^{\circ} \mathrm{C}$, is lower at $400^{\circ} \mathrm{C}$ and $750^{\circ} \mathrm{C}$, and higher at $900^{\circ} \mathrm{C}$. 


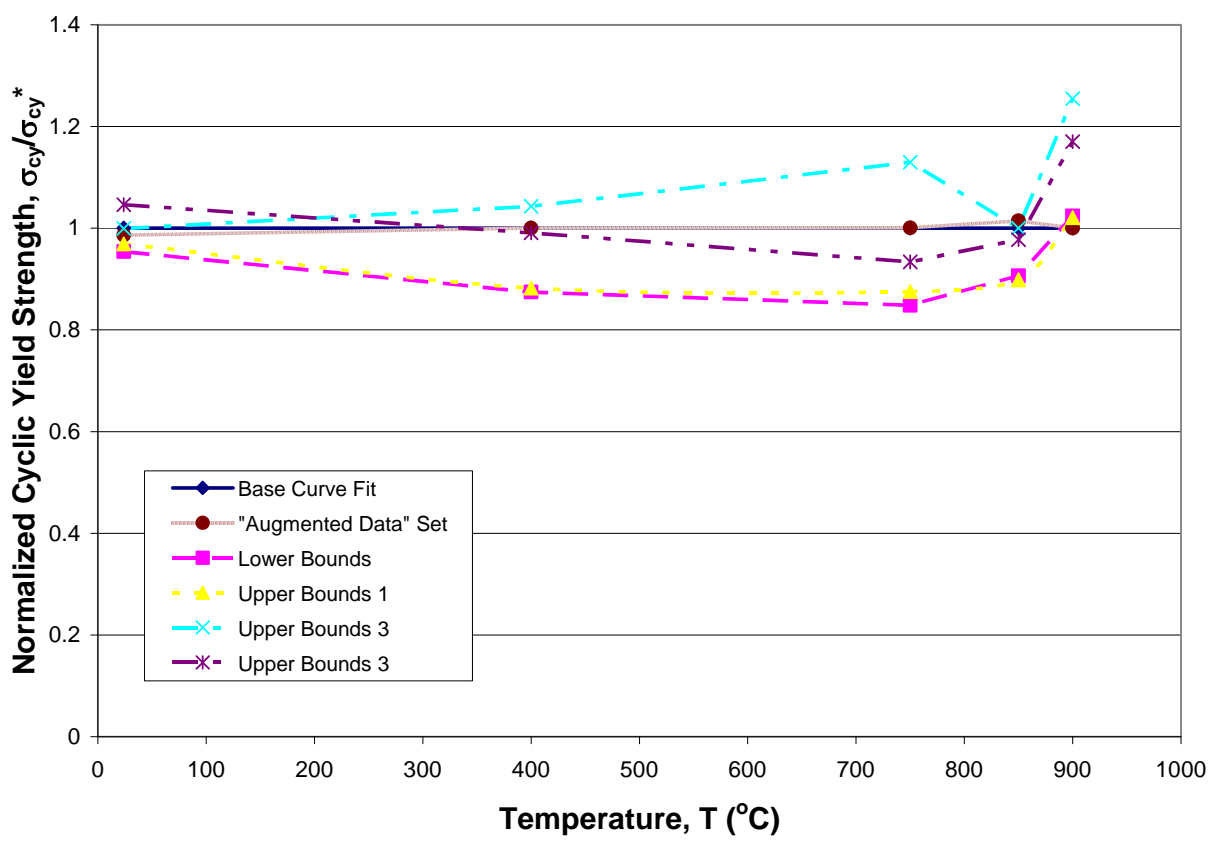

Figure 4.7. Comparison of calculated cyclic yield strengths using various methods.

The main goal of this project was to find the best extrapolation method using a base data set to predict the high strain range behavior. This is evaluated by calculating $\mathrm{R}^{2}$ by comparing the strains from the extrapolation methods to the actual strains from the additional high strain range tests. Since each method provides both a cyclic stress-strain and strain-life curve, the equally weighted average $\mathrm{R}^{2}$ from the two curves is considered the best description of the ability to extrapolate. More sophisticated approaches involving weighting the stress-strain response over the strain-life data, or vice-versa, are left for future studies. This can only be evaluated where high strain data has been collected at $24^{\circ} \mathrm{C}, 750^{\circ} \mathrm{C}$, and $850^{\circ} \mathrm{C}$. This $\mathrm{R}^{2}$ value is termed "Extrapolated."

A secondary objective is to determine if the resulting form of the extrapolation method will negatively impact the overall fit of the cyclic stress-strain or strain-life equation considering all of the available test data at each test temperature. This may be 
evaluated at all temperatures regardless of whether high strain data has been generated. This $\mathrm{R}^{2}$ value is termed "Overall."

There are five data points from the room temperature $\left(24^{\circ} \mathrm{C}\right)$ data. Two data points were generated with normalized strain ranges of 0.184 and below are considered base strain range data, and the data points with normalized strain ranges of 0.220 and above are considered high strain range. It is not clear which method provides the best model considering the stress-strain curve, as shown in Fig. 4.8a. Both LB and UB1 appear well below the higher strain range test data.

The few data points provided in the strain-life curve show little scatter, as shown in Fig. 4.8b. It is not qualitatively apparent which approximation is the best in the strainlife plots. It appears that UB3 shows the most variation from the test data. All approximations match well at low strain ranges, but at high strain ranges there is more scatter in the predictions and data.

The highest $\mathrm{R}^{2}$ for extrapolation or overall fit is provided by the augmented model, as expected as shown in Table 4.6. The $\mathrm{R}^{2}$ calculations show that the best extrapolation method is provided equally well by the base model or the UB2 model with an average $\mathrm{R}^{2}$ of 0.961 . The extrapolation method which provides the best overall fit with all the test data is also provided equally well by the base model or the UB2 model with an average $\mathrm{R}^{2}$ of 0.956 .

Table 4.6. Values of $\mathbf{R}^{2}$ from various extrapolation methods at $24^{\circ} \mathrm{C}$.

\begin{tabular}{|l|r|r|r|r|r|r|}
\hline Purpose & \multicolumn{3}{|c|}{ Extrapolation } & \multicolumn{3}{c|}{ Overall Fit } \\
\hline Method & $\begin{array}{l}\text { Stress- } \\
\text { strain }\end{array}$ & Strain-life & Average & $\begin{array}{l}\text { Stress- } \\
\text { strain }\end{array}$ & Strain-life & Average \\
\hline Augmented Data Model & 0.978 & 0.953 & 0.965 & 0.977 & 0.950 & 0.964 \\
\hline Base Data Model & 0.980 & 0.942 & 0.961 & 0.973 & 0.939 & 0.956 \\
\hline Lower Bounds Model & 0.902 & 0.942 & 0.922 & 0.661 & 0.937 & 0.799 \\
\hline Upper Bounds 1 Model & 0.966 & 0.949 & 0.958 & 0.940 & 0.943 & 0.942 \\
\hline Upper Bounds 2 Model & 0.980 & 0.941 & 0.961 & 0.974 & 0.938 & 0.956 \\
\hline Upper Bounds 3 Model & 0.981 & 0.910 & 0.946 & 0.956 & 0.894 & 0.925 \\
\hline
\end{tabular}



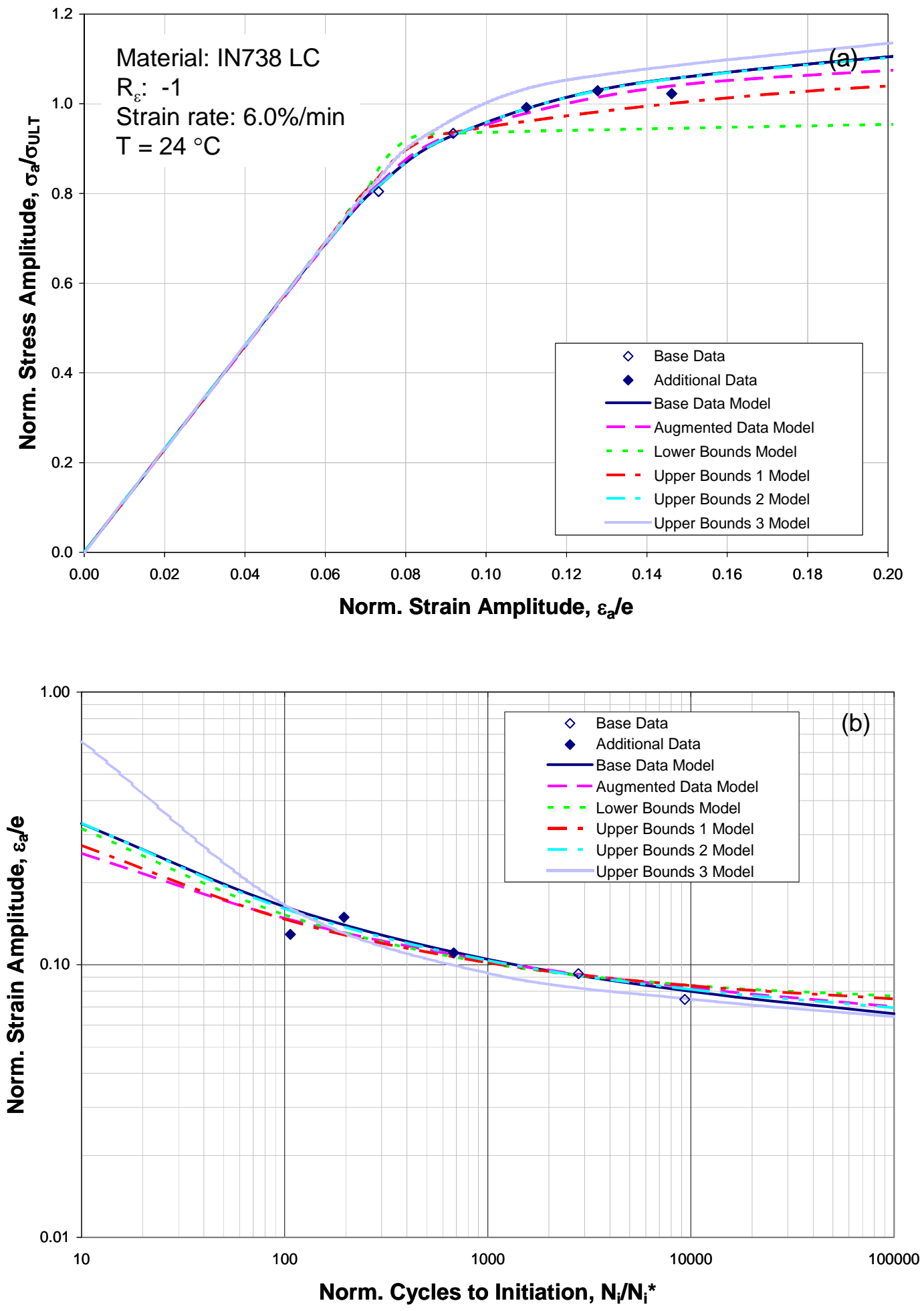

Figure 4.8. Comparison of (a) cyclic stress-strain models and (b) strain-life models for IN738 LC at $24^{\circ} \mathrm{C}$. 
No additional data was generated at $400^{\circ} \mathrm{C}$, and all of the data was consider in the base strain range. It is still worthwhile to consider which method will provide a best overall fit to the available base data set. A total of 16 base data points were available at this temperature for curve fitting. The data on the cyclic stress-strain curve matches that of the base curve fit, UB2 or UB3. Both the LB and UB1 are well below the other curves as shown in Fig. 4.9a.

The strain-life data at $400^{\circ} \mathrm{C}$ contains many low strain amplitude data points at high cycles, which are well above the normal maximum of 10,000 cycles. Only fatigue tests that were cycled to failure were included in the curve fit, as shown in Fig. 4.9b. There is much scatter in the curve fits at high strain amplitudes, and it is not clear which curve fit is the best match to test data.

The $400^{\circ} \mathrm{C}$ data set does not include any high strain data points. The results are used to calculate an $\mathrm{R}^{2}$ value for the best overall fit with all available test data. The best overall fit is provided by the UB3 extrapolation method with an average $\mathrm{R}^{2}$ value of 0.947, as shown in Table 4.7.

Table 4.7. Values of $\mathbf{R}^{2}$ for various methods at $400^{\circ} \mathrm{C}$.

\begin{tabular}{|l|r|r|r|}
\hline Purpose & \multicolumn{3}{|c|}{ Overall Fit } \\
\hline Method & $\begin{array}{l}\text { Stress- } \\
\text { strain }\end{array}$ & Strain-life & Average \\
\hline Base Data Model & 0.952 & 0.904 & 0.928 \\
\hline Lower Bounds Model & 0.687 & 0.907 & 0.797 \\
\hline Upper Bounds 1 Model & 0.710 & 0.906 & 0.808 \\
\hline Upper Bounds 2 Model & 0.965 & 0.921 & 0.943 \\
\hline Upper Bounds 3 Model & 0.947 & 0.947 & 0.947 \\
\hline
\end{tabular}



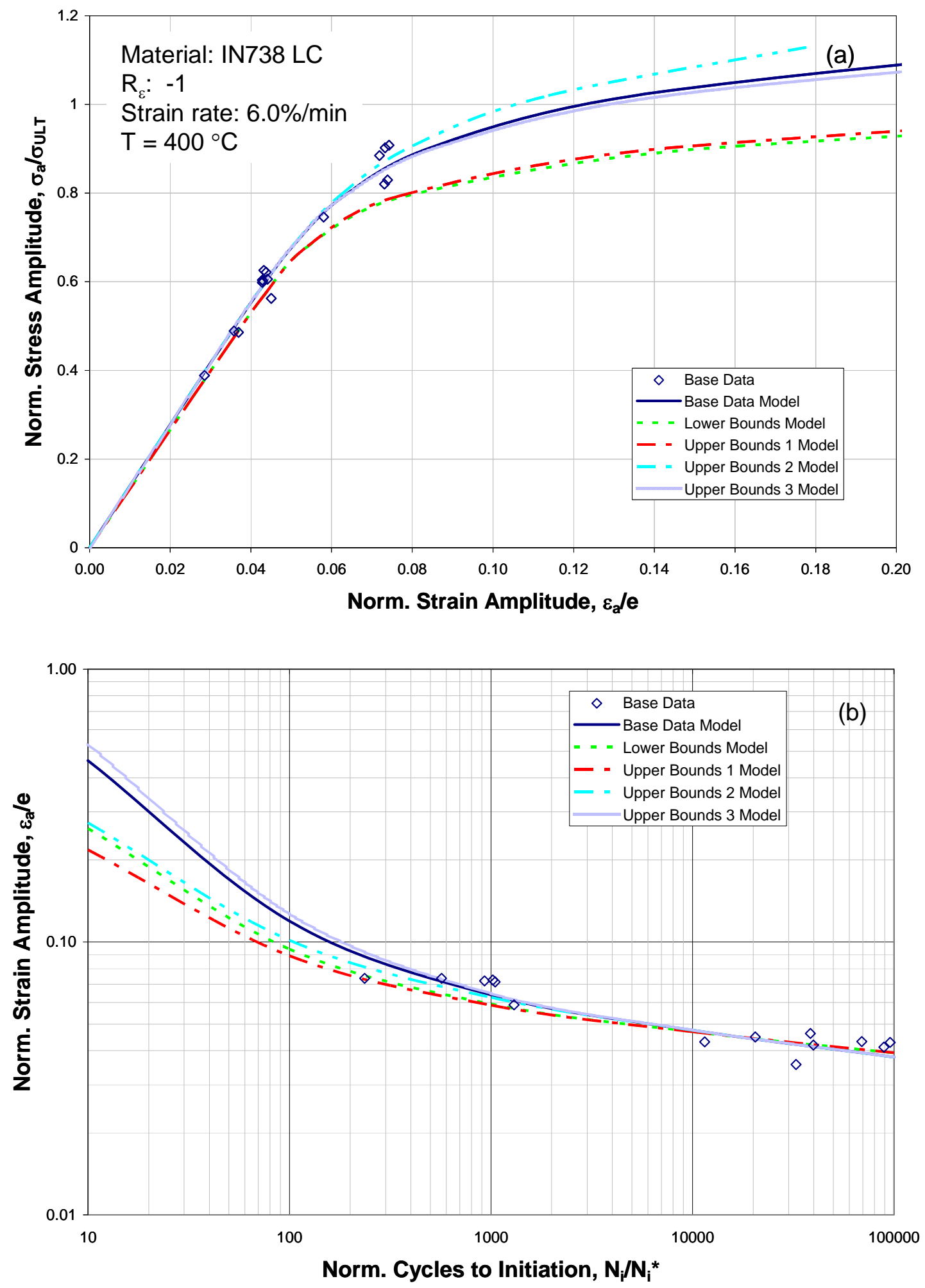

Figure 4.9. Comparison of (a) cyclic stress-strain models and (b) strain-life models for IN738 LC at $400^{\circ} \mathrm{C}$. 
The next temperature for comparison is $750^{\circ} \mathrm{C}$. A total of six data points exist in the base data set, which were supplemented by three additional high strain range tests. The cyclic stress-strain curves are shown for comparison in Fig. 4.10a. It is not visually apparent which approximation provides the best fit, but the base model and UB2 give the best correlation. Both LB1 and UB1 appear well below the high strain range test data.

The test data show moderate scatter in the strain-life plot at $750^{\circ} \mathrm{C}$. Both the base curve fit and the UB2 have very little deviation from the augmented data curve fit, as shown in Fig. 4.10b. The LB1 and UB2 models show much deviation from the test data, but it is noted that these curves provide the only conservative estimate of behavior at the high strain range data points.

As expected, the augmented data model provides the highest $\mathrm{R}^{2}$ value of any method. The method providing the highest $\mathrm{R}^{2}$ for extrapolation and overall fit is provided by the base data model as shown in Table 4.8. The UB2 method is the $2^{\text {nd }}$ best extrapolation method based on $\mathrm{R}^{2}$ for extrapolation and overall fit.

Table 4.8. Values of $\mathbf{R}^{2}$ for various methods at $750^{\circ} \mathrm{C}$.

\begin{tabular}{|l|r|r|r|r|r|r|}
\hline Purpose & \multicolumn{3}{|c|}{ Extrapolation } & \multicolumn{3}{c|}{ Overall Fit } \\
\hline Method & $\begin{array}{l}\text { Stress- } \\
\text { strain }\end{array}$ & \multicolumn{1}{l|l}{ Strain-life } & Average & $\begin{array}{l}\text { Stress- } \\
\text { strain }\end{array}$ & \multicolumn{1}{l|}{ Strain-life } & Average \\
\hline Augmented Data Model & 0.978 & 0.999 & 0.989 & 0.974 & 0.958 & 0.966 \\
\hline Base Data Model & 0.978 & 0.998 & 0.988 & 0.975 & 0.957 & 0.966 \\
\hline Lower Bounds Model & 0.874 & 0.988 & 0.931 & 0.771 & 0.897 & 0.834 \\
\hline Upper Bounds 1 Model & 0.923 & 0.985 & 0.954 & 0.854 & 0.890 & 0.872 \\
\hline Upper Bounds 2 Model & 0.977 & 0.996 & 0.987 & 0.971 & 0.954 & 0.962 \\
\hline Upper Bounds 3 Model & 0.974 & 0.998 & 0.986 & 0.971 & 0.947 & 0.959 \\
\hline
\end{tabular}



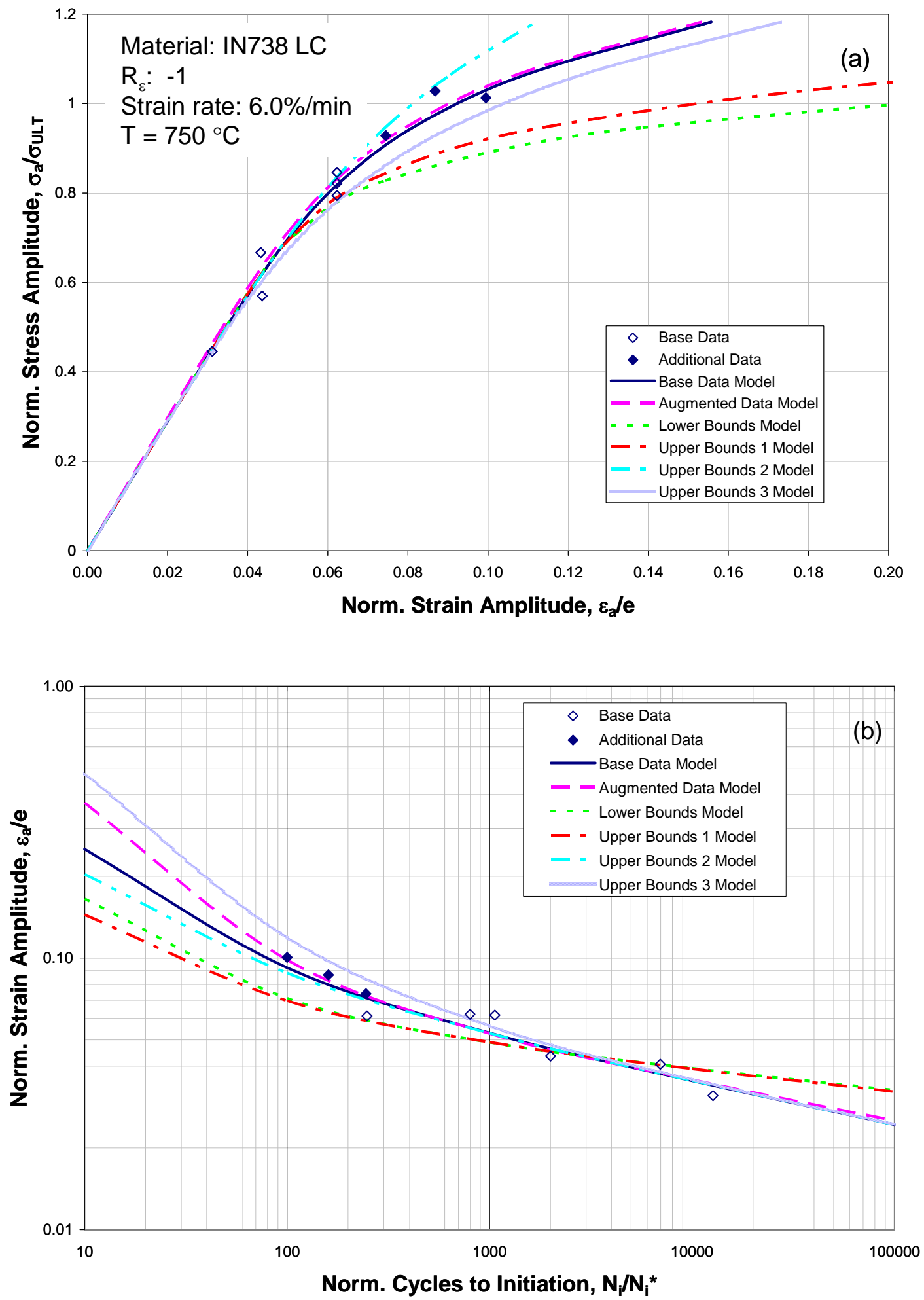

Figure 4.10. Comparison of (a) cyclic stress-strain models and (b) strain-life models for IN738 LC at $750^{\circ} \mathrm{C}$. 
The temperature with the most test data is $850^{\circ} \mathrm{C}$ including 16 base data points, which were supplemented by 3 high strain amplitude data points. The resulting stressstrain curves at $850^{\circ} \mathrm{C}$ are shown in Fig. 4.11a. The data correlate well with the base curve fit, UB2 and UB3. The LB1 and UB1 curve fits are well below the other methods in terms of stress.

Limited scatter is seen in the strain-life curve data points. As a result most of the extrapolation methods are in good agreement over the full range of the test data, as shown in Fig. 4.11b. It is noted that all of the high strain data points are above the LB1 and UB1 curve fits.

Another notable trend is seen in the $\mathrm{R}^{2}$ calculations at $850^{\circ} \mathrm{C}$. The UB2 model performs as well as the augmented data model for extrapolation with an average $\mathrm{R}^{2}$ of 0.981 as well as the overall fit with an average $R^{2}$ value of 0.958 . The $R^{2}$ calculations are shown in Table 4.9.

Table 4.9. Values of $\mathbf{R}^{2}$ for various methods at $850^{\circ} \mathrm{C}$.

\begin{tabular}{|l|r|r|r|r|r|r|}
\hline Purpose & \multicolumn{3}{|c|}{ Extrapolation } & \multicolumn{3}{c|}{ Overall Fit } \\
\hline Method & $\begin{array}{l}\text { Stress- } \\
\text { strain }\end{array}$ & \multicolumn{1}{|c|}{ Strain-life } & Average & $\begin{array}{l}\text { Stress- } \\
\text { strain }\end{array}$ & \multicolumn{1}{l|}{ Strain-life } & Average \\
\hline Augmented Data Model & 0.972 & 0.990 & 0.981 & 0.958 & 0.959 & 0.958 \\
\hline Base Data Model & 0.968 & 0.988 & 0.978 & 0.954 & 0.955 & 0.955 \\
\hline Lower Bounds Model & 0.887 & 0.993 & 0.940 & 0.868 & 0.953 & 0.911 \\
\hline Upper Bounds 1 Model & 0.870 & 0.993 & 0.932 & 0.850 & 0.952 & 0.901 \\
\hline Upper Bounds 2 Model & 0.968 & 0.993 & 0.981 & 0.954 & 0.962 & 0.958 \\
\hline Upper Bounds 3 Model & 0.927 & 0.986 & 0.957 & 0.916 & 0.951 & 0.934 \\
\hline
\end{tabular}



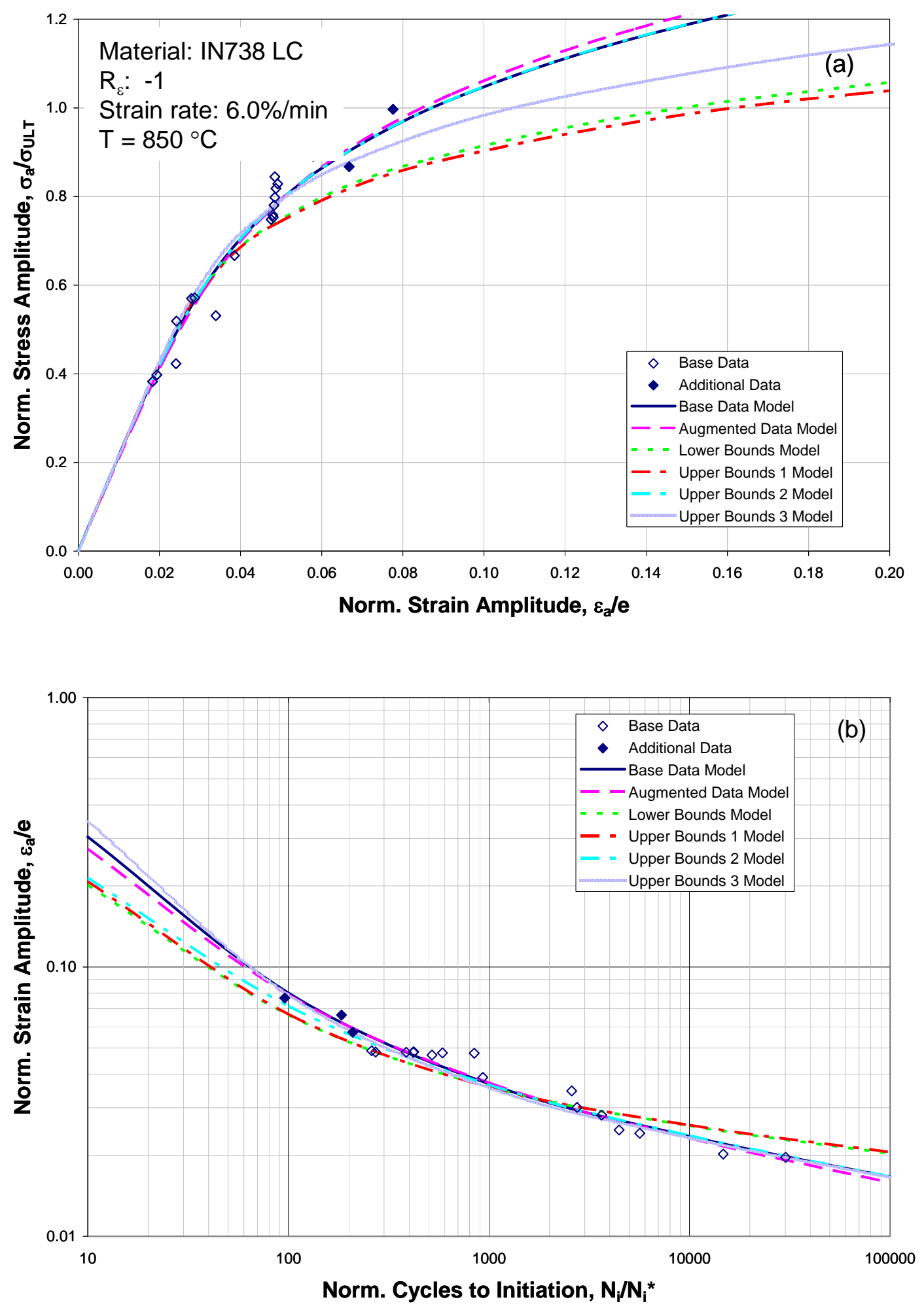

Figure 4.11. Comparison of (a) cyclic stress-strain models and (b) strain-life models for IN738 LC at $850^{\circ} \mathrm{C}$. 
The $900^{\circ} \mathrm{C}$ data include 8 data points all of which are considered low strain range, and in the base data set. The data set is being evaluated to find which method provides the best overall fit to the test data. An unusual trend is observed in the cyclic stress-strain response since the LB1 and UB1 trend well with the test data, but the UB2 and UB3 tend to over-estimate the behavior as shown in Fig. 4.12a.

The strain-life data at $900^{\circ} \mathrm{C}$ shows a marked increase in life at high strain ranges. These results place the curve fit strain life curve well above all extrapolation method predictions as shown in Fig. 4.12b. The $\mathrm{R}^{2}$ calculations show that the best overall fit is provided by the UB3 extrapolation method as shown in Table 4.10.

Table 4.10. Values of $\mathrm{R}^{2}$ for various methods at $900^{\circ} \mathrm{C}$.

\begin{tabular}{|l|r|r|r|}
\hline Purpose & \multicolumn{3}{|c|}{ Overall Fit } \\
\hline Method & $\begin{array}{l}\text { Stress- } \\
\text { strain }\end{array}$ & Strain-life & Average \\
\hline Base Data Model & 0.906 & 0.982 & 0.944 \\
\hline Lower Bounds Model & 0.929 & 0.932 & 0.931 \\
\hline Upper Bounds 1 Model & 0.927 & 0.931 & 0.929 \\
\hline Upper Bounds 2 Model & 0.924 & 0.972 & 0.948 \\
\hline Upper Bounds 3 Model & 0.932 & 0.980 & 0.956 \\
\hline
\end{tabular}



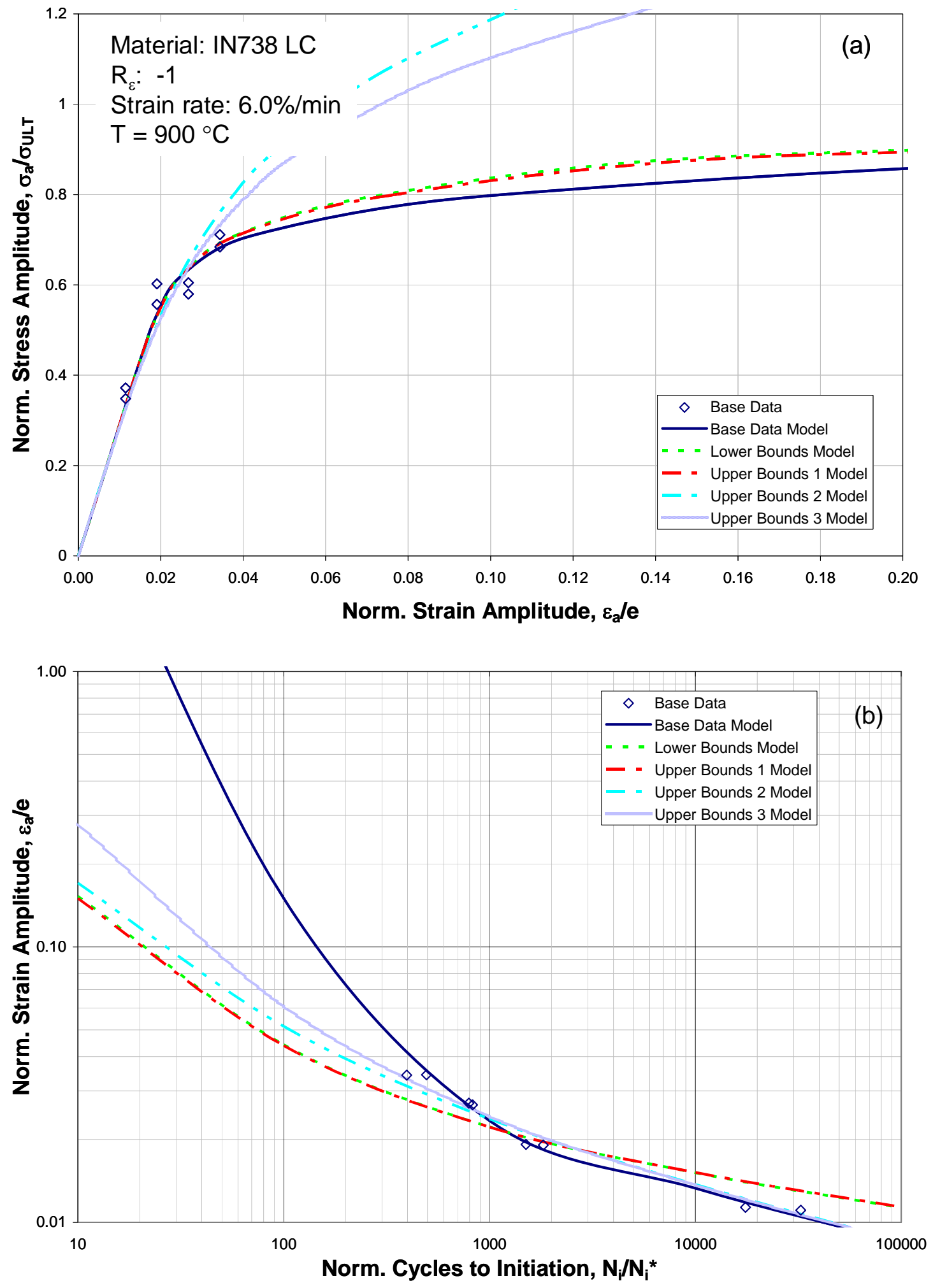

Figure 4.12. Comparison of (a) cyclic stress-strain models and (b) strain-life models for IN738 LC at $900^{\circ} \mathrm{C}$. 
The primary objective of this research is to develop a method for providing extrapolation of LCF data to high stress amplitudes using an existing strain range data set. Data was available to test the extrapolation methods at $24^{\circ} \mathrm{C}, 750^{\circ} \mathrm{C}$, and $850^{\circ} \mathrm{C}$. The equally weighted average $\mathrm{R}^{2}$ reveals the expected result that the augmented data set is the best approximation method, as shown in Table 4.11. Both the base data model and UB2 model share as the best approximation method with an average $\mathrm{R}^{2}$ value of 0.976 . The $\mathrm{R}^{2}$ of LB1, UB1, and UB3 are lower than the base data model, which indicates that these methods are in fact less desirable than a standard regression curve fit for extrapolation of an existing LCF data set to high strain ranges.

Table 4.11. Temperature average values of $R^{2}$ for extrapolation methods.

\begin{tabular}{|l|r|r|r|r|}
\hline & \multicolumn{3}{|c|}{ Temperature ${ }^{\circ} \mathrm{C}$} & \\
\hline Method & 24 & 750 & 850 & Average \\
\hline Augmented Data Model & 0.965 & 0.989 & 0.981 & 0.978 \\
\hline Base Data Model & 0.961 & 0.988 & 0.978 & 0.976 \\
\hline Lower Bounds Model & 0.922 & 0.931 & 0.940 & 0.931 \\
\hline Upper Bounds 1 Model & 0.958 & 0.954 & 0.932 & 0.948 \\
\hline Upper Bounds 2 Model & 0.961 & 0.987 & 0.981 & 0.976 \\
\hline Upper Bounds 3 Model & 0.946 & 0.986 & 0.957 & 0.963 \\
\hline
\end{tabular}

A secondary objective of this research was to insure that the approximation method does not negatively affect the match of curve fit to test data over the entire data range. This effect has again been evaluated by calculating a temperature averaged $\mathrm{R}^{2}$ value based on the overall best fit of 1) the base data model, 2) augmented data model, and 3) and the approximation methods, as shown in Table 4.12. The resulting calculations intuitively indicate that the best fit is provided obtained by the augmented data model. This shows that there is no better substitute than actual experimental data. 
Of the approximation approaches, however, the best methodology is provided by the UB2 with an $\mathrm{R}^{2}$ value of 0.954 . UB2 has an advantage over the base linear regression process or base data model with an $\mathrm{R}^{2}$ of 0.950 . This suggests that the small improvement in fit offered by UB2 is more significant over the entire data range than at the high strain data points. It is noted that the UB3 approximation was the highest at both $400^{\circ} \mathrm{C}$ and $900^{\circ} \mathrm{C}$. The other approximation methods (LB and UB1) consistently showed lower $\mathrm{R}^{2}$ values than the base curve, which indicates that these methods are less desirable than a standard curve fit over the full data range.

Table 4.12. Temperature average values of $R$-squared error for best fit over all test data.

\begin{tabular}{|l|r|r|r|r|r|r|}
\hline & \multicolumn{7}{|c|}{ Temperature ${ }^{\circ} \mathrm{C}$} & \\
\hline Method & 24 & 400 & 750 & 850 & 900 & Average \\
\hline Augmented Data Model & 0.964 & N/A & 0.966 & 0.958 & N/A & 0.963 \\
\hline Base Data Model & 0.956 & 0.928 & 0.966 & 0.955 & 0.944 & 0.950 \\
\hline Lower Bounds Model & 0.799 & 0.797 & 0.834 & 0.911 & 0.931 & 0.854 \\
\hline Upper Bounds 1 Model & 0.942 & 0.808 & 0.872 & 0.901 & 0.929 & 0.890 \\
\hline Upper Bounds 2 Model & 0.956 & 0.943 & 0.962 & 0.958 & 0.948 & 0.954 \\
\hline Upper Bounds 3 Model & 0.925 & 0.947 & 0.959 & 0.934 & 0.956 & 0.944 \\
\hline
\end{tabular}




\section{DISCUSSION}

The following section provides a discussion of the results considering each method individually. Also, the rationale for the performance of each method is explained.

\subsection{Augmented Data Model}

The augmented data set method applied the standard regression procedure to the augmented data set. Recall that the augmented data set includes both the base data set along with the additional high strain data points conducted as part of this research. The cyclic stress-strain curves are shown in Fig. 5.1a. Intuitively, this method provides the

best option for characterizing the high strain data points. Likewise, this method provided the best method for an overall match to test data. These were demonstrated by $\mathrm{R}^{2}$ being higher than any approximation method for "extrapolation” or "overall” as shown in Table 4.11, and Table 4.12.

The resulting augmented data set models include data over the entire fatigue life range designating the LCF regime from 100 to 10,000 normalized cycles, as shown in Fig. 5.1b. Recall that at high mechanical strain amplitudes, the plastic range is of the same magnitude as the elastic strain range $\left(\Delta \varepsilon_{p l} \approx \Delta \varepsilon_{e l}\right)$, and the plastic strains have a significant impact on the measured cyclic lives. It is noted that the strain-life model does show an increase in slope with temperature at high strain amplitudes when high strain data is included in the data set. 

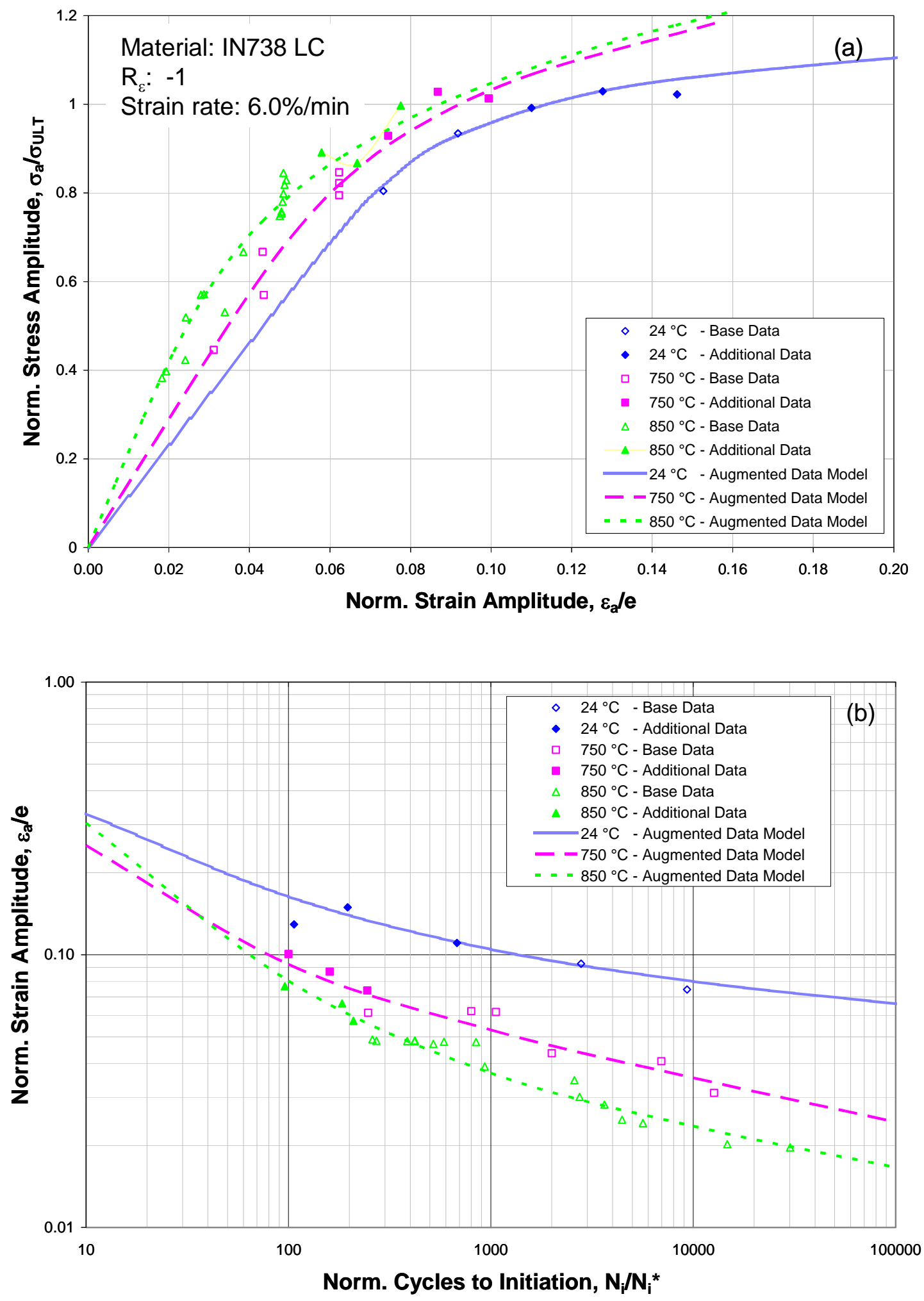

Figure 5.1. Comparison of (a) cyclic stress-strain curve and (b) strain-life curves using the augmented data model and data for IN738 LC at various temperatures. 


\section{2. $\quad$ Base Data Model}

The base data model provides the baseline for predicting the stress-strain and strain-life curves at high strain ranges. The base model applied standard linear regression using the base data set as described in the reference methods. A plot of the stress-strain curve using the base model is shown in Fig. 5.2a. Note that only the base data are included in the regression analysis to provide this model. The results show that the base model correlates well with the additional high strain data points.

The strain-life curves provided by the base model using the base data set worked very well at predicting the high strain range behavior of the material at $24^{\circ} \mathrm{C}, 750^{\circ} \mathrm{C}$, and $850^{\circ} \mathrm{C}$ as shown in Fig. 5.2b. The model shows more questionable results at $400^{\circ} \mathrm{C}$ and $900^{\circ} \mathrm{C}$, but unfortunately high strain data was not able to be collected at these temperatures.

It is somewhat difficult to compare the strain-life models at $400^{\circ} \mathrm{C}$ and $750^{\circ} \mathrm{C}$ due to the method of normalization. However, it is noted that the strain-life data at $400^{\circ} \mathrm{C}$ intersects the data at $750^{\circ} \mathrm{C}$ between 400 and 1,000 normalized cycles. This is unexpected since LCF life is expected to decrease with temperature. One possible explanation is that serrated yielding may be causing reduced life and / or high scatter in the data at this temperature. This hypothesis is supported by the testing experience in this project, and is also shown by the low $\mathrm{R}^{2}$ value using the existing strain-life data at $400^{\circ} \mathrm{C}$ despite the relatively large number of data points (16) in the data set.

At $900^{\circ} \mathrm{C}$ there is another potential anomaly since a very sharp slope increase is found in the strain-life curve at less than 1,000 normalized cycles. One explanation is a lack of test data. Since only 8 data points are in this data set, it is possible that some 
outlying data points are causing the apparent deviation. Another possibility is that the test environment could be affecting the results. It is noted that these tests were done in air, and a fair amount of oxidation may be occurring at this temperature. This could be causing low measured cyclic lives, which are affecting the fit of the model. Marchionni [11] has published a paper about the influence of testing IN738 LC at elevated temperatures in air versus inert atmosphere. Re-running these tests in an inert atmosphere may reduce this effect.

There is little evidence provided in this work to suggest that the standard curve fitting procedure is flawed. Despite all of the efforts to find a better method for estimating the high strain behavior of this material, simply extrapolating from the base data model provided identical $\mathrm{R}^{2}$ values as using the best approximation method (UB2). 

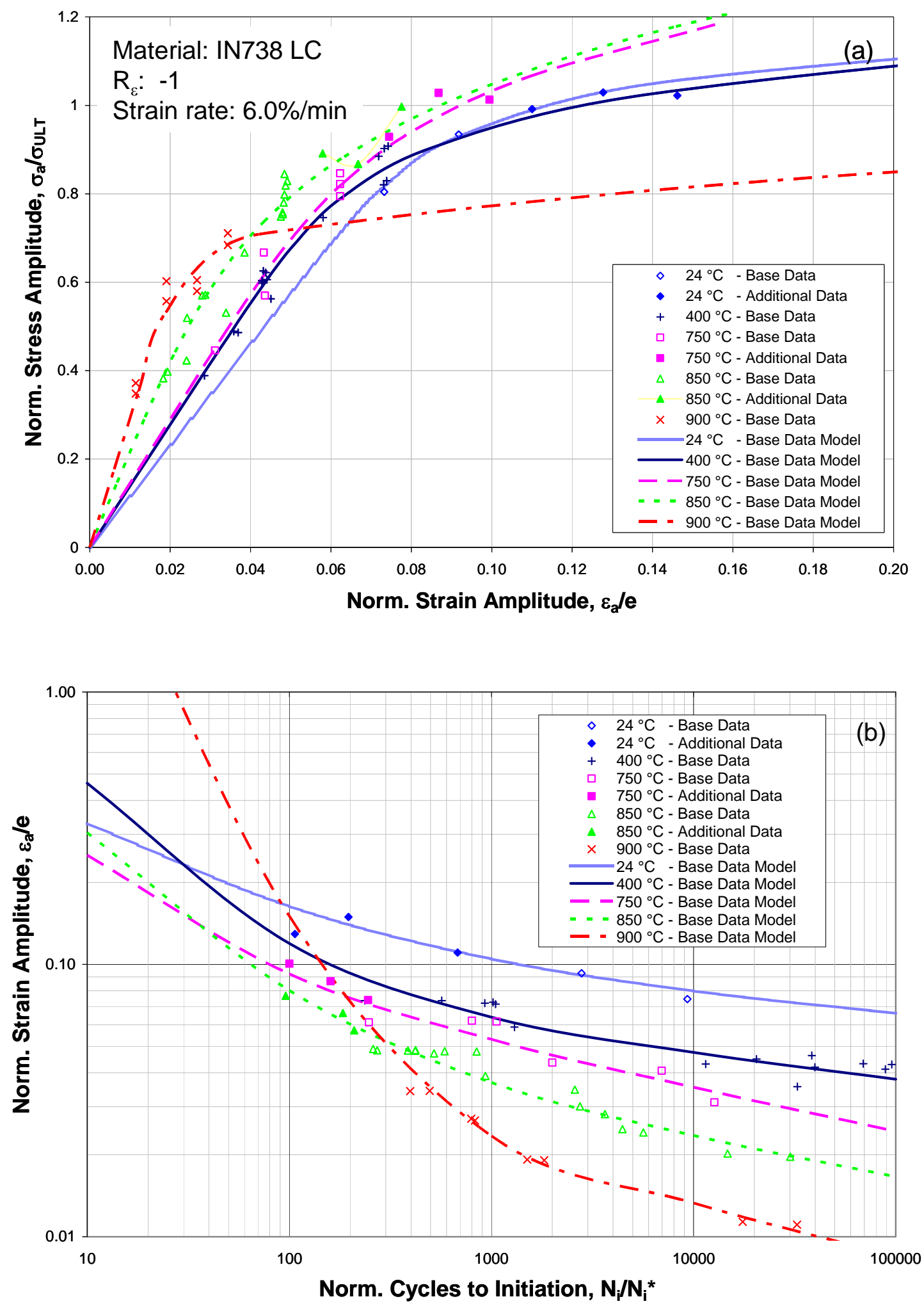

Figure 5.2. Comparison of (a) cyclic stress-strain curve and (b) strain-life curves using the base model and base data for IN738 LC at various temperatures. 


\subsection{Lower Bound Model}

The LB model was conjectured to be a good estimate for the lower bounds of the material. Recall that the LB model includes an anchor point in the LCF data during the regression process.

One goal of the project was to acquire very high strain range data to determine if the cyclic stress amplitude merges with the monotonic stress amplitudes as suggested by the data from Morrow and Tuler [8]. Their data suggested that this would occur at about 3.0\% strain range with IN713 LC at room temperature. It was not possible to achieve such high strain ranges with the series of tests provided in this project. However, it is noted that the data at $24^{\circ} \mathrm{C}$ did show a maximum normalized stress amplitude of 1.029 at a normalized strain range of 0.257 , which reduced to the normalized stress amplitude of 1.022 at a normalized strain range of 0.294 . Likewise, the 0.174 normalized strain range at $750^{\circ} \mathrm{C}$ showed s a higher normalized stress amplitude of 1.028 than the 0.199 normalized strain range value of 1.013 as shown in Fig. 5.3a. This appears to correlate with the data from Morrow and Tuler by showing that there is a strain range which maximizes the strain hardening effect, above which the strain hardening effect diminishes. Fatigue testing at higher strain ranges would be needed for further confirmation.

It is noted that $850^{\circ} \mathrm{C}$ does not show the same trend, since the stress amplitude continued to increase at the highest normalized strain amplitude tested. This was not unexpected since strain softening should show the opposite trend to strain hardening, where the stress range increases with strain amplitude at high strain amplitudes, 
eventually merging with the monotonic ultimate strength curve as the effect of strain softening diminish.

However, it was unexpected to see that the $\mathrm{LB}$ model $850^{\circ} \mathrm{C}$ remains below the data at $850^{\circ} \mathrm{C}$. It was anticipated that the LB model would over-predict stress for a given strain due to strain-softening, which is not the case considering the cyclic stress-strain curve. Additionally, since there is minimal strain softening occurring at $850^{\circ} \mathrm{C}$ it was hypothesized that the LB model would provide accurate cyclic stress-strain curve, which is also not the case. Therefore, the LB method did not perform as anticipated in accuracy or in trends when minimal strain-softening occurs.

The LB strain-life curve did in general provide a lower bounds for the strain-life curve, as shown in Fig. 5.3b. This is an acceptable result considering that this method was not meant to accurately predict behavior. 

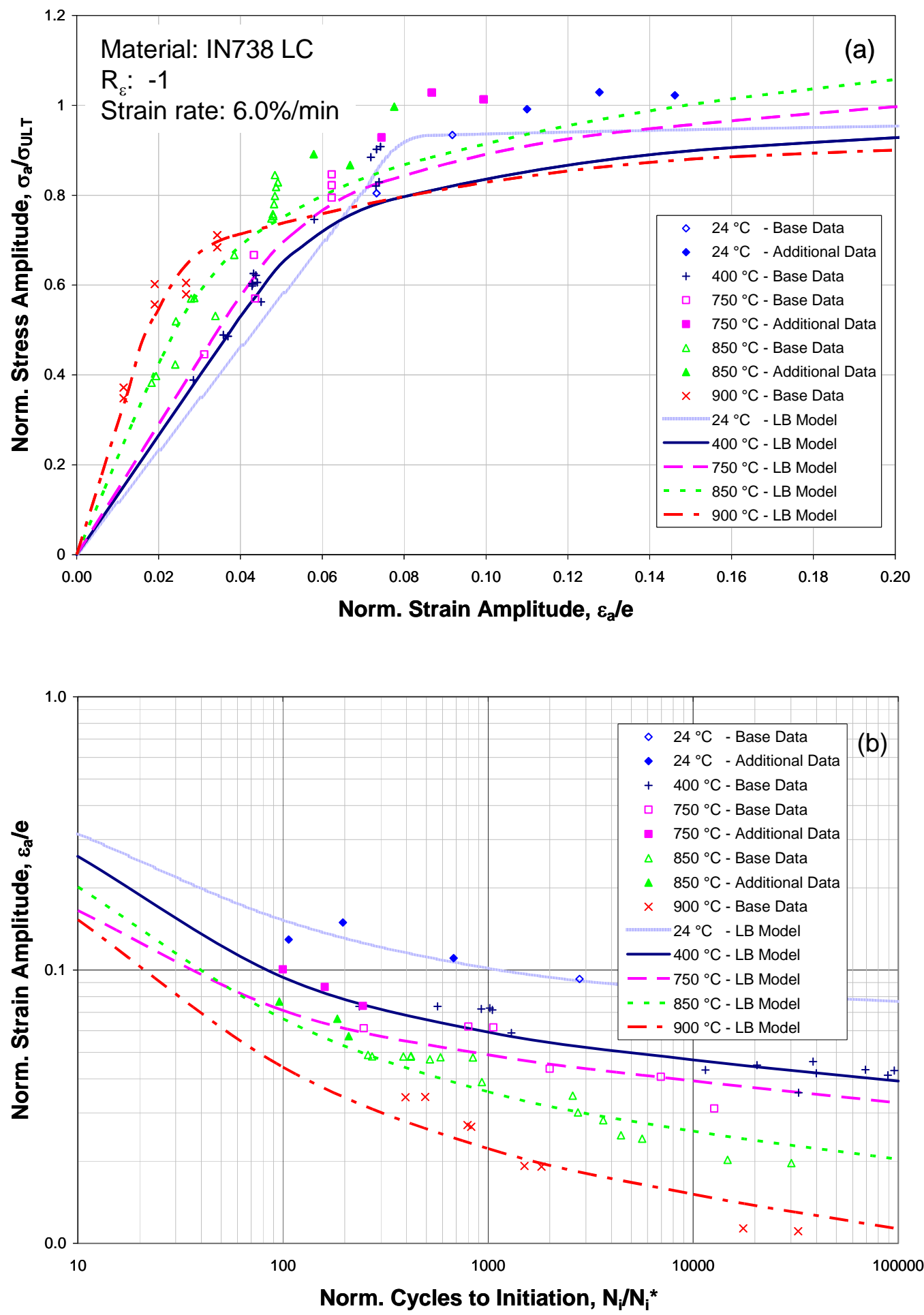

Figure 5.3. Comparison of (a) cyclic stress-strain curve and (b) strain-life curves using the LB model and base data for IN738 LC at various temperatures. 


\section{4. $\quad$ Upper Bounds 1 Model}

The UB1 model did not perform as expected, and in general performed much like the LB model rather than an accurate prediction of material behavior. This method adjusted the standard anchor point used in the LB model by using the shape change in the hysteresis loops between the initial and mid-life cycles. The stress-strain curves produced by this method are often conservative, and show a lower stress for a given strain compared to actual test data, as shown in Fig. 5.4a. The resulting strain-life curves are often overly conservative as well, when compared to the test data, as shown in Fig. 5.4b.

Recall that this method assumed a linear relationship between the initial plastic and mid-life plastic strain as well as between the initial stress range and mid-life stress range, as shown in Fig. 3.3a and 3.3b. Initially, regression was performed using only the base data set. To further investigate the applicability of this method, linear regression was again performed using the augmented data set (base plus additional high strain data). This resulted in a limited change in the scaling constants as shown in Table 5.1, of less than $13 \%$. Applying the revised scaling factors did not significantly change the outcome of the UB1 method, and had a negligible effect on the $\mathrm{R}^{2}$ values for this method.

Table 5.1. Constants $C_{1}$ and $C_{2}$ from linear regression with base data set and augmented data set.

\begin{tabular}{|r|l|l|r|l|l|l|}
\hline $\begin{array}{l}\text { Temperature } \\
\left({ }^{\circ} \mathrm{C}\right)\end{array}$ & $\begin{array}{l}\text { C1 - Base } \\
\text { Data } \\
\text { Model }\end{array}$ & $\begin{array}{l}\text { C1 }- \\
\text { Augmented } \\
\text { Data Model }\end{array}$ & $\begin{array}{l}\text { Change } \\
(\%)\end{array}$ & $\begin{array}{l}\text { C2 - Base } \\
\text { Data } \\
\text { Model }\end{array}$ & $\begin{array}{l}\text { C2 - } \\
\text { Augmented } \\
\text { Data Model }\end{array}$ & $\begin{array}{l}\text { Change } \\
(\%)\end{array}$ \\
\hline 24 & 1.090 & 1.099 & -0.8 & 0.694 & 0.770 & -9.8 \\
\hline 400 & 1.437 & & - & 0.543 & & - \\
\hline 750 & 1.049 & 1.181 & -11.2 & 0.632 & 0.690 & -8.4 \\
\hline 850 & 0.876 & 0.908 & -3.5 & 1.105 & 0.980 & 12.8 \\
\hline
\end{tabular}



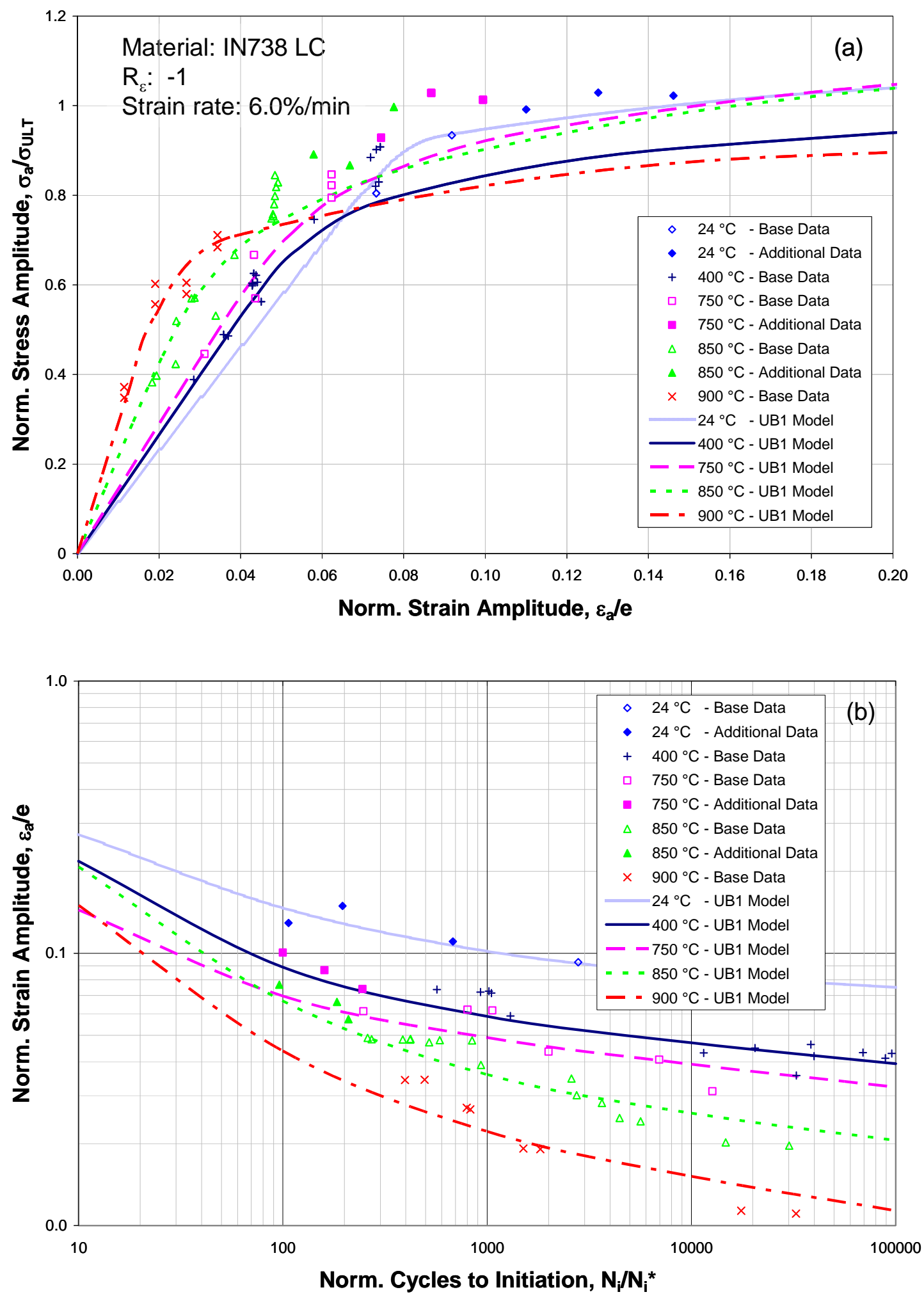

Figure 5.4. Comparison of (a) cyclic stress-strain curve and (b) strain-life curves using the UB1 model and base data for IN738 LC at various temperatures. 


\section{5. $\quad$ Upper Bounds 2 Model}

It was demonstrated that the UB2 method is equally valid as the base method at predicting the high strain behavior of the extrapolated behavior of IN738 LC at high strain amplitudes outside of the existing test data. Recall that this method used strain compatibility to estimate the failure stress, which would occur at $1 / 2$ cycle. It also assumed a failure strain equal to the failure elongation of a tensile test. This method is unique amongst the other methods since the failure stress is actually determined utilizing the existing LCF data set, and an assumption of behavior at $1 / 2$ cycle.

The UB2 method provides the best overall fit through data points (including the high strain data points) of all the approximation methods. However, the margin of improvement was small over the base model. This method showed very similar behavior in predicting the stress-strain curve behavior of the base curve fit, as shown in Fig. 5.5a.

The UB2 method does provide more consistent looking stress-strain and strainlife curves. The stress-strain and strain-life curves trend well with temperature as shown in Fig. 5.5 as apposed to the base model (Fig. 5.2), which showed a steep slope change especially at $900^{\circ} \mathrm{C}$. The strain-life curves are especially improved since the regressions fit the anticipated behavior, which is that decreasing temperature leads to an increase in the cycles to crack initiation for a given strain amplitude. 

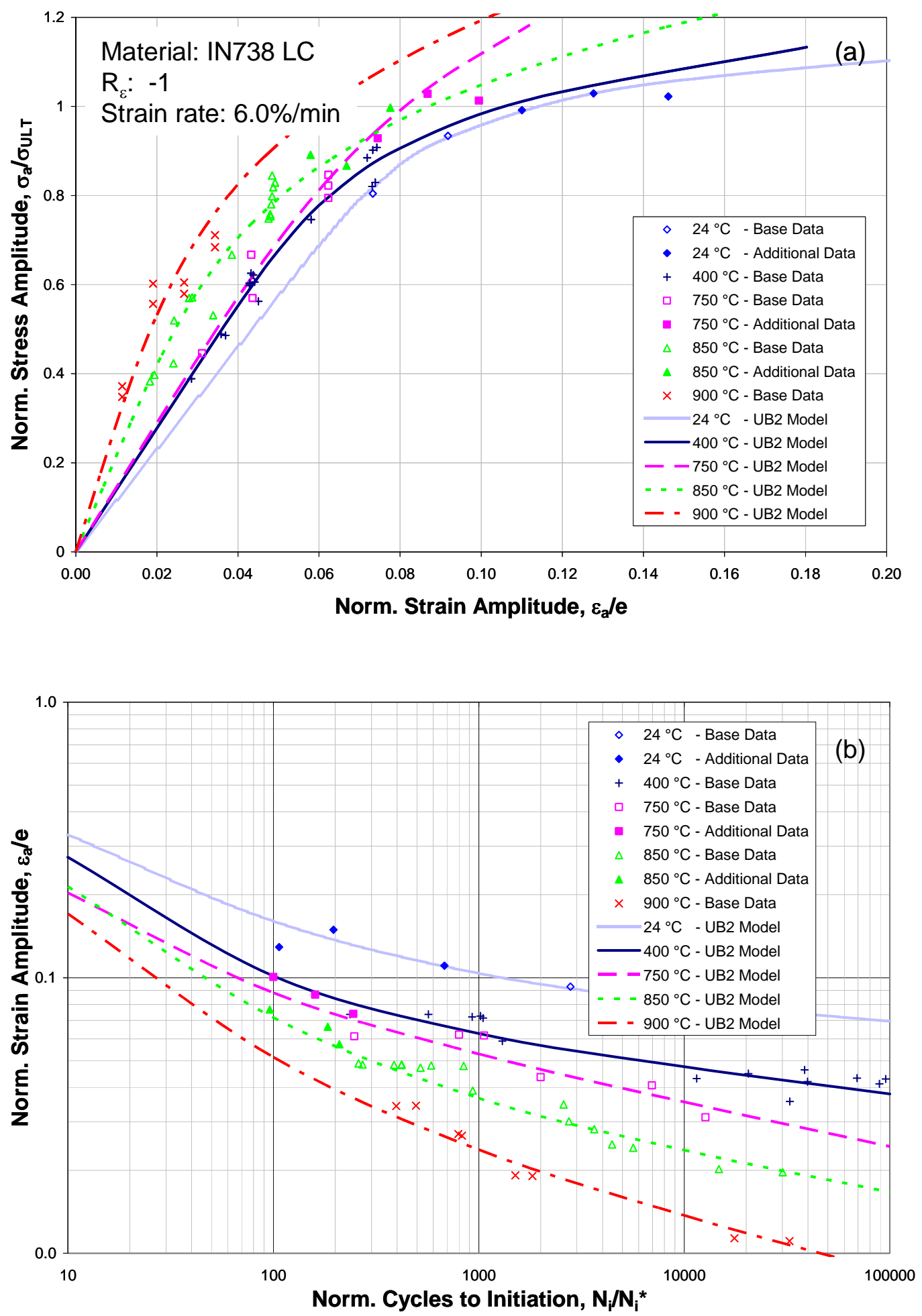

Figure 5.5. Comparison of (a) cyclic stress-strain curve and (b) strain-life curves using the UB2 model and base data for IN738 LC at various temperatures. 


\section{6. $\quad$ Upper Bounds 3 Model}

The UB3 method was more accurate than other methods when significant scatter or potential anomalies exist in the data set at a certain temperature. Recall that this procedure grouped all temperatures of the plastic strain data together to find both constants describing the Coffin-Manson equation $\left(\varepsilon_{f}^{\prime}, c\right)$. The assumption was that the error induced by assuming a temperature independent Coffin-Manson equation would be offset by a significant reduction in the scatter in the plastic strain-life data.

The resulting stress-strain and strain-life curves show a reasonable fit with the test data. As expected, the high strain portions of all the strain-life equations are reaching an asymptote due to using the same Coffin-Manson constants as shown in Fig. 5.6b. The asymptotic slope is, however, higher than that found in the base models (Fig. 5.2b). This is likely due to that fact that most of the plastic strain data is at $850^{\circ} \mathrm{C}$, which has a steeper slope with respect to temperature. This apparently has skewed the curve towards the high temperature data slope, and negatively affected the quality of the strain-life model.

It is noted that this method worked best when there were questionable trends observed in the data. For example, at $400^{\circ} \mathrm{C}$ and $900^{\circ} \mathrm{C}$ the UB3 method provided the overall fit to test data. Both of these temperatures may have experienced testing problems (serrated yielding at $400^{\circ} \mathrm{C}$, and oxidation at $900^{\circ} \mathrm{C}$ ), therefore, it is possible that an indicator of outside testing issues is provided when this method has the highest $\mathrm{R}^{2}$ relative to other methods. 

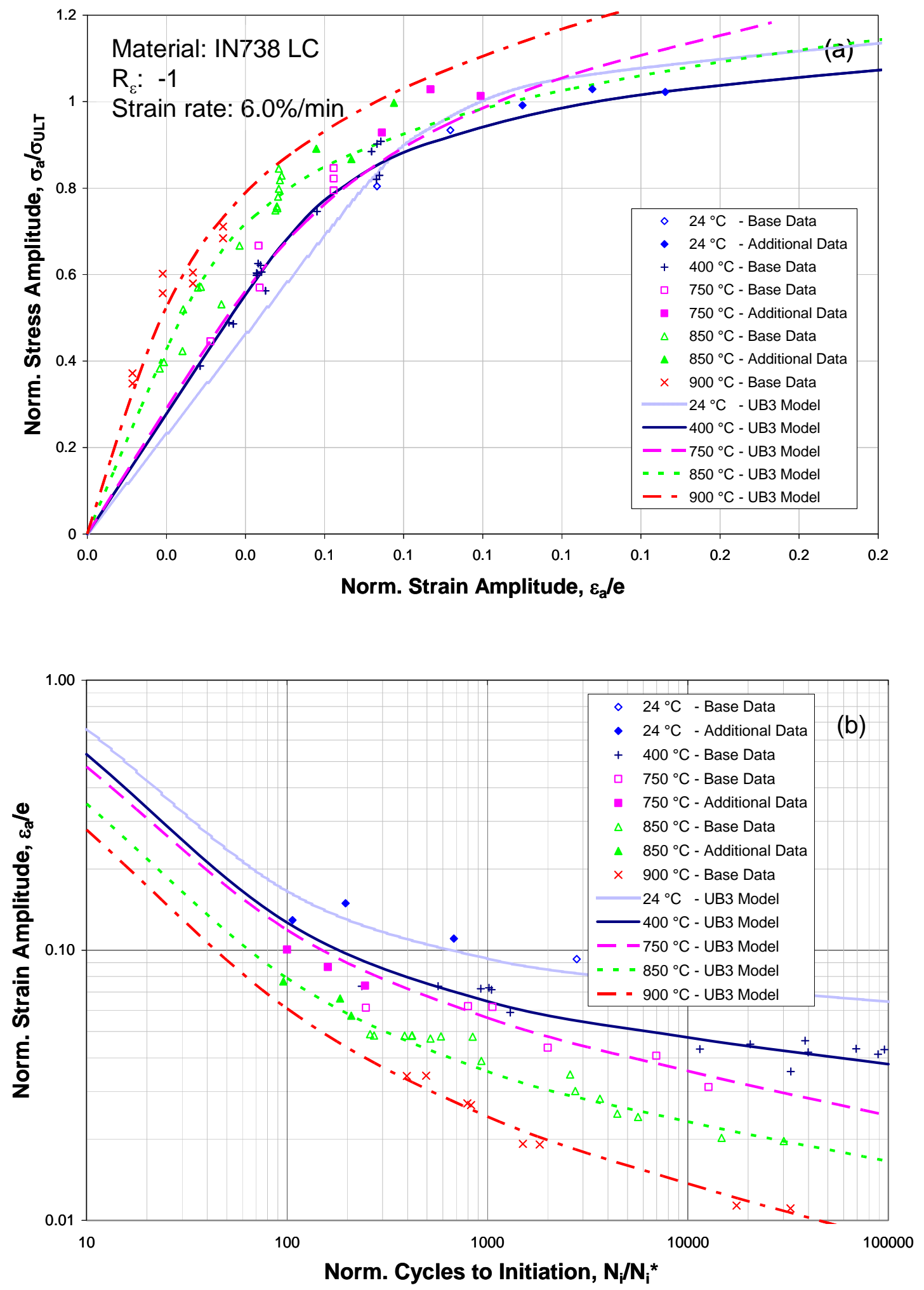

Figure 5.6. Comparison of (a) cyclic stress-strain curve and (b) strain-life curves using the UB3 model and base data for IN738 LC at various temperatures. 
A simple ranking is applied to the $\mathrm{R}^{2}$ values presented in Table 4.11 and Table 4.12 to look for additional trends from the data. The overall evaluation of the extrapolation methods shows that the augmented data model is the most valid predictor of extrapolated high strain range behavior. The base model and UB2 approximation models are equally useful for prediction of the high strain range behavior at any of the test temperatures used as shown in Table 5.2. The UB1 was the weakest performer since it was intended to be a valid predictor of behavior.

Table 5.2. Temperature average values of $\mathbf{R}^{2}$ for extrapolation methods.

\begin{tabular}{|c|c|c|c|c|}
\hline & \multicolumn{3}{|c|}{ Temperature ${ }^{\circ} \mathrm{C}$} & \\
\hline Method & 24 & 750 & 850 & Average \\
\hline Augmented Data Model & 1 & 1 & 1 & 1.0 \\
\hline Base Data Model & 2 & 2 & 2 & 2.0 \\
\hline Lower Bounds Model & 5 & 6 & 4 & 5.0 \\
\hline Upper Bounds 1 Model & 3 & 5 & 5 & 4.3 \\
\hline Upper Bounds 2 Model & 2 & 3 & 1 & 2.0 \\
\hline Upper Bounds 3 Model & 4 & 4 & 3 & 3.7 \\
\hline
\end{tabular}

Similarly, a ranking was applied to the overall fit through all data at each temperature. These results show that the augmented data set is the best option, closely followed by the UB2 model, and then by the base data model, as shown in Table 5.3. It is notable that the UB3 model does perform well at $400^{\circ} \mathrm{C}$ and $900^{\circ} \mathrm{C}$. A correlation was noted between high $\mathrm{R}^{2}$ values of UB3 relative to other methods, and identification of potential outside testing issues. The UB1 shows that it is not well-suited to predict overall data for this particular material. 
Table 5.3. Temperature average values of $\mathbf{R}^{2}$ error for best overall test data.

\begin{tabular}{|l|r|r|r|r|r|r|}
\hline & \multicolumn{7}{|c|}{ Temperature ${ }^{\circ} \mathrm{C}$} & \\
\hline Method & 24 & 400 & 750 & 850 & 900 & Average \\
\hline Augmented Data Model & 1 & & 1 & 1 & & 1.0 \\
\hline Base Data Model & 2 & 3 & 1 & 2 & 3 & 2.2 \\
\hline Lower Bounds Model & 5 & 5 & 4 & 4 & 4 & 4.4 \\
\hline Upper Bounds 1 Model & 3 & 4 & 5 & 5 & 5 & 4.4 \\
\hline Upper Bounds 2 Model & 2 & 2 & 2 & 1 & 2 & 1.8 \\
\hline Upper Bounds 3 Model & 4 & 1 & 3 & 3 & 1 & 2.4 \\
\hline
\end{tabular}

The original intention of this work was to develop a method for extrapolating from an existing LCF data set into high strain ranges outside of the data set. The best method for this is actually acquiring the high strain data points. In lieu of this, the best overall method is to apply UB2 or use of the base model curve fit. Use of the UB2 method also had the unexpected result of improving the overall fit with all available test data. Where high amount of variation or questionable trends are found in the test data, the UB3 method proved useful.

Another option for use of these methods is extrapolation in the early stages of setting up a test matrix for the material. If tensile test data and HCF data is available, the UB2 methodology could be used to estimate the LCF behavior of the material. This information could be used for planning a matrix for acquiring LCF test data.

It may be tempting to use these methodologies in an effort to provide an additional test data point in an existing test matrix with sparse data points. A note of caution is added that any extrapolation methods presented in this work will not improve the quality level of the database. These methods are not meant as a substitute for a characterization of a material by a sufficient quantity of valid test data. 


\section{CONCLUSIONS}

The best most accurate method for improving the understanding of high strain LCF properties of IN738 LC is by including high strain range tests in the test matrix. It was demonstrated that more difficulty in achieving strain control may occur during high strain range tests. These difficulties may be addressed in part by making tuning adjustments for each specimen prior to testing.

It was demonstrated that the best method for extrapolating from an existing set of IN738 LC data set to high stress amplitudes was shared between the UB2 method (strain compatibility / anchor point combination) and the base model. Test data was used at $24^{\circ} \mathrm{C}, 750^{\circ} \mathrm{C}$, and $850^{\circ} \mathrm{C}$ to demonstrate these effects. The UB2 method had the unexpected result of providing an overall better match with test data than the base linear regression method, which was demonstrated using data at $24^{\circ} \mathrm{C}, 400^{\circ} \mathrm{C}, 750^{\circ} \mathrm{C}, 850^{\circ} \mathrm{C}$, and $900^{\circ} \mathrm{C}$.

Testing anomalies which occurred at $400^{\circ} \mathrm{C}$ indicate a potential cause of unexpected trends may be due to testing issues specific to these temperatures rather than a fundamental problem with the base linear regression modeling technique. Additional evidence is provided by the observation that the $900^{\circ} \mathrm{C}$ tests occurred in air at a temperature where significant oxidation may be affecting the measured cyclic lives. The current modeling technique using linear regression curve fitting does not provide an indicator of the occurrence of outside testing issues.

The LB option (conventional anchor point) provided the expected affect of overpredicted the stress-strain behavior at moderate strain range levels at $24^{\circ} \mathrm{C}$ and $750^{\circ} \mathrm{C}$. However, when strain-softening occurred at $850^{\circ} \mathrm{C}$, the stress-strain curve was over- 
predicted rather than under-predicted as expected. A strain range at which the stabilized stress range was maximized appeared to occur at $24^{\circ} \mathrm{C}$ and $750^{\circ} \mathrm{C}$. The $850^{\circ} \mathrm{C}$ did not show such a peak, but since strain softening was observed at this temperature, a peak would in fact not be expected. It was not possible to confirm whether the upper bounds option merged with the lower bounds options at very high strains since these tests were not achieved.

The UB1 method (hystersis loop adjusted anchor point) proved poor at describing an upper bounds of the cyclic stress-strain and strain-life equation. Linearly extrapolating from stress range and strain range changes between the initial and stable mid-life cycle to scale a conventional anchor point had only a minor effect on the base anchor point.

The UB3 option (temperature independence of the Coffin-Manson equation) had a mixed performance as an upper bounds of material behavior. In general this method did not perform well. However, a correlation was noted between UB3 having the highest $\mathrm{R}^{2}$ value, and high scatter in material data at $400^{\circ} \mathrm{C}$. The UB3 option also had the highest $\mathrm{R}^{2}$ value at $900^{\circ} \mathrm{C}$ where possible influence due to oxidation may have influenced the measured cyclic lives. This indicates that the UB3 may be best used when large scatter or questionable results are present in the data set, or an indicator of outside testing issues. 


\section{RECOMMENDATIONS}

As an outcome of this investigation, several avenues for further investigation exist for improving the results from this study. Since limited quantities of test data may show unusual behavior, additional test data at all strain range levels would help confirm the behavior found in this project. It is noted that even the augmented data sets provide only a preliminary quality level at $24^{\circ} \mathrm{C}, 750^{\circ} \mathrm{C}$, and $900^{\circ} \mathrm{C}$.

Additional tests to clarify the behavior at temperatures with unusual behavior $\left(400^{\circ} \mathrm{C}\right.$ and $\left.900^{\circ} \mathrm{C}\right)$ are necessary. Options that may alleviate the issues of testing at $400^{\circ} \mathrm{C}$ may include changing the strain rate of the test, and additional fine tuning of the control settings. It would be beneficial to determine if there is questionable data at $900^{\circ} \mathrm{C}$. Additional tests could be provided in air at $900^{\circ} \mathrm{C}$ at high strain ranges. Also, it is worth comparing tests in an inert environment at $900^{\circ} \mathrm{C}$ especially at low strain ranges, and high lives to determine if oxidation is affecting the data at high cyclic lives.

If true, valid high strain range test data could be provided to observe failure in a few cycles, then a more appropriate approximation method could be devised. This would most likely require tests above 2.0\% strain range, and the ASTM standard E606 suggests an hourglass specimen for these tests. It is also noteworthy to consider that both the data from Morrow and Tuler [8], and the data from Marchionni [11] provided test data above $2.0 \%$ strain range. Both of these sources used tubular specimens as typically used for induction heating, and it is possible that a tubular specimen design allows for greater testing ease at high strain ranges. It would be advisable to conduct these tests at room temperature to reduce cost and expense during the learning period. The room temperature tests also required the least adjustment of the control settings to achieve 
constant strain. After methods are developed at room temperature, the high temperature tests could follow. 
APPENDIX A - EXPERIMENTAL HYSTERESIS LOOPS AND STRESS HISTORIES 

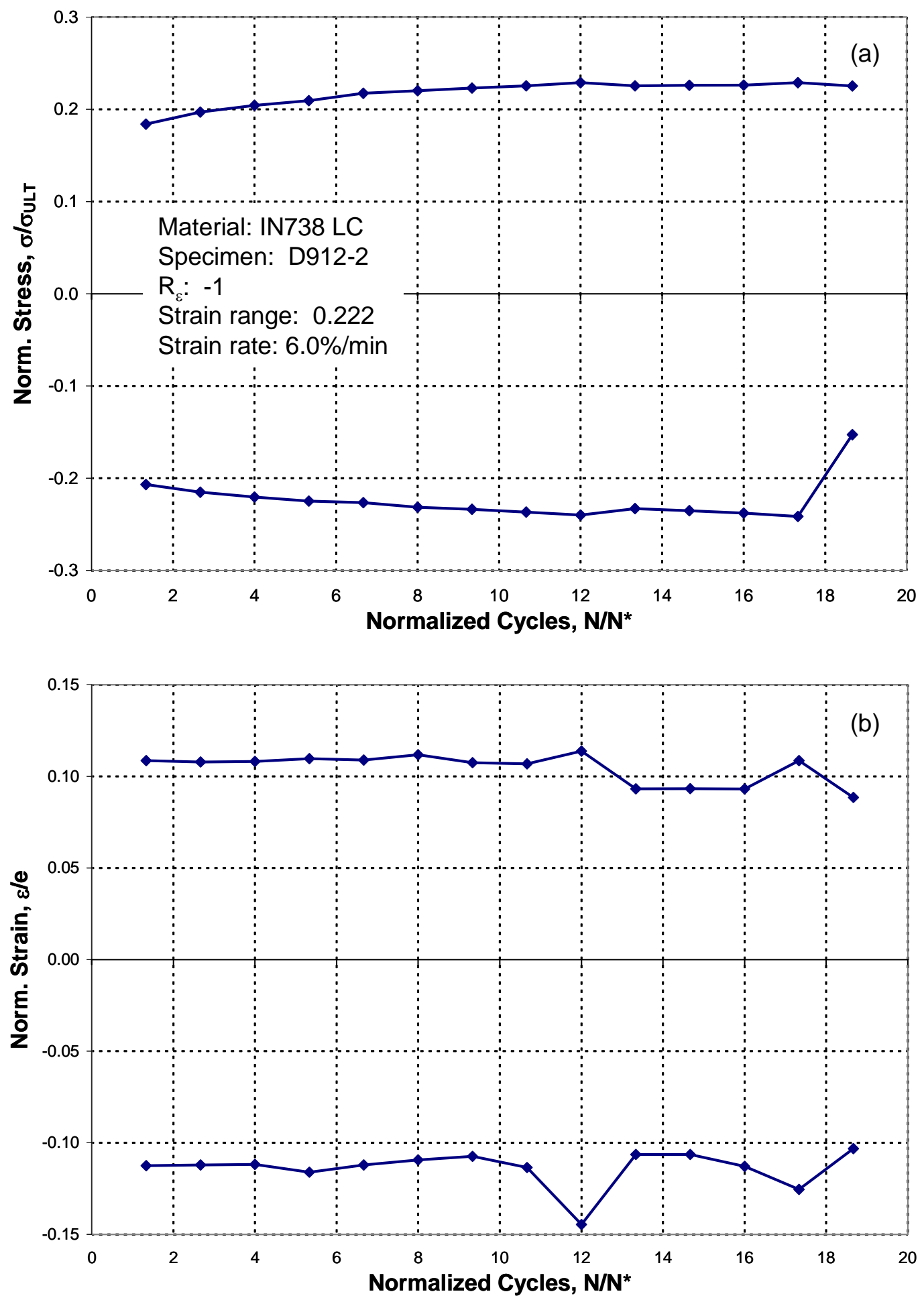

Figure A.1. Cyclic (a) stress and (b) strain histories for test specimen D912-2 at $400^{\circ} \mathrm{C}$. 

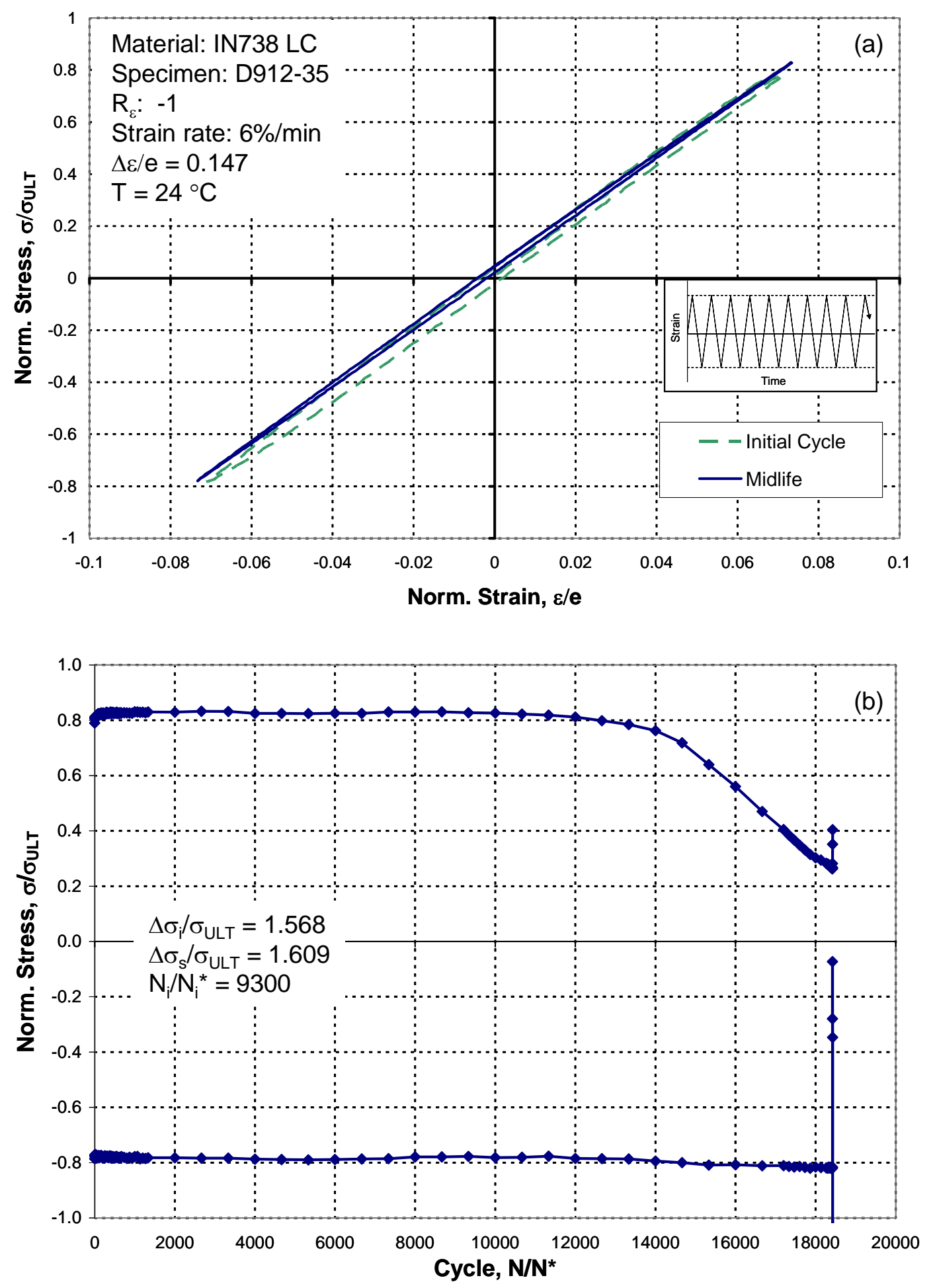

Figure A.2. (a) Hysteresis loops and (b) stress cycle plots for LCF test specimen D912-35 at $24^{\circ} \mathrm{C}$. 

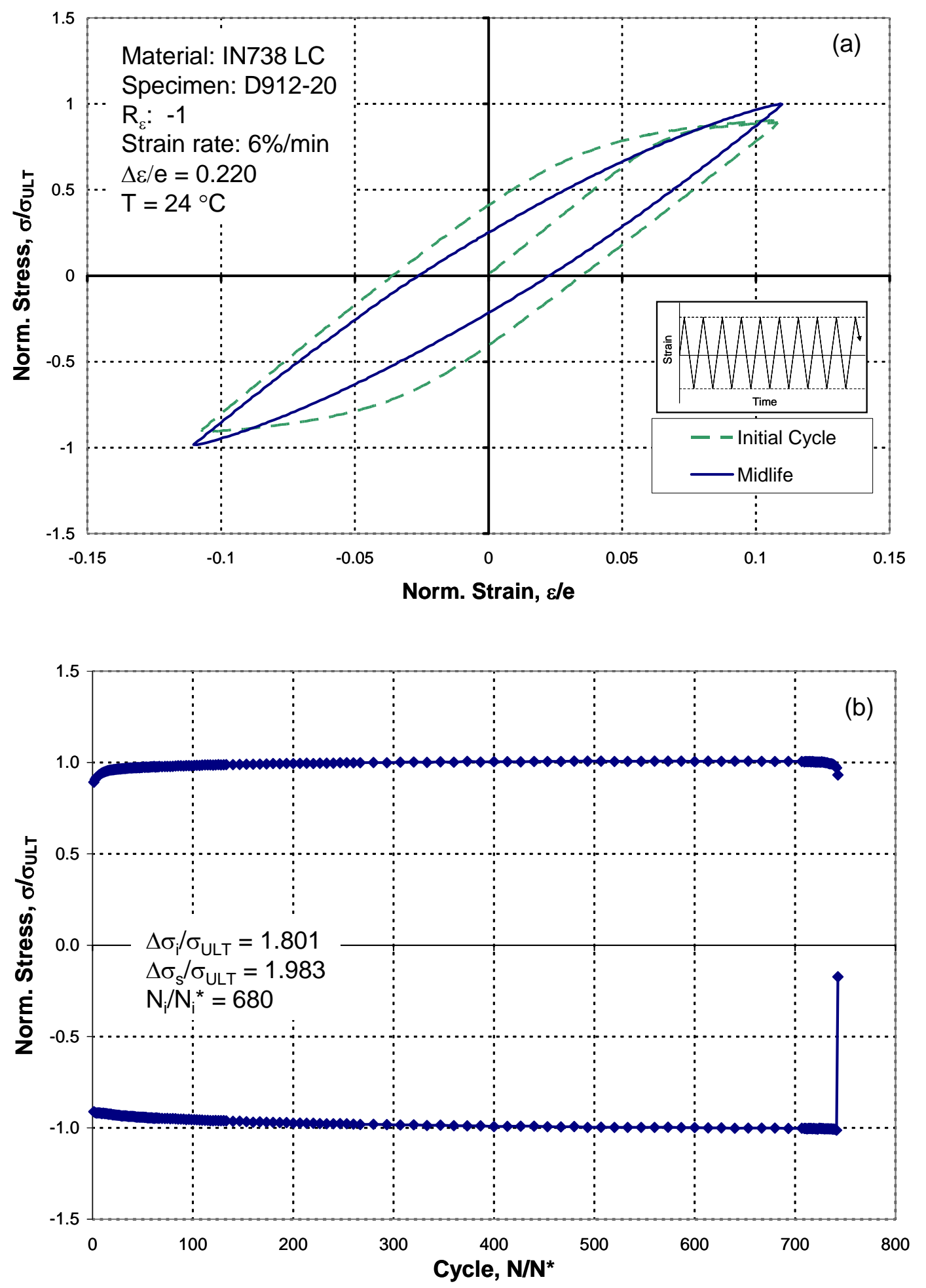

Figure A.3. (a) Hysteresis loops and (b) stress cycle plots for LCF test specimen D912-20 at $24^{\circ} \mathrm{C}$. 

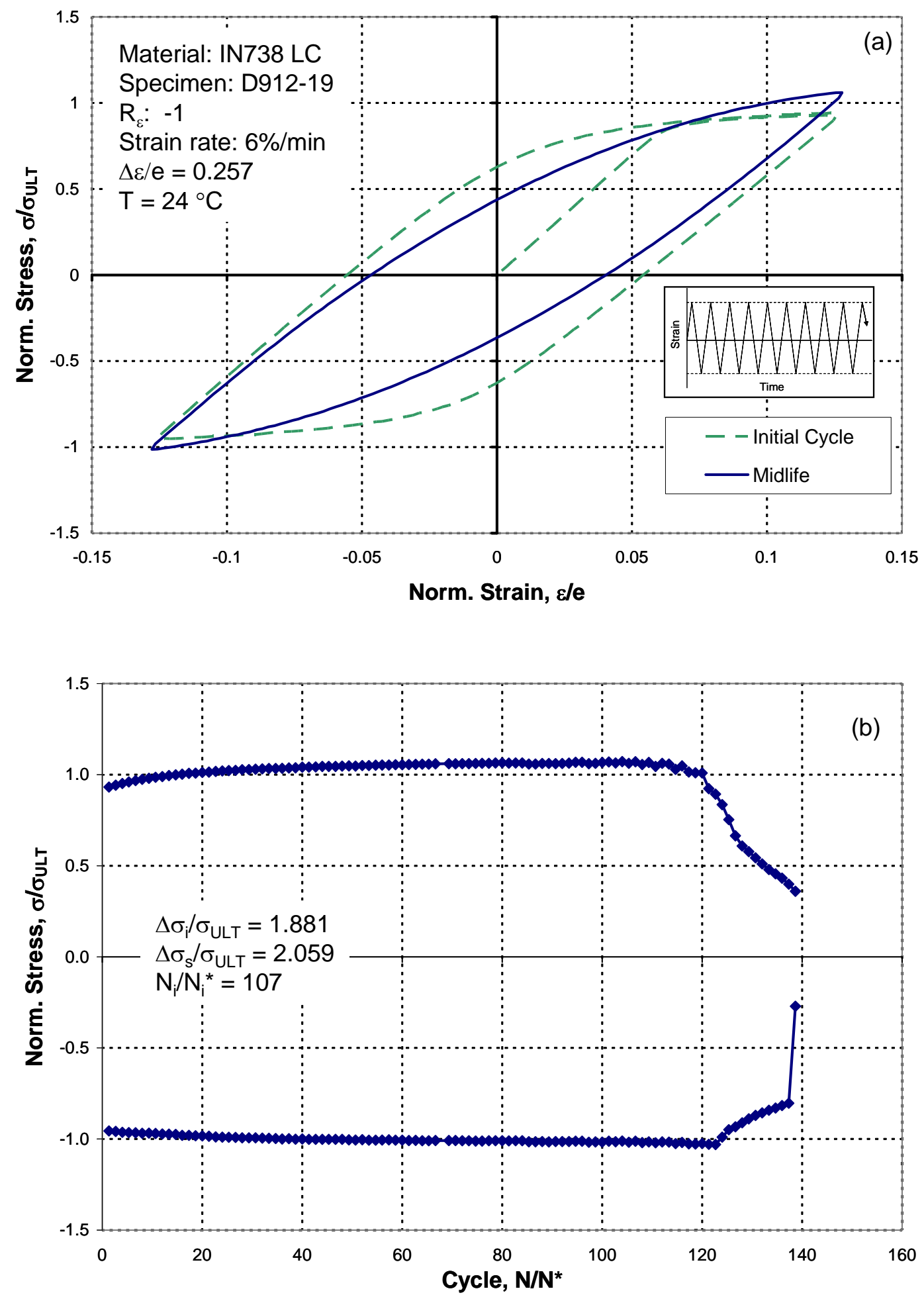

Figure A.4. (a) Hysteresis loops and (b) stress cycle plots for LCF test specimen D912-19 at $24^{\circ} \mathrm{C}$. 

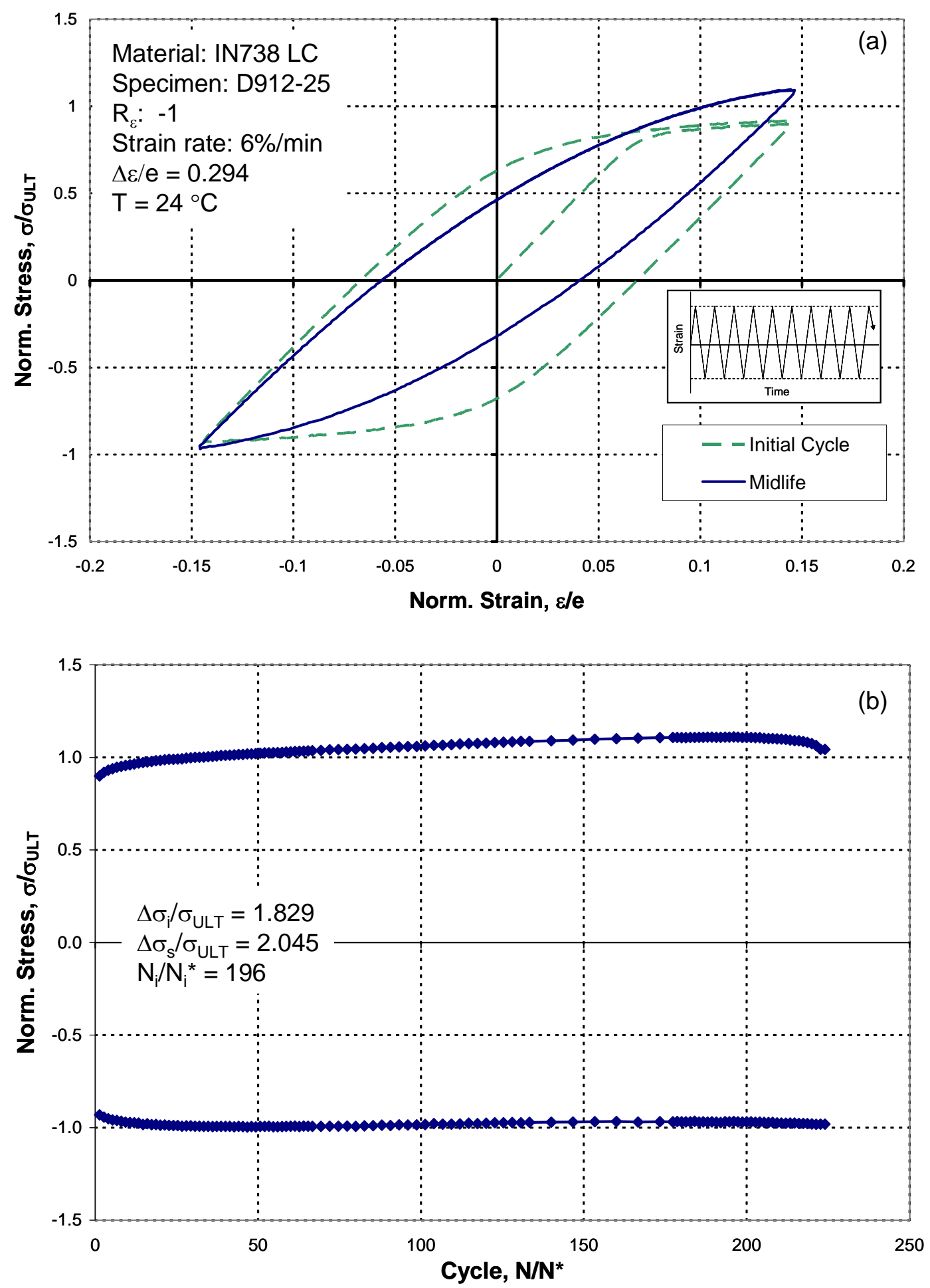

Figure A.5. (a) Hysteresis loops and (b) stress cycle plots for LCF test specimen D912-25 at $24^{\circ} \mathrm{C}$. 

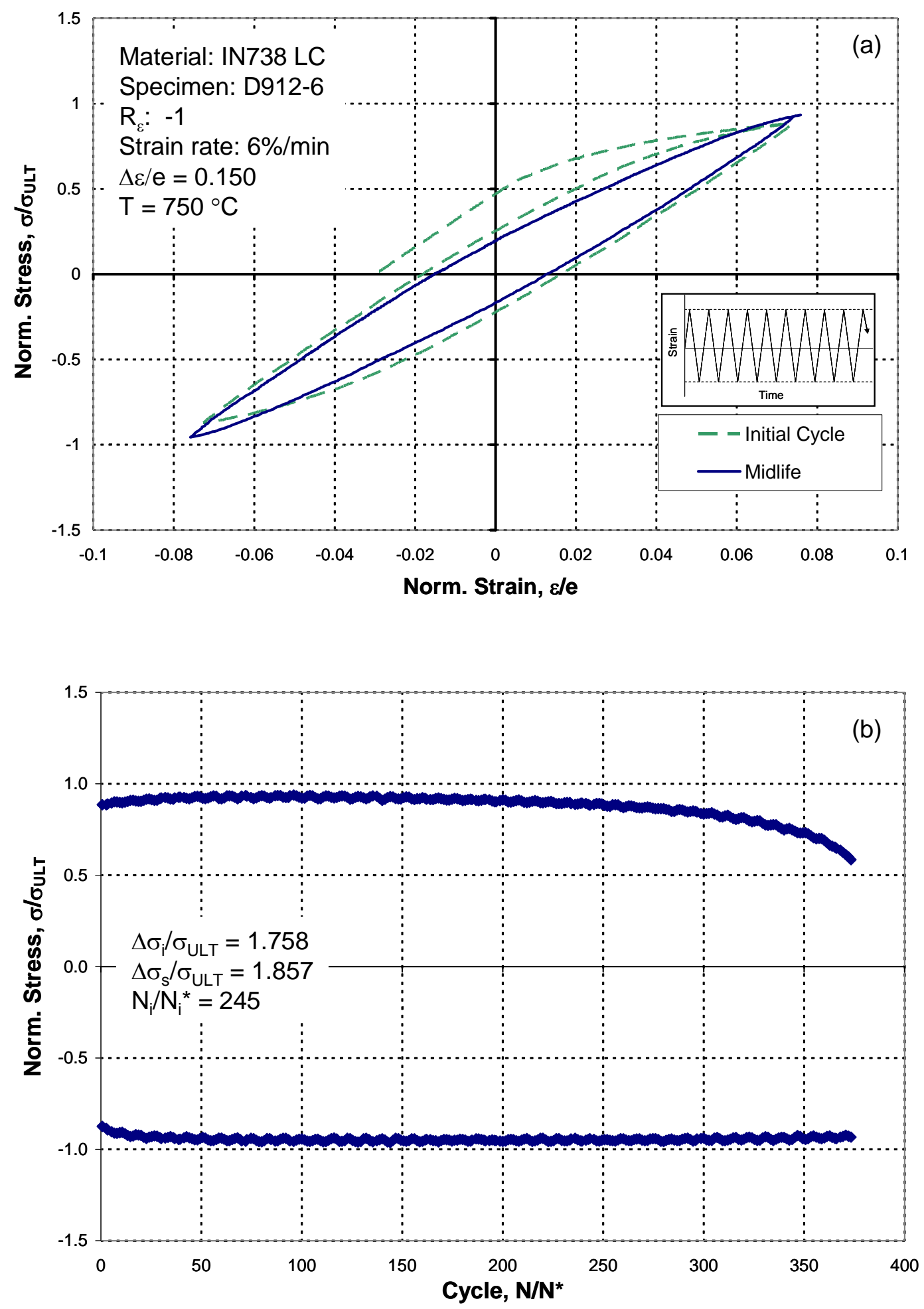

Figure A.6. (a) Hysteresis loops and (b) stress cycle plots for LCF test specimen D912-6 at $750^{\circ} \mathrm{C}$. 

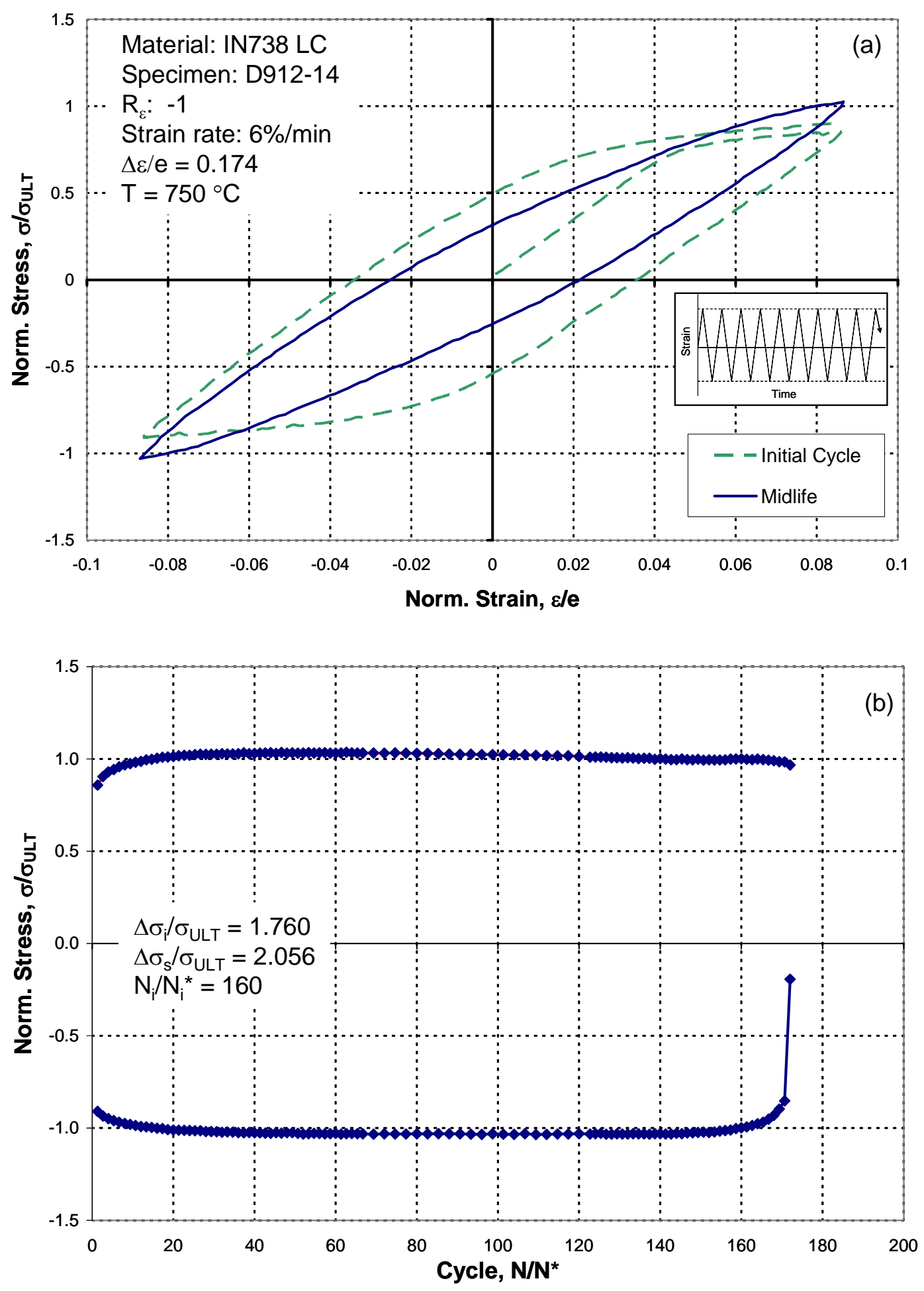

Figure A.7. (a) Hysteresis loops and (b) stress cycle plots for LCF test specimen D912-14 at $750^{\circ} \mathrm{C}$. 

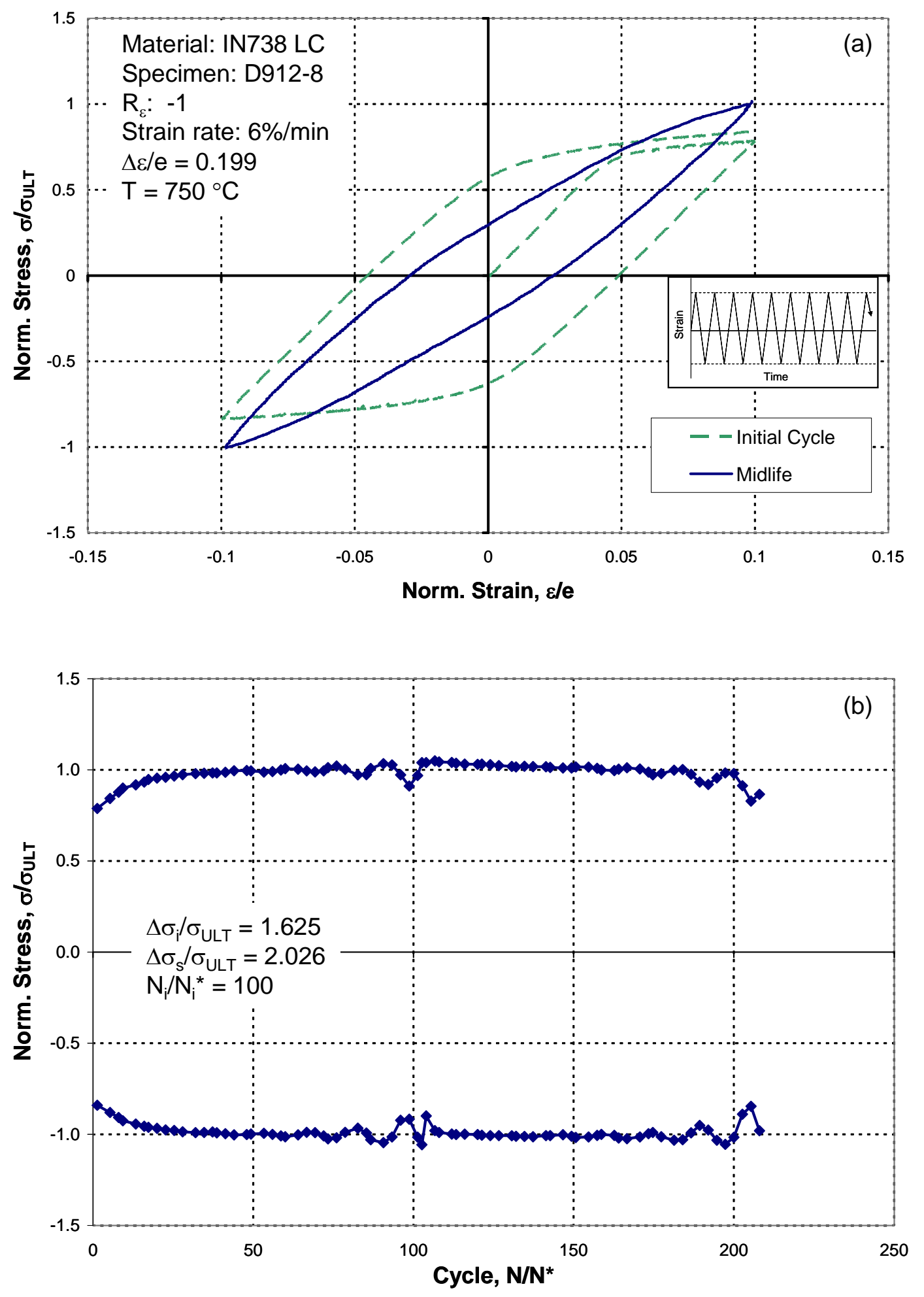

Figure A.8. (a) Hysteresis loops and (b) stress cycle plots for LCF test specimen D912-8 at $750^{\circ} \mathrm{C}$. 

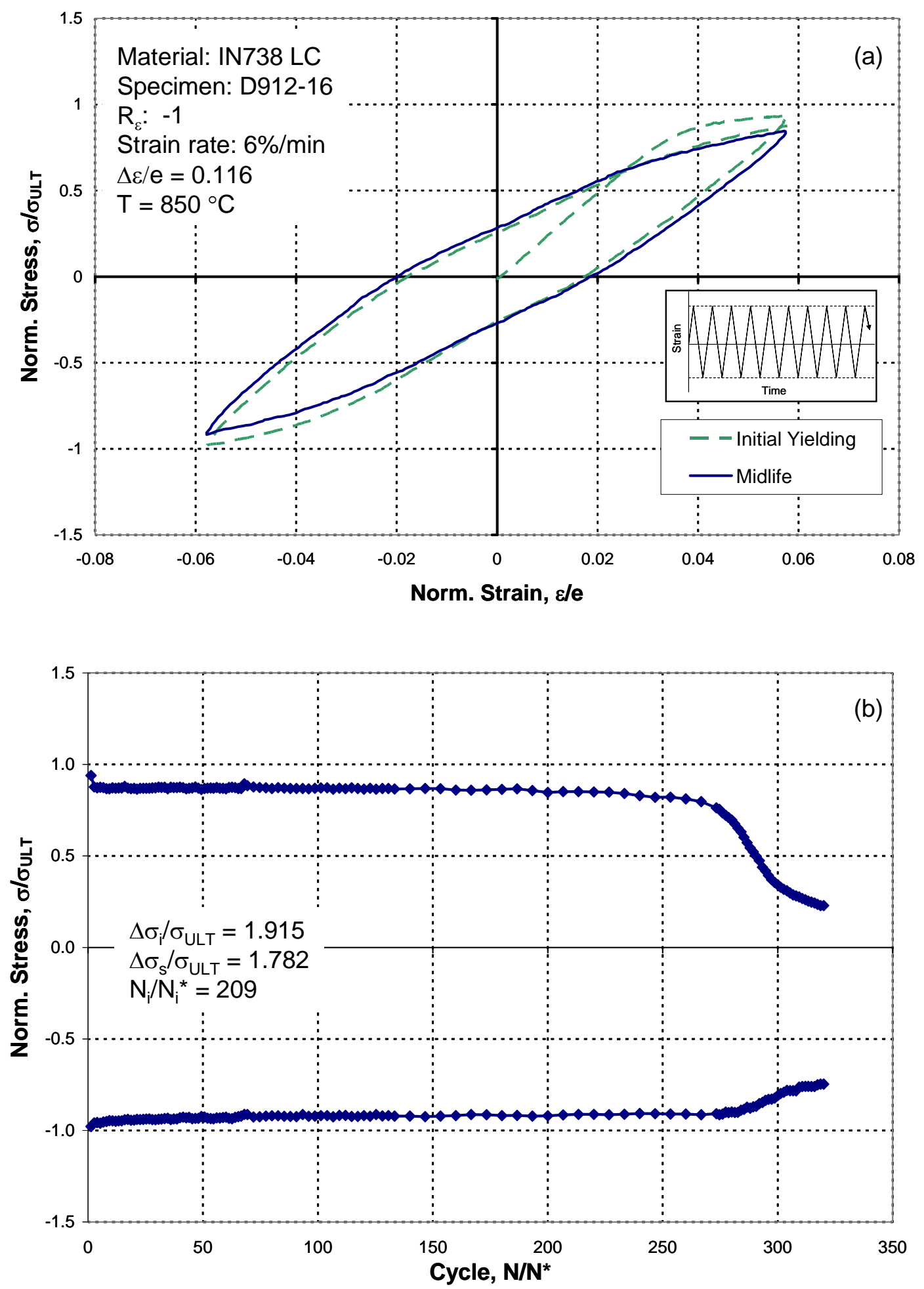

Figure A.9. (a) Hysteresis loops and (b) stress cycle plots for LCF test specimen D912-16 at 850 ${ }^{\circ} \mathrm{C}$. 

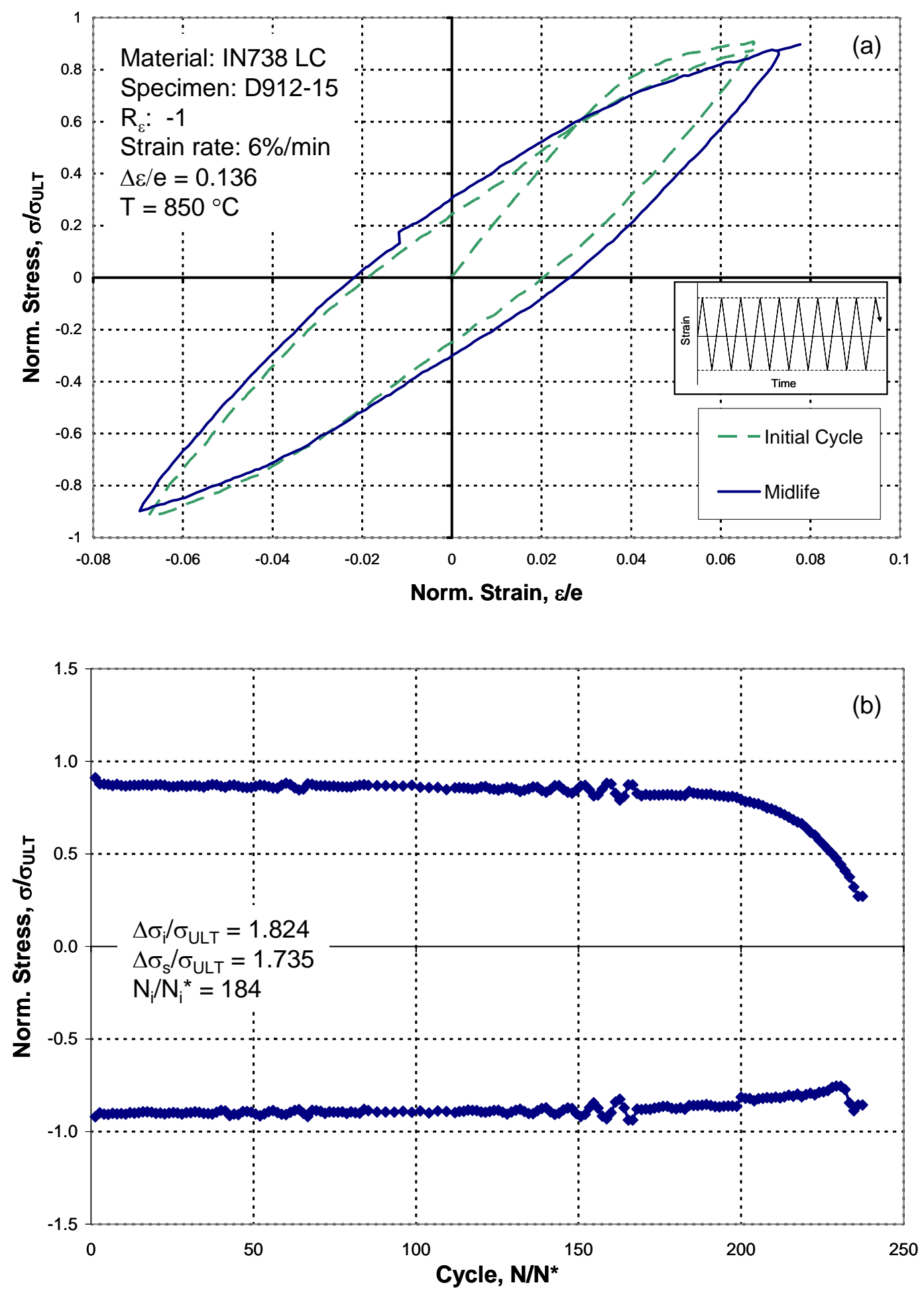

Figure A.10. (a) Hysteresis loops and (b) stress cycle plots for LCF test specimen D912-15 at $850^{\circ} \mathrm{C}$. 

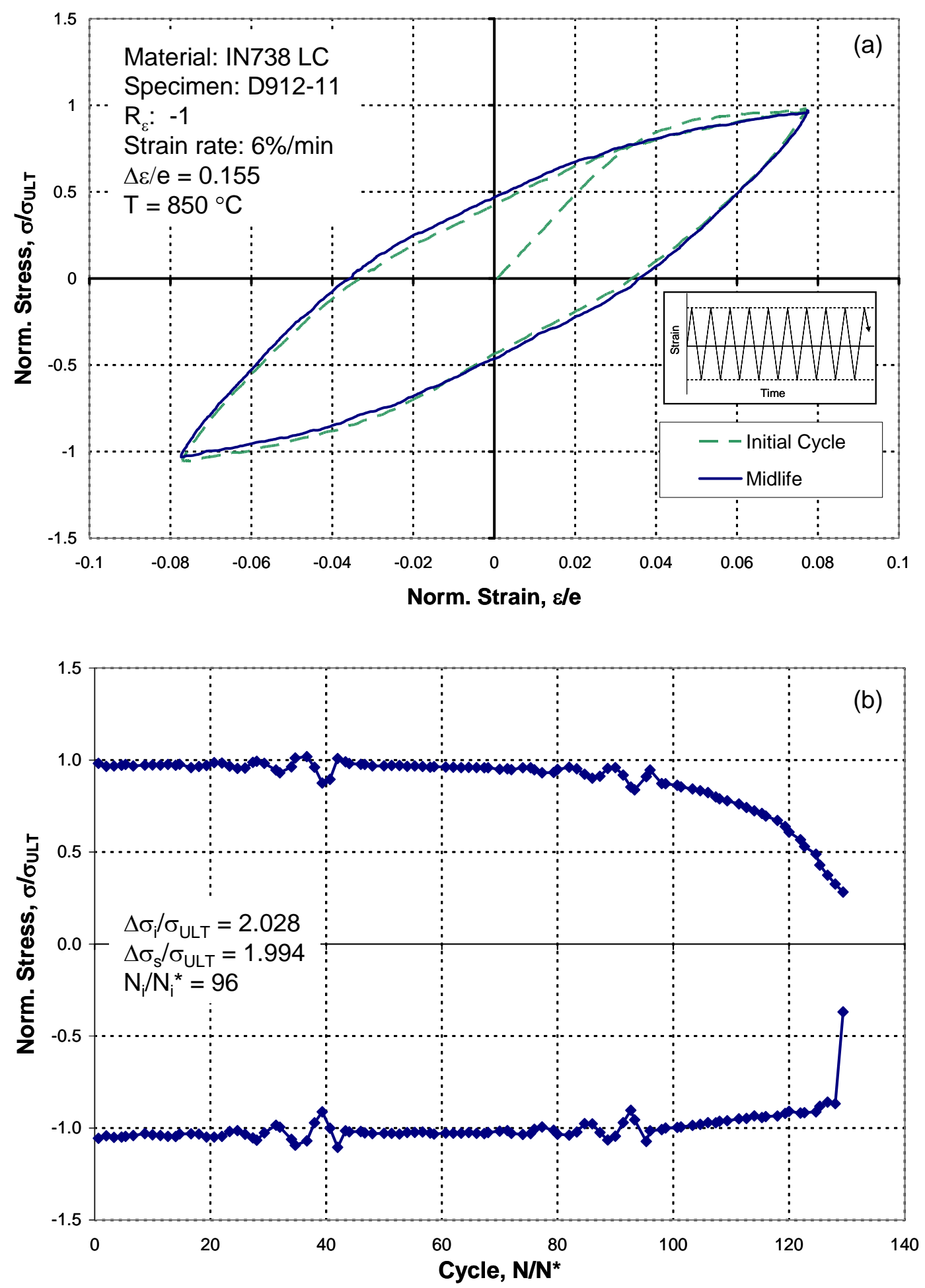

Figure A.11. (a) Hysteresis loops and (b) stress cycle plots for LCF test specimen D912-11 at $850^{\circ} \mathrm{C}$. 
APPENDIX B - SPECIMEN PHOTOGRAPHS 


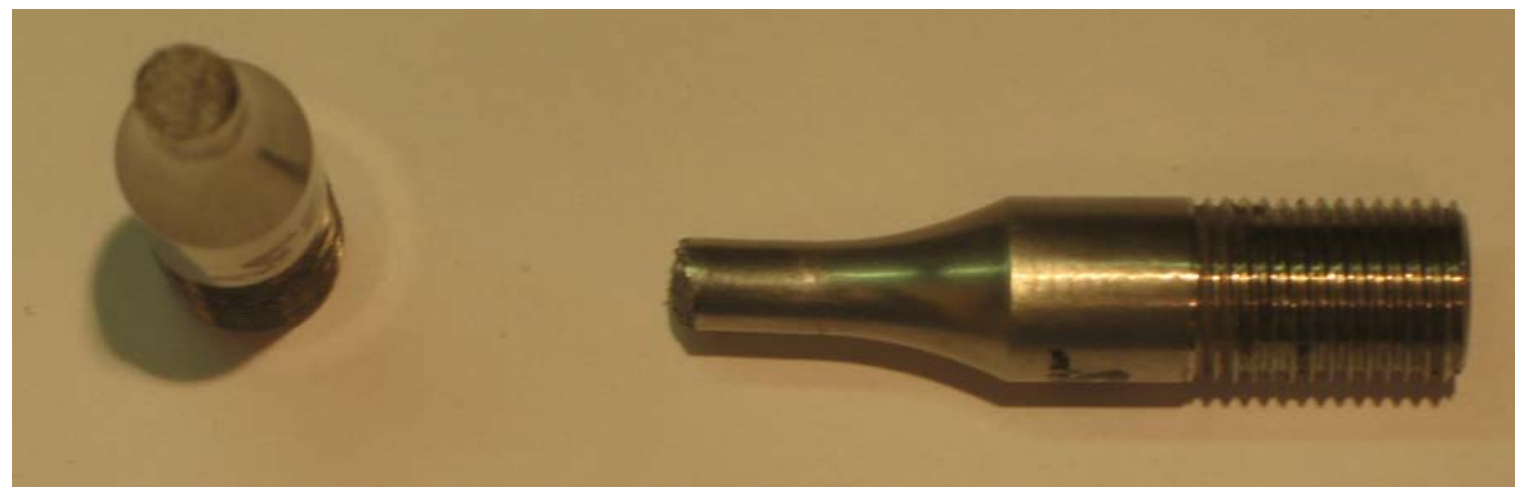

Figure A.12. Photograph of fractured specimen D912-35, $24^{\circ} \mathrm{C}$ test temp and 0.147 norm. strain range.

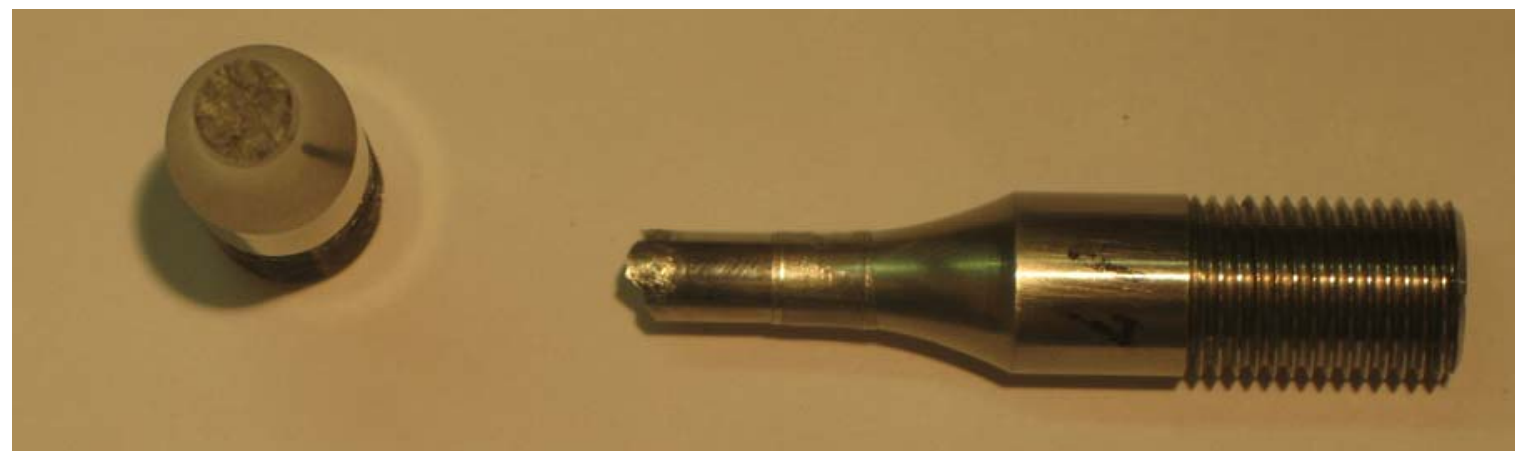

Figure A.13. Photograph of fractured specimen D912-17, $24^{\circ} \mathrm{C}$ test temp and 0.184 norm. strain range.

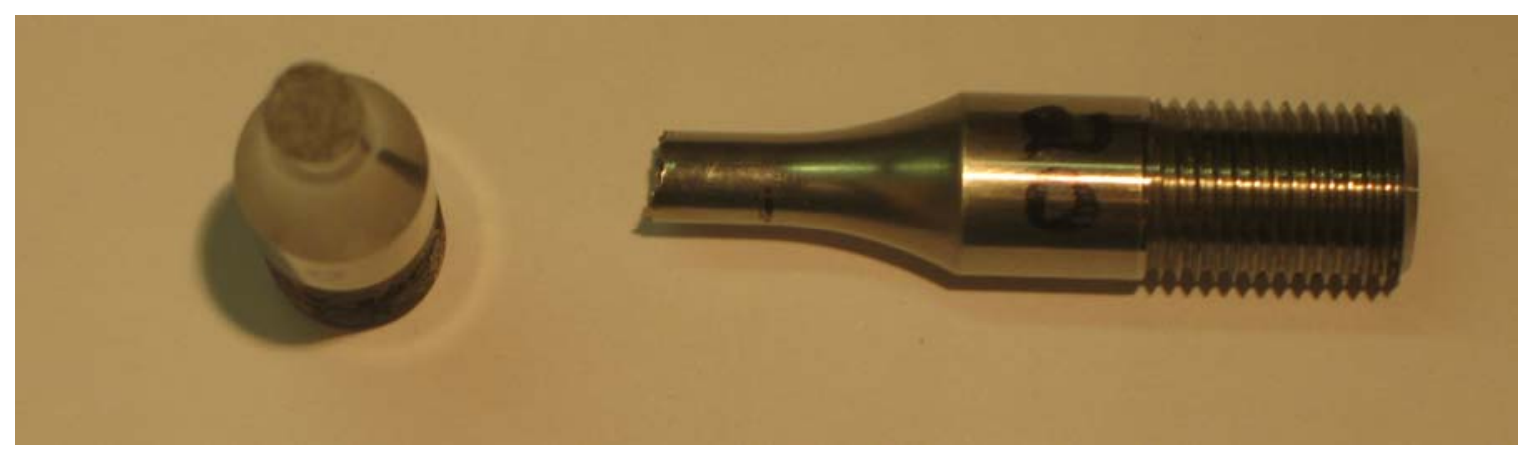

Figure A.14. Photograph of fractured specimen D912-20, $24^{\circ} \mathrm{C}$ test temp and 0.222 norm. strain range. 

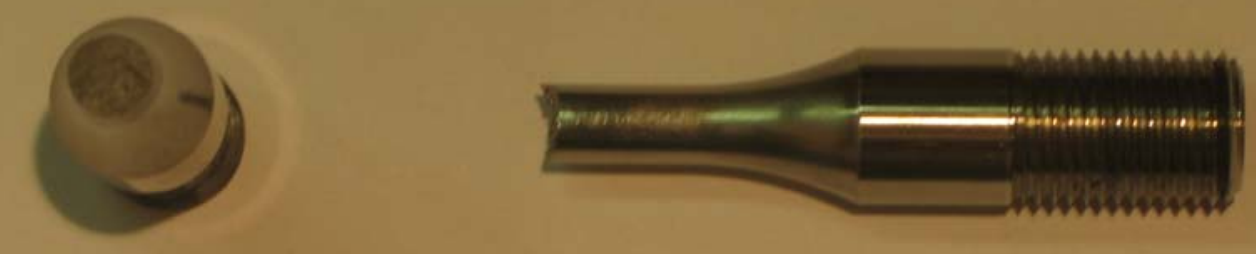

Figure A.15. Photograph of fractured specimen D912-19, $24^{\circ} \mathrm{C}$ test temp and 0.257 norm. strain range.

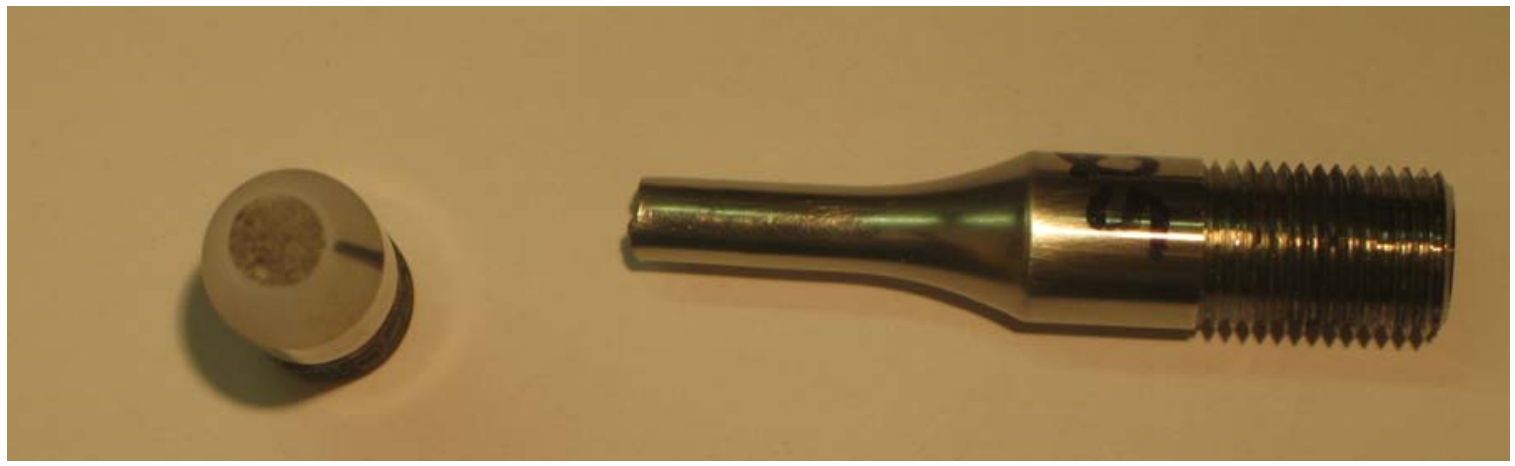

Figure A.16. Photograph of fractured specimen D912-25, $24^{\circ} \mathrm{C}$ test temp and 0.294 norm. strain range.

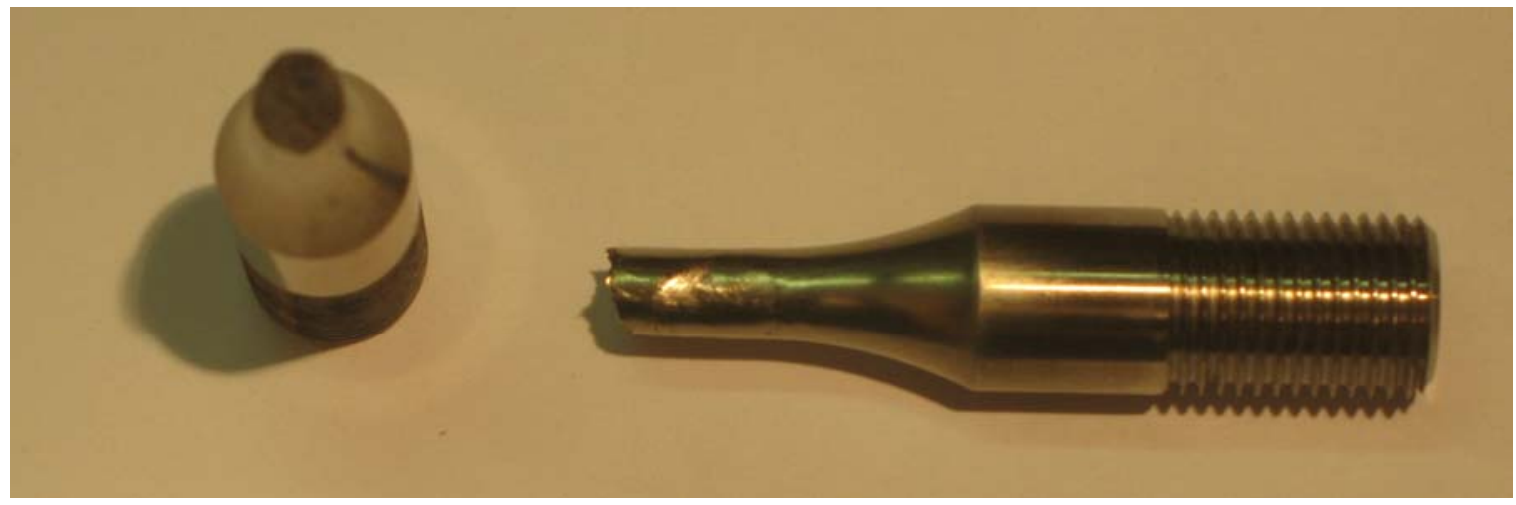

Figure A.17. Photograph of fractured specimen $\mathrm{D} 912-33,400^{\circ} \mathrm{C}$ test temp and 0.177 norm. strain range. 


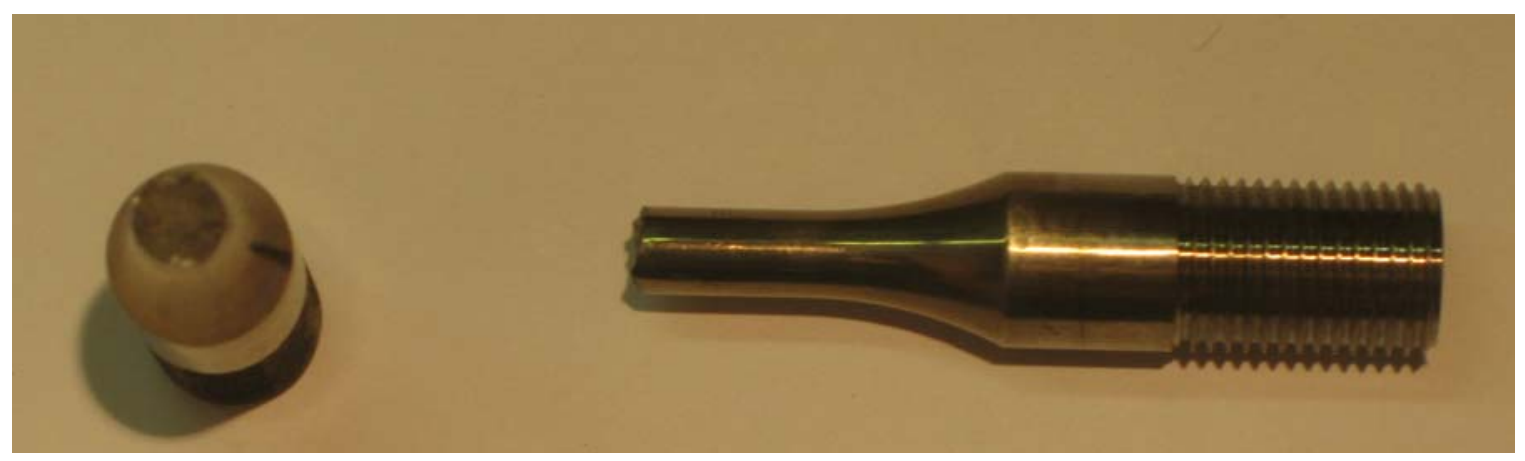

Figure A.18. Photograph of fractured specimen D912-1, $400^{\circ} \mathrm{C}$ test temp and 0.222 norm. strain range.

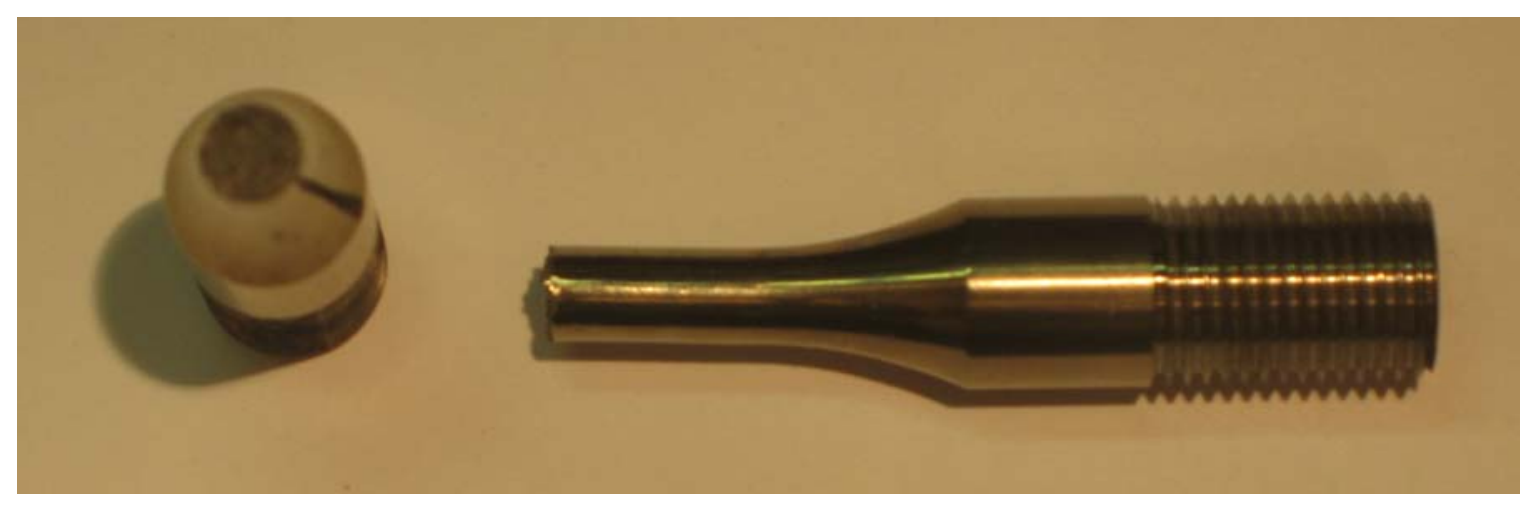

Figure A.19. Photograph of fractured specimen D912-2, $400^{\circ} \mathrm{C}$ test temp and $0.222 \mathrm{norm}$. strain range.

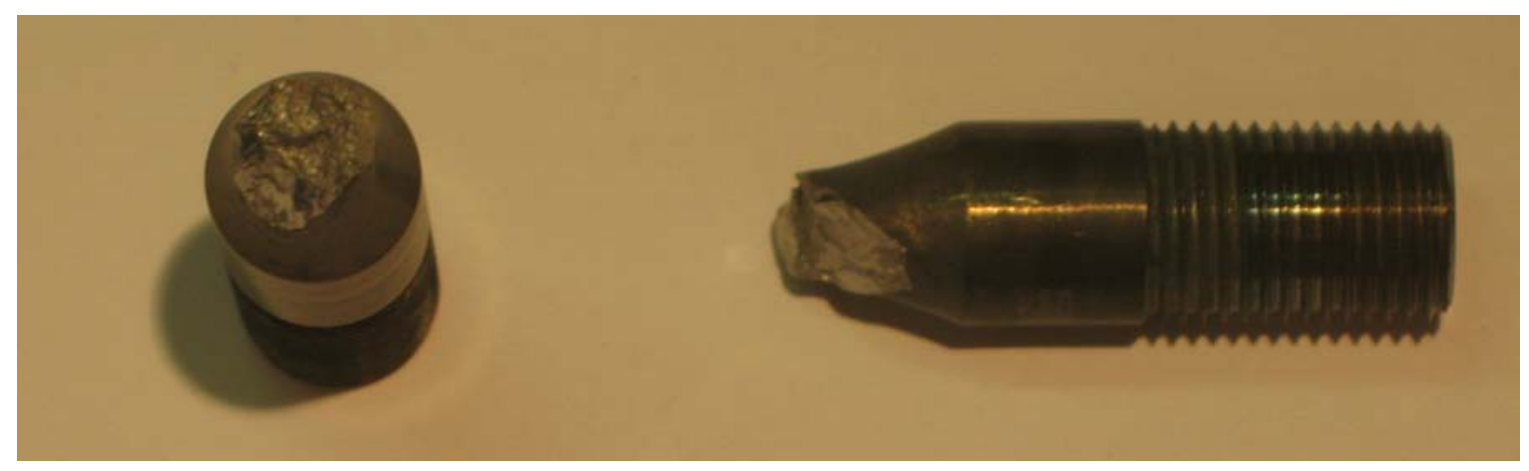

Figure A.20. Photograph of fractured specimen D912-6, $750^{\circ} \mathrm{C}$ test temp and 0.150 norm. strain range. 


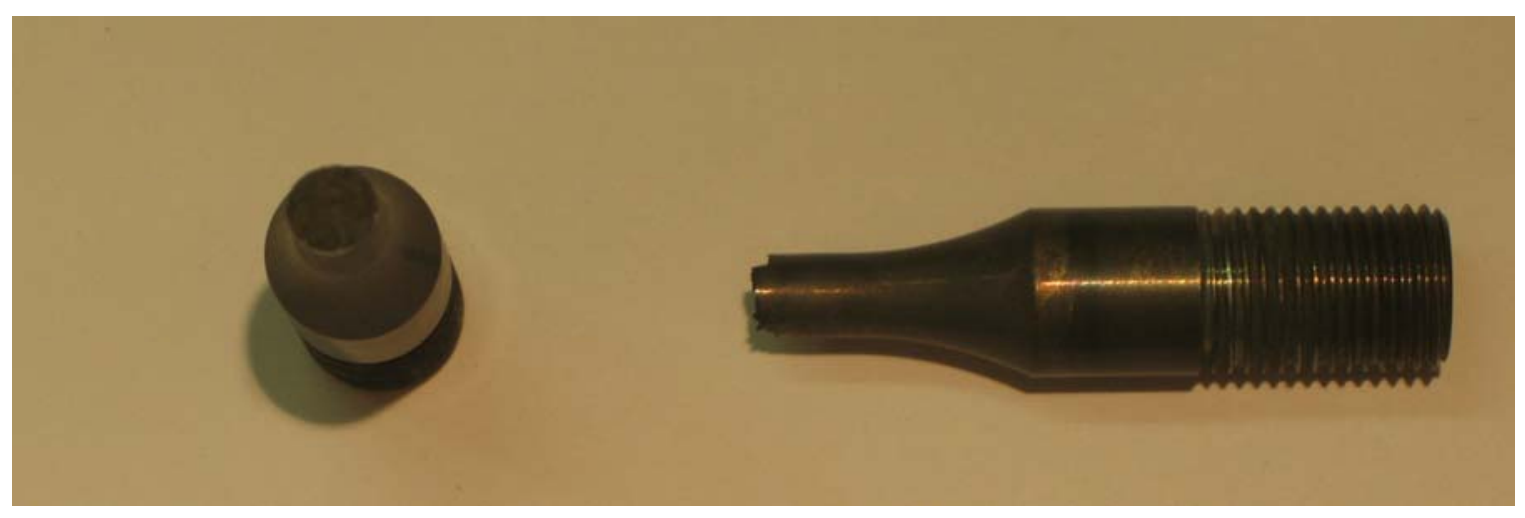

Figure A.21. Photograph of fractured specimen D912-14, $750^{\circ} \mathrm{C}$ test temp and 0.174 norm. strain range.

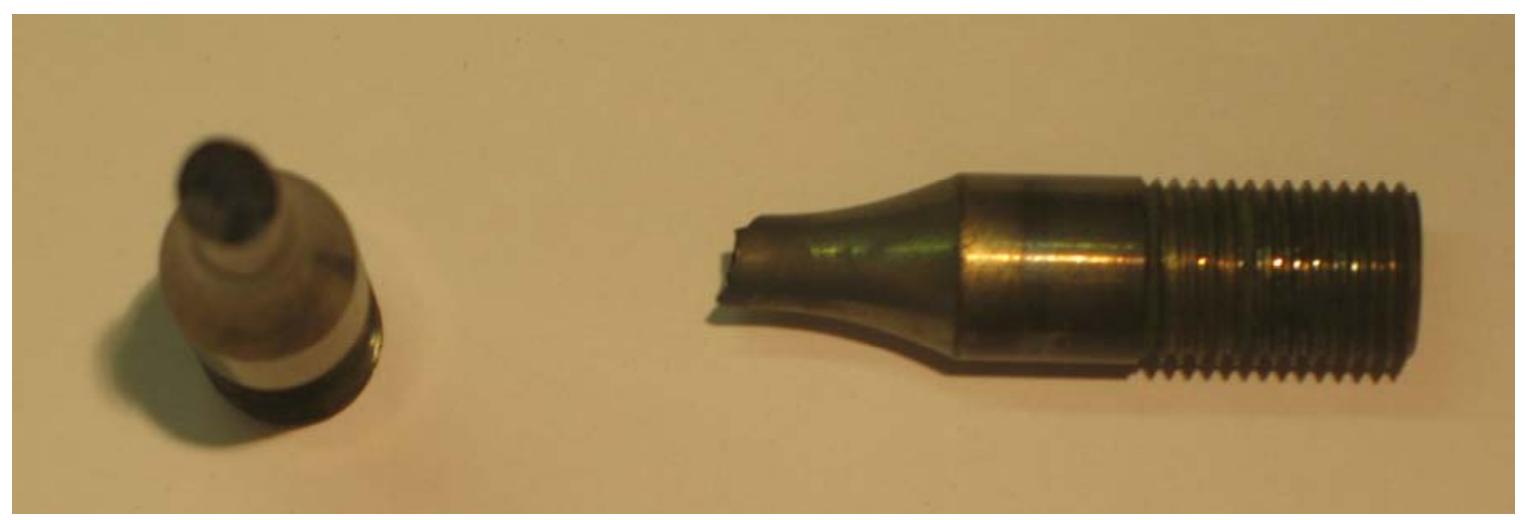

Figure A.22. Photograph of fractured specimen D912-8, $750^{\circ} \mathrm{C}$ test temp and 0.199 norm. strain range.

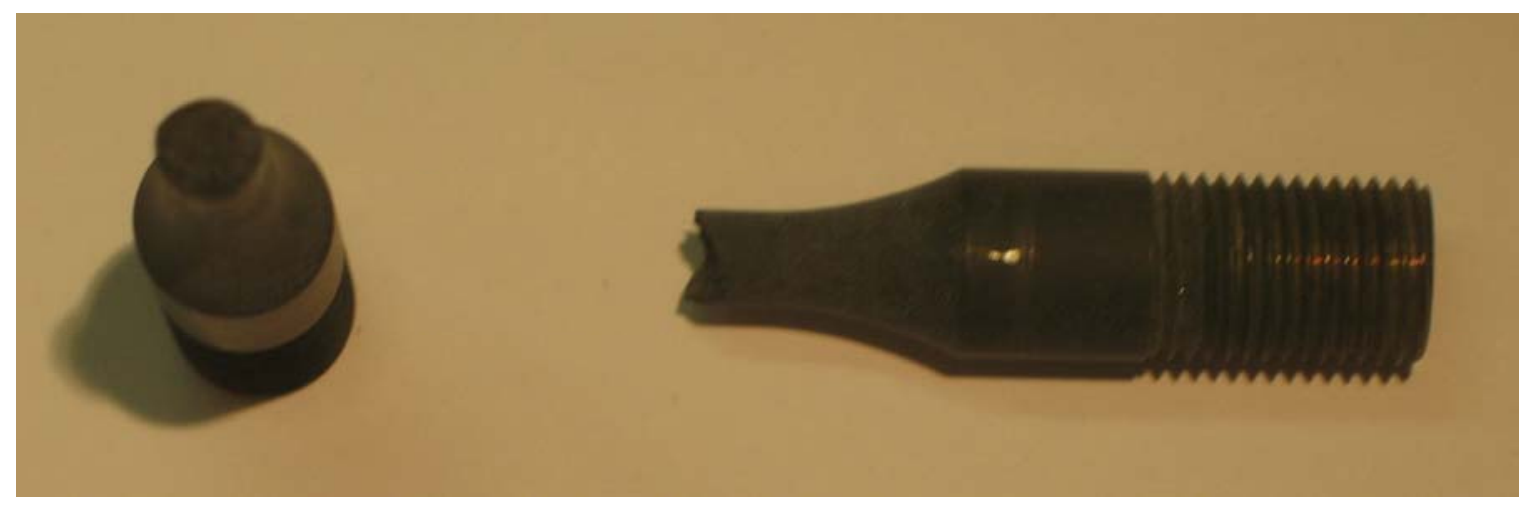

Figure A.23. Photograph of fractured specimen D912-16, $850^{\circ} \mathrm{C}$ test temp and $0.116 \mathrm{norm}$. strain range. 


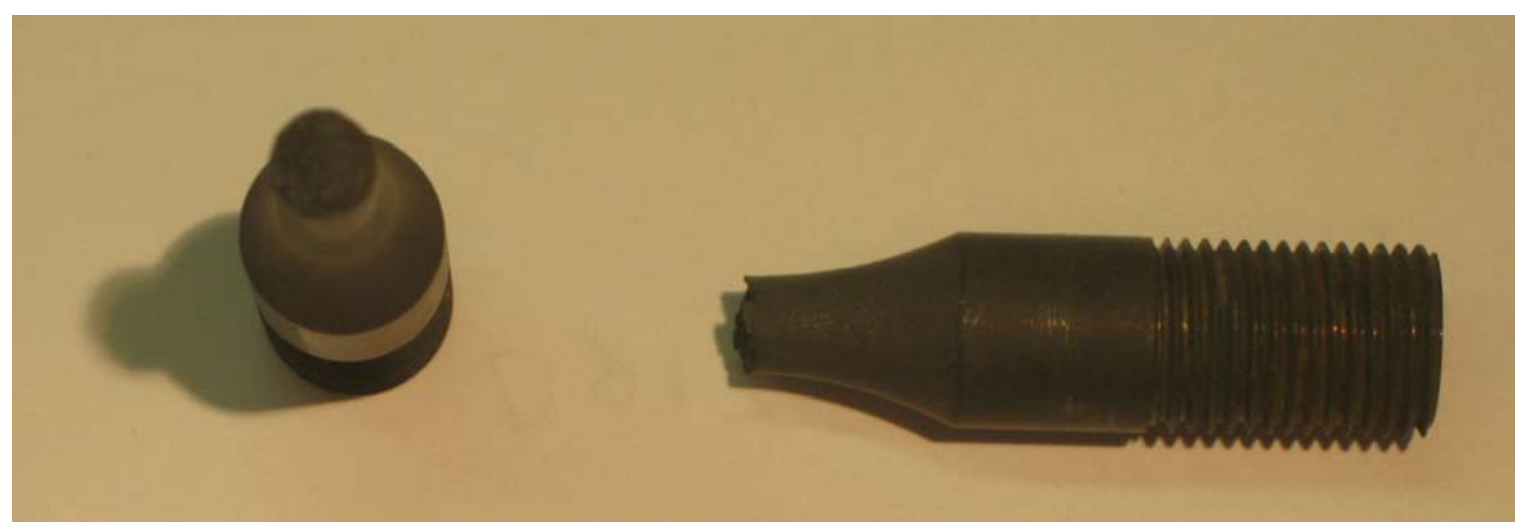

Figure A.24. Photograph of fractured specimen D912-15, $850^{\circ} \mathrm{C}$ test temp and 0.136 norm. strain range.

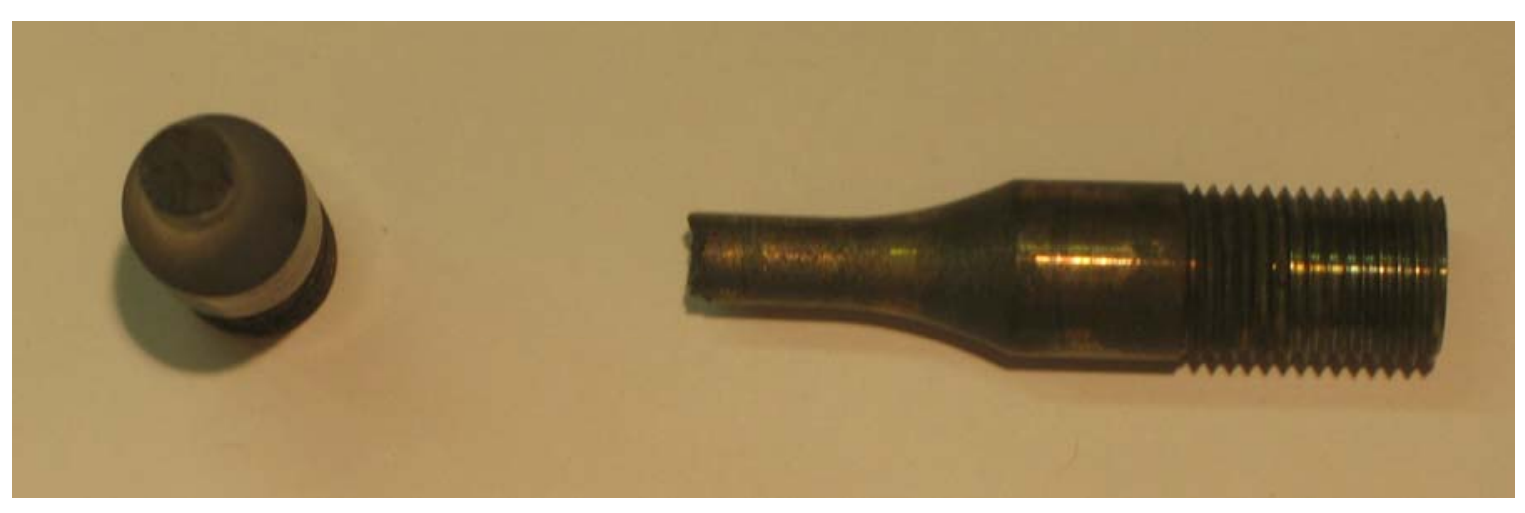

Figure A.25. Photograph of fractured specimen D912-11, $850^{\circ} \mathrm{C}$ test temp and 0.155 norm. strain range. 


\section{REFERENCES}

1 Xia, J., Kovac, J., and McQuiggan, G., Wolfe, B., "SGT6-5000F (W501F) Engine Enhancements to Improve Operation Flexibility.” POWER-GEN International 2005 - Las Vegas, Nevada, 2005.

2 EPRI Report. "Reducing Life Cycle Costs for Gas Turbine Hot Section Components”. Product ID: 1014679. November 2006.

3 Viswanathan, R., "Damage Mechanisms and Life Assessment of High-Temperature Components,” ASM International, Metals Park, Ohio.

4 ASTM International, "Standard Terminology Relating to Fatiuge and Fracture Testing,” E1823-96, West Conshohocken, PA. 2002.

5 Lemaitre, J., Dufailly J., “Modeling Very Low Cycle Fatigue,” International Journal of Damage Mechanics, Vol. 4 - April 1995, p. 153-170.

6 Dowling, N.E., "Mechanical Behavior of Materials," $2^{\text {nd }}$ Ed. Prentice Hall, New Jersey, 1999.

7 Bannantine, J.A., Comer, J.J., Handrock, J.L, “Fundamentals of Metal Fatigue Analysis,” Prentice-Hall, New Jersey, 1990.

8 Morrow, JoDean, Tuler F.R., "Low Cycle Fatigue Evaluation of Inconel 713C and Waspaloy," Transactions of the ASME, Journal of Basic Engineering, Volume 87, Series D, June 1965, p 275-289.

9 Balikci, Ercan, "Microstructure Evolution and Its Influence on Thermal Expansion and Tensile Properties of the Superalloy IN738LC at High Temperatures,” Ph.D. Thesis, Lousiana State University., 1998. 
10 Burke, M.A., Beck, C.G., “The High Temperature Low Cycle Fatigue Behavior of the Nickel Base Alloy IN-617,” Metallurgical Transactions A, V 15A, April 1984 -661.

11 Marchionni, M., Ranucci, and D., Picco, E., “High-Temperature Low-Cycle Fatigue Behavior of IN738LC Alloy in Air and In Vacuum,” High temperature alloys for gas turbines conference proceedings, 1982, p 791-804.

12 Stephens, R.I., Fatemi, A., Stephens, R. R., and Fuchs, H.O., "Metal Fatigue in Engineering,” $2^{\text {nd }}$ Ed, John Wiley \& Sons, New York.

13 ASTM International, "Standard Practice for Statistical Analysis of Linear of Linearized Stress-Life (S-N) and Strain-Life ( $\varepsilon-N)$ Fatigue Data.” E739-91, West Conshohocken, PA. 2004.

14 Manson, S.S., "Fatigue - Complex subject - Some simple approximations,” Experimental Mechanics, v5, n7, July 1965, p193-226.

15 Kim, K.S., Chen X., Han, C., and Lee, H.W., “Estimation methods for fatigue properties of steels under axial and torsional loading,” International Journal of Fatigue, 24 (2002) p. 783-793.

16 Park, Jun-Hyub, Song, and Ji-Ho, “Detailed evaluation of methods for estimation of fatigue properties,” International Journal of Fatigue, vol. 17, No 5, 1995, p. 365-373.

17 Ong, J.H., “An improved technique for the prediction of axial fatigue life from tensile data,” International Journal of Fatigue, vol. 15, No 3, 1993, p. 213-219.

18 Meggiolaro, M.A., and Castro J.T.P., "Statistical evaluation of strain-life fatigue crack initiation predictions,” International Journal of Fatigue, vol. 26, 2004, p. 463476. 
19 Brown, W.F. Jr, and Hill L.R., “Aerospace Structural Metals Handbook, $37^{\text {th }}$ Ed. Code 4217. CINDAS/USAF CRDA Handbooks Operation, Purdue University, West Lafayette, IN. 2001.

20 Yandt, Scott A., "Development of a Thermal-Mechanical Fatigue Testing Facility,” M.S. Thesis, 2000, Carleton University, Canada.

21 Danzer, R., and Bressers, J., “The Application of Stress Rupture Data for the Prediction of the High Temperature Low Cycle Fatigue Lives of Two Nickel-Base Alloys,” Proceedings of a Conference Held in Lie’ge, Belgium. 1996.

22 Neter, J., Wasserman, W., and Kutner, M., “Applied Linear Statistical Models,” $3^{\text {rd }}$ Ed., Irwin, Burr Ridge Illinois. 1990.

23 ASTM International, “Standard Practice for Strain-Controlled Fatigue Testing,” E 606 -04, West Conshohocken, PA. 2004.

24 Huron, E.S., “Serrated Yielding in a Nickel-Base Superalloy,” Superalloys 1992. The Minerals, Metals, \& Materials Society 1992. 